\title{
Experimentelle Untersuchungen über die Entwicklung der Hypophyse bei Anuren (Bufo).
}

\author{
Von
}

\section{Tomomasa Uyematsu.}

Aus dem Anatomischen Institut der Kaiserlichen Universität zu Kyoto.

(Direktor: Prof. Dr. Ch. Ogawa).

\section{Mit 45 Textabbildungen.}

Inhalt.

Einleitung. . . . . . . . . . . . . . . . . . . 392

Material und Methode. . . . . . . . . . . . . . . . . . 393

I. Die normale Entwicklung des Infundibulums und des Lobus glandularis. . . . . . . . . . . . . . . . . . . . . 397

I. X-Y-Figur der Neuralplatte. . . . . . . . . . . . . . 397

2. Infundibulum. . . . . . . . . . . . . . . . . . 398

3. Lobus glandularis. . . . . . . . . . . . . . . . . . . . . . 400

IJ. Experimente an der Anlage des Infundibulums. . . . . . . . . . . 400

I. Bestimmung der Anlage. . . . . . . . . . . . . . . . 400

Schluss. . . . . . . . . . . . . . . . . . . 403

2. Totale Exstirpation. . . . . . . . . . . . . . . . . . . . 403

a. Befund nach der Operation. . . . . . . . . . . . . . . . 404

b. Lobus glandularis beim Fehlen des Lobus nervosus. . . . . 405

Diskussion. . . . . . . . . . . . . . . . . 4 40

Schluss. ...................... . . 412

3. Teilweise Exstirpation. . . . . . . . . . . . . . 4 $4^{\mathrm{I} 2}$

Diskussion. . . . . . . . . . . . . . . . . . . . 414

Schluss. . . . . . . . . . . . . . . . . . . 416

4. Kraniokaudale Umkehrung (Determinationsfrage). . . . . . . . $4^{17}$

Diskussion. . . . . . . . . . . . . . . . . . 42I

Schluss. . . . . . . . . . . ... . . . . . . . . . 423

III. Experimente an der Anlage des Lobus glandularis. . . . . . . . . . 424

I. Exstirpation. . . . . . . . . . . . . . . . . . . . . . . . 424

a. Infundibulum beim Fehlen des Lobus glandularis. . . . . . 424

b. Lobus nervosus beim Fehlen des Lobus glandularis. . . . . 425

Diskussion. . . . . . . . . . . . . . . . 43 I

Schluss. . . . . . . . . . . . . . . . . . . . . . . . . . 434

2. Affinität zwischen dem Lobus glandularis und dem Lobus nervosus bzw. den anderen naheliegenden Organen. . . . . 435

Diskussion. . . . . . . . . . . . . . . . . . . . . 443 


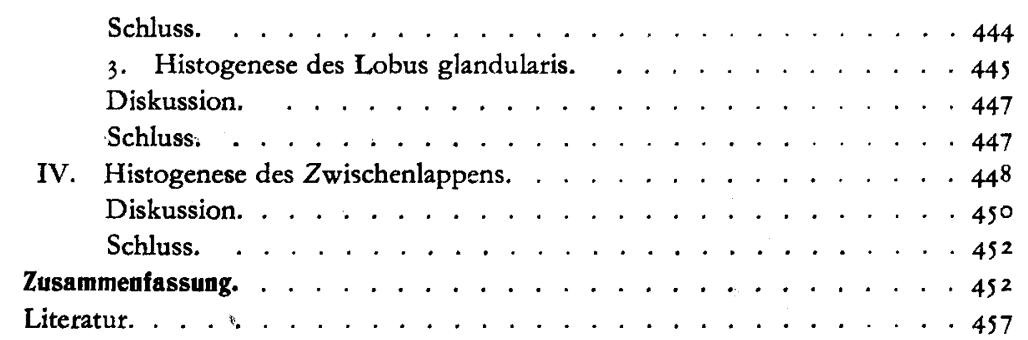

\section{Einleitung.}

Es finden sich ziemlich viel Experimente, die die Hypophyse betreffen, die meisten jedoch von ihnen befassen sich mit der Untersuchung der Hormone oder der zwischen der Hypophyse und den anderen Organen bestehenden Korrelation. Was die Entwicklung der Hypophyse anbetrifft, so sind meines Wissens nur etwa die folgenden Experimente aufzuführen. $S \mathrm{mith}$ (1920, Rana boylei Baird und Bufo boreas) wies nach, dass der Lobus nervosus nach der Exstirpation der Anlage des Lobus glandularis deutlich kleiner als normal sei und seine vollständige Entwicklung daher vom Lobus glandularis abhängig ist. Blou nt $\mathrm{t}^{4}$ (1932, Amblystoma punctatum Linn., A. mexicanum und A. tigrinum) behauptete, dass der Lobus glandularis nach der Isolierung und Transplantation seiner Anlage allein nicht aufgefunden werde, und er demnach zu seiner Entwicklung der Verbindung mit dem Lobus nervosus bedürfe. Ein stichhaltiger Beweis wurde aber bis jetzt hierfür noch nicht erbracht. Die meisten Autoren haben den Lobus glandularis für rein ektodermal gehalten. Kupffer ${ }^{9)}$ (1894) und Terato ${ }^{13}$ ) (1935) wollten jedoch festgestellt haben, dass die Zellen des Entoderms sich vom vorderen Ende des Kopfdarmes in den Lobus glandularis mischen. Niemand hat, um die sich hier erhebende Frage zu lösen, Experimente angestellt. Was ferner die Histogenese des Zwischenlappens betrifft, besitzen wir ebenfalls nur das Experiment von Gaillard6) (1937, Kaninchen), der in diesem Falle die Gewebskultur verwandte. Die während der Entwicklung zwischen den einzelnen Lappen bestehende Korrelation und die Histogenese der einzelnen Lappen sind noch in vielen Punkten unklar. Ausserdem sind auch die Anlage des Infundibulums in der Neuralplatte, das Stadium seiner Determination, weiter das Stadium der Determination des Lobus glandularis, die Ursache, warum der Lobus glandularis sich von seinem Mutterboden kaudalwärts verschiebt und das Infundibulum erreicht, usw. noch völlig unerforscht. Die Hypophyse spielt, wie bekannt, als eins der endokrinen Organe eine wichtige Rolle, Warum ruht ihre Entwicklung dennoch für uns in vieler Hinsicht im Dunklen? Der Grund ist vielleicht der, dass wegen der Art der Anlage der 
Hypophyse und ihrer eigentümlichen Entwicklung experimentelle Untersuchungen ausser an Amphibien fast unmöglich sind. Die Hypophyse wird, wie bekannt, durch die Vereinigung zweier getrennter Anlagen gebildet. Die eine entwickelt sich am Infundibulum. Die andere aber bildet sich als Verdickung der tiefen Schicht des Ektoderms, welches ventrokranial an den das kraniale Ende der Neuralplatte umrändernden schmalen Neuralwulst grenzt ; sie erleidet eine kaudale Verschiebung und erreicht das Infundibulum. In ersterem Falle handelt es sich um die Anlage des Lobus nervosus, in letzterem um die des Lobus glandularis. Bei den bisherigen Operationen war das Stadium der Schwanzknospe das früheste der Ausführung; keine Operation wurde bereits im Stadium der Neuralplatte vorgenommen. Doch schon im Stadium der Schwanzknospe lässt sich nicht mehr die Anlage des Lobus nervosus allein entfernen. Auch die Anlage des Lobus glandularis wuchert schon in diesem Stadium tief und keilförmig und legt sich dicht an die Hirnbasis. Das Infundibulum liegt anderseits desto mehr kranial, je jünger die Larve ist. Die Hirnbasis, besonders die Anlage des Infundibulums, wird daher bei der Exstirpation des Lobus glandularis leicht der Gefahr der Schädigung ausgesetzt. Die vollständige Entfernung der Anlage des Lobus glandularis ist deshalb in diesem Stadium nicht nur schwer, sondern es ist auch nicht einwandfrei, aus dem Resultat die Veränderungen des Infundibulums, besonders des Lobus nervosus ablesen zu wollen. Richtige Operationen auszuführen ist also in den Stadien, später als das Stadium der Neuralplatte, fast unmöglich. Unter der Leitung von Prof. Dr. Ch. Og a w a habe ich nun folgende Experimente bei Bufo im Stadium der Neuralplatte ausgeführt. In diesem Stadium stellt die Anlage des Lobus glandularis noch erst eine ganz leichte Verdickung dar und auch die Anlage des Lobus nervosus lässt sich leicht am Hirnteil der Neuralplatte feststellen. ' $\mathrm{Da}$ beide Anlagen ganz voneinander getrennt sind, so kann man, sie gleichzeitig ins Auge fassend, die eine operieren, ohne die andere zu schädigen, und eine Verletzung des Hirnteils seht wohl vermeiden. Die hier veröffentlichten Experimente wurden in Fortsetzung von 1937 bis 1939 durchgeführt.

\section{Material und Methode.}

Als Material benutzte ich Bufokeime. Es wurde mir jedes Jahres etwa fünf Monate lang, von Anfang Januar bis etwa Ende Mai, aus verschiedenen Gegenden, am frühesten südlich von Kyushu und Shikoku, darauf aus den Provinzen um Kyoto und am spätesten nördlich aus der Provinz Niigata, geliefert. Die Keime oder einige Krötenpaare, welche gerade vor dem Laichen waren, wurden hierher gesandt. $\mathrm{Da}$ im letżeren Falle die Kröten im 
Institut laichten, vermochte ich also ganz frische Keime zur Operation zu verwenden. Im allgemeinen waren die Keime aus Kyushu und Shikoku etwas grösser, dieselben aus Niigata dagegen etwas kleiner.

Die Operation wurde unter der Binokularlupe mit einer scharfen Nadel, W e ckers Pinzettenschere und einer kleinen Pinzette ausgeführt.

Die Anlage des Infundibulums betreffend wurden die drei folgenden Operationen ausgeführt. Ich benutzte hierbei die Keime des Neurulastadiums (Körperlänge : ca. 2.6-2.8 mm), genauer gesagt, die Keime des von mir so genannten X-Y-Stadiums (s. unter, , X-Y-Figur der Neuralplatte “).

(I) Totale Exstirpation der Anlage : die viereckige Stelle, welche die von $\mathrm{X}$ und $\mathrm{Y}$ umgrenzte Anlage des Infundibulums enthält, wurde mit ihrer Unterlage beseitigt (Abb. I). Deshalb entstand hier ein Loch, welches die Kopfdarmhöhle erreicht.

(2) Teilweise Exstirpation der Anlage : nur die rechte Hälfte derselben Stelle wurde samt ihrer Unterlage entfernt (Abb. 2).

(3) Kraniokaudale Umkehrung der Anlage : die obige viereckige Stelle wurde samt ihrer Unterlage um $180^{\circ}$ kraniokaudal gedreht. Das Viereck wurde bei der Umkehrung meist absichtlich in der Richtung kaudalwärts etwas verlängert. Also befand sich die Anlage des Infundibulums in der umgekehrten Lage meist etwas kaudalwärts verschoben.

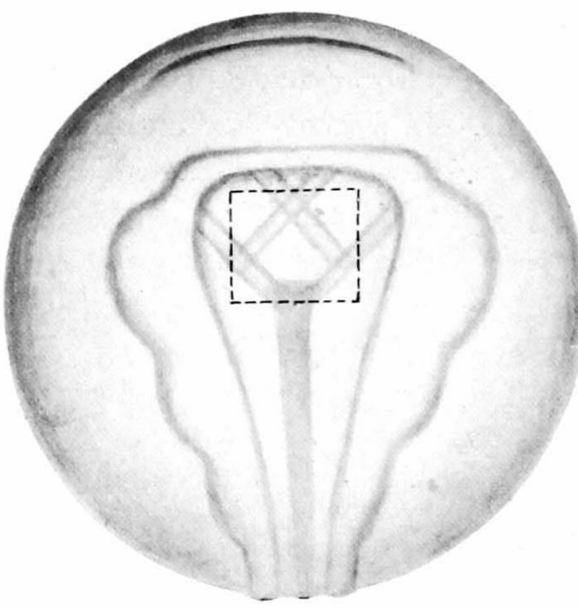

Abb. I. Totale Exstirpation der Anlage des Infundibulums. Schema der Operation. Dorsokraniale Ansicht eines Keimes. Exstirpierte Stelle punktiert.

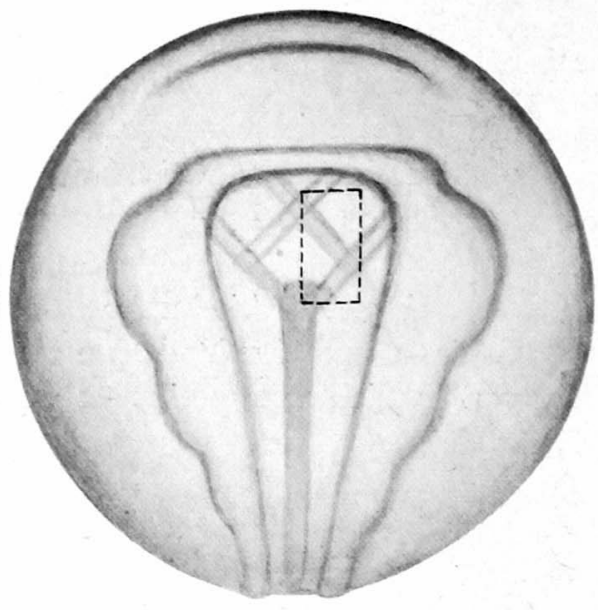

Abb. 2. Teilweise Exstirpation der Anlage des Infundibulums. Schema der Operation.

Bei der Operation der Anlage des Lobus glandularis benutzte ich Keime des Stadiums, welches sich an das X-Y-Stadium anschliesst, d.h. des Stadiums, 
wo die Figur $\mathrm{X}$ schon undeutlich wird und die Neuralrinne sich zu bilden beginnt (Körperlänge : ca. 2.6-2.8 mm). Die vier folgenden Operationen wurden ausgeführt.

(1) Einfache Exstirpation der Anlage : die ganze Schicht des Ektoderms wurde in viereckiger Gestalt, die Anlage enthaltend, entfernt (Abb. 3 a). Die tiefe Schicht des Ektoderms wurde dabei vollständig beseitigt, die Unterlage aber geschont. Gleichzeitig wurde jedoch auch ein Teil des Neuralwulstes, welcher das kraniale Ende der Neuralplatte umrändert, entfernt.

(2) Exstirpation der Anlage und homoioplastische Transplantation der Anlage eines Saugnapfes auf diese Stelle : die Anlage des Lobus glandularis wurde wie im vorigen Falle entfernt und auf dieselbe Stelle die Anlage des Saugnapfes eines anderen Keimes des gleichen Stadiums (Abb. 3 b) transplantiert.

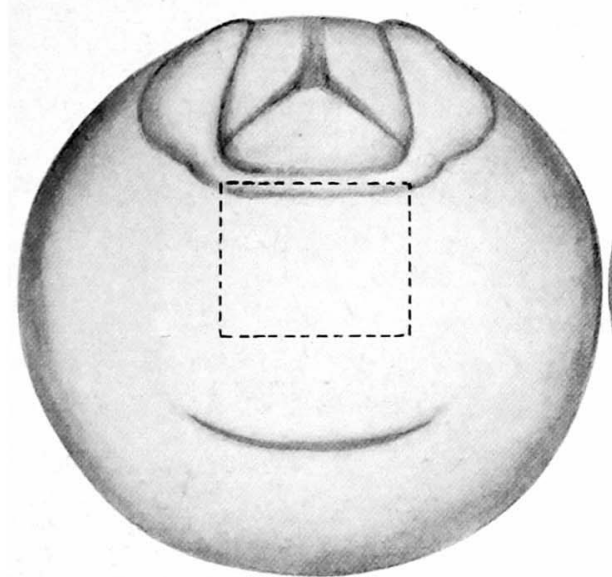

a

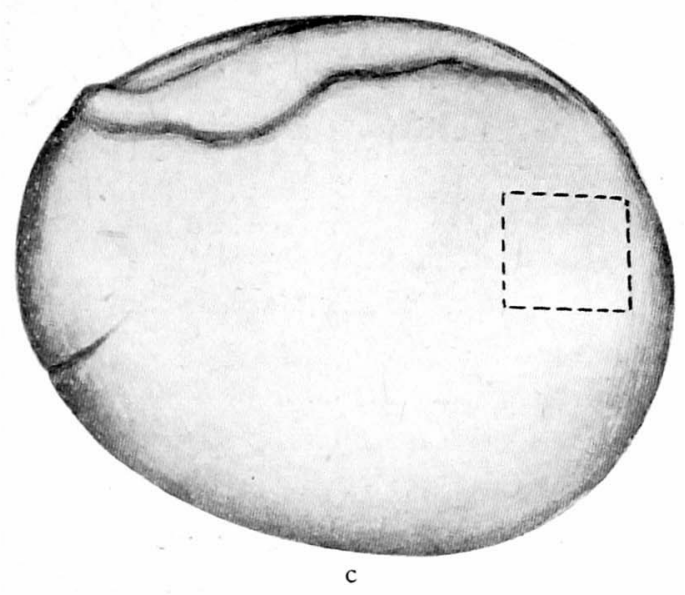

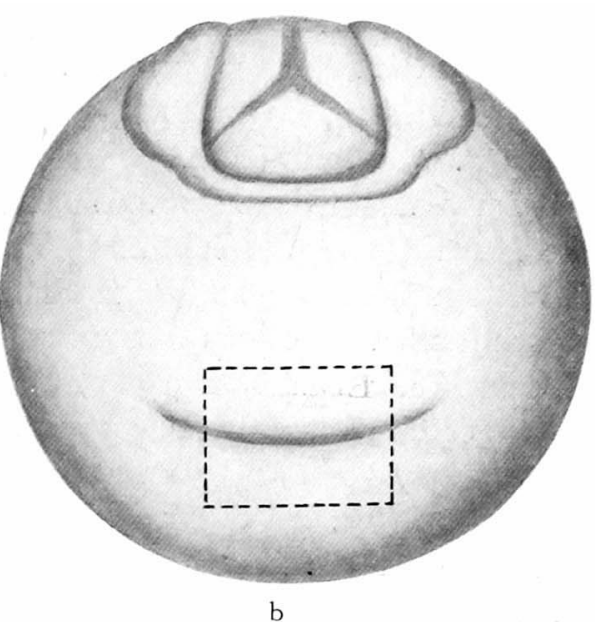

Abb. 3. Experimente an der Anlage des Lobus glandularis. Schema der Operation.

a = Einfache Exstirpation. Kraniale Ansicht eines Keimes.

$b=$ Transplantat aus der Anlage des Saugnapfes. Kraniale Ansicht des Spenders.

$c=$ Transplantat aus dem präsumtiven seitlichen Rumpfteile. Kraniolaterale Ansicht des Spenders. 
(3) Exstirpation der Anlage und homoioplastische Transplantation des Ektoderms des präsumtiven seitlichen Rumpfteiles auf diese Stelle : nach der Exstirpation der Anlage, wurde auf dieselbe Stelle das Ektoderm(Deckschicht mit tiefer Schicht) des präsumtiven seitlichen Rumpfteiles eines anderen Keimes des gleichen Stadiums (Abb. 3 c) transplantiert.

(4) Exstirpation der Anlagen bei zwei Keimen und deren Parabiose : mit zwei Keimen, bei denen die Anlagen beseitigt wurden, wurde parabiose in den Operationswunden veranlasst.

Gleichzeitige Exstirpation sowohl der Anlage des Infundibulums wie des Lobus glandularis : bei Keimen des X-Y-Stadiums wurde zuerst die Anlage des Lobus glandularis und gleich darauf dic Anlage des Infundibulums exstirpiert. Die Methoden sind dieselben wie bei der Exstirpation einer einzelnen Anlage.

Sonst wurden im Anfangsstadium der Schwanzknospe, d.h. beim Keime (Körperlänge : ca. 3.8-4.0 mm) kurz nach der Bildung des Neuralrohres die Exstirpation des Gehirns, die kraniokaudale Umkehrung desselben usw. ausgeführt (Abb. 4).

Im Stadium der Neuralplatte ist die Enthüllung des Keimes und die Züchtung desselben nach der Operation schwer. Für die Enthüllung benutzte ich ausschliesslich Weckers Pinzettenschere und die kleine Pinzette. Die Enthüllung geht, wenn man sich darin eine Zeit übt, etwas leichter vonstatten. Aber es ist sehr schwer, die in solchem Stadium operierten Keime zu züchten. Da bei der Züchtung im Leitungswasser fast alle oder alle Keime binnen drei bis fünf Tagen nach der Operation sterben, gehen grosse Mühe und kostbare Zeit verloren. Die Sterblichkeit war besonders hoch in der kalten Zeit. Nachdem ich die Instrumente nach Woerdeman ${ }^{i 5)}$ (1930) aseptisch gemacht und die Keime im filtrierten Wasser gezüchtet hatte, wurde das Verhältnis der Mortalität zu der Zahl der Ueberlebenden umgekehrt. Dies befreite mich von

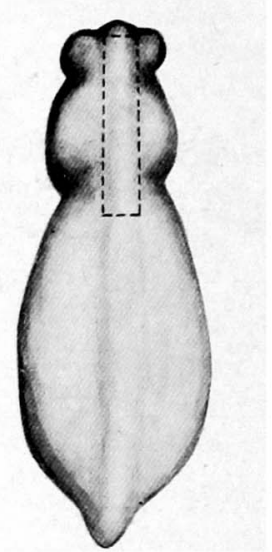

Abb. 4. Exstirpation des Gehirns und kraniokaudale Umkehrung desselben. Schema der Operation. Dorsale Ansicht eines Keimes (kurz nach der Bildung des Neuralrohres, Körperlänge : ca. $3.8-4.0 \mathrm{~mm}$ ). der Sorge um die allzu grosse Sterblichkeit. Bis die Keime lebhaft zu schwimmen begannen, wurden sie nach der Methode von Woerdeman gezüchtet. Dann wurden sie in Glasschalen mit Leitungswasser getan.

Als Nahrung wurden Wasserpflanzen, ein leichtes Gebäck aus Weizenmehl und ein für den Goldfisch hergestellter Köder verwandt. Besondere Hormonpräparate aber, Organ- und Gewebsstücke von anderen Tieren usw. wurden gar nicht gegeben. 
Die Larven wurden eine Zeit lang bezüglich der.Veränderung der Farbtöne ihrer Haut, des Stattfindens oder Ausbleibens der Metamorphose, deren $\mathrm{Zu}$ stände usw. beobachtet. Es erfolgt dann Fixieren in Bouins Gemisch oder in $10 \%$ iger wässeriger Formollösung, Einbetten in Paraffin, Herstellung der Serienschnitte (го Eosin, Boraxkarmin-Pikrinsäure usw..

Ausserdem habe ich, um die Anlage des Infundibulums und die Histogenese des Lobus glandularis sowie des Zwischenlappens zu bestimmen, die lokale Farbmarkierung mit Nilblausulfat angewandt. Genaueres hierüber bringen die betreffenden Kapitel.

\section{Die normale Entwicklung des Infundibulums und des Lobus glandularis.}

I. X-Y-Figur der Neuralplatte.

Bei meiner Untersuchung fiel mir ein Bild auf, das im Neurulastadium in der Neuralplatte aufzutreten pflegt. Es hat bei diesem das Aussehen, als ob die unteren Schenkel von $\mathrm{X}$ und die Schenkel von $\mathrm{Y}$ aufeinanderliegen (Abb. 5). Ich bezeichne diese Lage vorläufig als „X-Y-Figur”. Die Linie, welche dem Stiel von $Y$ entspricht, tritt am deutlichsten vor; sie wird von alters her als "Rückenrinne " beschrieben (Goette, ${ }^{7}$ I 875). Ueber alles Sonstige aber finden sich noch keine Aussagen. Das Auftreten und Verschwinden dieser Figur ist in grossen Zügen wie folgt. Bald nach dem Auftreten der Neuralplatte wird der Stiel von Y sichtbar. Sein kaudales Ende erreicht den Randwulst des Urmundes. Darauf treten die

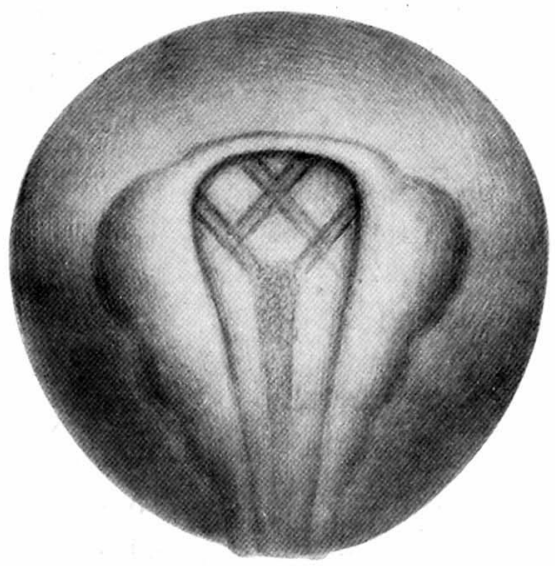

Abb. 5. Schematische Darstellung der $\mathrm{X}$-Y-Figur der N̦euralplatte. Dorsokraniale Ansicht eines Keimes. zwei Schenkel von Y auf. Sie verlaufen vom ktanialen Ende des Stieles symmetrisch und geradlinig kraniolateralwärts. $X$ tritt danach als Kreuzung zweier. gerader Linien kranial von $\mathrm{Y}$ auf. Anfangs kreuzen $\mathrm{X}$ und $\mathrm{Y}$ sich nicht, später aber verlängern sich die Schenkel von $X$ und $Y$ und kreuzen sich einander. Schliesslich erreichen die Schenkel von X und Y den Rand der Neuralplatte und enden dort plötzlich. In diesem Stadium erscheinen statt der späteren bestimmten einzelnen Linien erst einfache, streifenförmige, seichte Vertiefungen. Bald aber erhalten die Vertiefungen eine gewisse 
Breite. Genau gesehen, hat jede Vertiefung zu beiden Seiten je ein tieferes schmales Tal. Deshalb besitzen alle Vertiefungen, welche den Schenkeln von $X$ und $Y$ entsprechen, an ihren Seitenrändern je ein Tal, eins als kraniale und eins als kaudale Begrenzung. Nur der Stiel von $Y$ ist von keinem solchen Tal begleitet. Die Schenkel von X sind kaudal von ihrer Kreuzungsstelle mit $Y$ weit undeutlicher als kranial von dieser Stelle. Der Neuralwulst ist noch nicht deutlich. In der Fläche der Neuralplatte haben sich nirgends Grübchen gebildet. Die Fläche des von X und Y umfassten Bezirkes ist platt. Um bei den nachfolgenden Kapiteln die wiederholte Beschreibung dieses Stadiums auslassen zu können, möchte ich es vorläufig das „, X-Y-Stadium “ der Neuralplatte nennen.

Der Fortschritt in der Entwicklung ist bis hierher relativ langsam, wird dann aber schneller. Die von $\mathrm{X}$ und $\mathrm{Y}$ umfasste Fläche erhebt sich nun ein wenig, bald aber beginnt an dieser Stelle sich eine leichte Einsenkung zu zeigen. Der Neuralwulst ist jetzt schon deutlich sichtbar. Auch in den kranialen und lateralen Abschnitten, welche durch $\mathrm{X}$ geteilt sind, treten Grübchen auf, und $\mathrm{X}$ wird daher undeutlich. Das von $\mathrm{X}$ und $\mathrm{Y}$ eingefasste Grübchen ist nahe seinem kranialen Ende am tiefsten, kaudalwärts wird es allmählich flacher. Diese Grübchen vereinigen sich miteinander jedoch $\mathrm{zu}$ einer Grube und bilden gleichzeitig den kranialen Abschnitt der Neuralfurche. Die Lage des Grübchens, welches anfangs von $X$ und $Y$ eingefasst war, wird daher unklar Auch die Schenkel von Y verschwinden. Nur der Stiel von Y bleibt sichtbar, bis die Neuralfurche ziemlich tief geworden ist. Danach schliesst sich die Neuralfurche.

2. Infundibulum.

Das Infundibulum ist eine eigentümlich gestaltete Ausbuchtung des Hypothalamus, welche kranial vom dorsokaudalen Abschnitt des Chiasma opticum beginnt und kaudal am Tuberculum posterius endet (Abb.6 a). Es findet sich beinahe im Querschnittsniveau des Ganglion prooticum (Abb.6 b). Seine Entwicklung ist wie folgt. Das Infundibulum entwickelt sich schon im Stadium der Schwanzknospe, welche die Larve binnen einigen Tagen nach dem Abschluss des Stadiums der Neuralplatte zeigt, als eine Ausbuchtung am Boden des Zwischenhirns. Mit fortschreitender Gestaltwerdung nimmt die Dicke seiner Wand ab und die Form seiner Zellen verändert sich. Seine Wand hat anfangs eine ungefähr gleichmässige Dicke und besteht aus einigen bis mehreren Schichten von dorsoventral hohen Zellen, welche zylindrisch oder spindelförmig sind. Die Kerne sind rundlich oder oval. Die Wand wird mit Ausnahme des kranialen Abschnittes immer dünner und schliesslich zu einer Schicht der Ependymzellen. Auch diese Zellen sind anfangs zylindrisch oder 

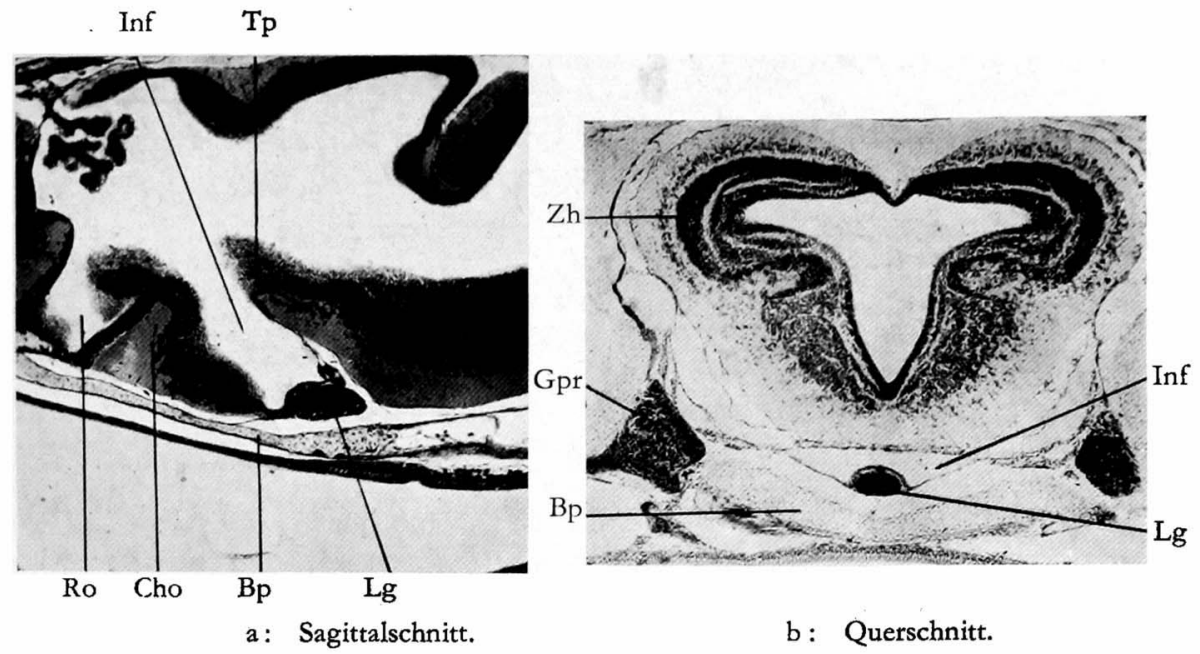

Abb. 6. Infundibulum eines normalen Individuums am Ende der Metamorphose. Vergr. etwa 4omal.

$\mathrm{Bp}=$ Basalplatte, $\quad \mathrm{Cho}=$ Chiasma opticum, $\quad \mathrm{Gpr}=$ Ganglion prooticum, Inf $=$ Infundibulum, $\quad \mathrm{Lg}=$ Lobus glandularis, $\quad \mathrm{Ro}=$ Recessus opticus, $\mathrm{Tp}=$ Tuberculum posterius, $\mathrm{Zh}=\mathrm{Zwischenhirn.}$

spindelförmig, werden danach aber kubisch. Ihre Kerne verändern sich dementsprechend und werden rundlich. Die ganzen kubischen Zellen bilden sich weiter in eine Schicht platter Zellen um. Auch ihre Kerne werden niedrig. Man beobachtet solch ein membranöses Bild im kaudalen Abschnitt der ventralen Wand sowie der lateralen Wand und in der ganzen kaudalen Wand. Das Infundibulum ist also nur im kranialen Abschnitt dickwandig. In diesem Stadium dehnt es sich stark ventrokaudalwärts aus. Dies ist der Zustand in dem Stadium, da der Lobus glandularis gerade das kraniale Ende des Infundibulums erreicht hat. Auf die ventrale Wand des Infundibulums findet später vom Lobus glandularis aus dorsalwärts ein Eindruck statt. Die kaudale Wand neigt sich schief von ventrokaudal nach dorsokranial und erreicht das Tuberculum posterius. Der von dem Lobus glandularis erzeugte Eindruck in die ventrale Wand und die Neigung der kaudalen Wand werden nach der Ausbildung der Basalplatte deutlicher. Der Lobus nervosus entwickelt sich kontinuierlich, indem folgende Teile an seinem Wachstum beteiligt sind : ein Teil des dicken kranialen Abschnittes der ventralen Wand, der sich der membranösen ventralen Wand anschliesst, die ganze membranöse ventrale Wand, ein Teil der lateralen membranösen Wand, der an die ventrale Wand grenzt, und ein Teil der kaudalen Wand, der ebenfalls an die ventrale Wand grenzt. Die membranöse Struktur geht also in diesen Teilen verloren. 
3. Lobus glandularis.

Der Lobus glandularis beginnt sich als eine Verdickung der tiefen Schicht des Ektoderms, welches von ventrokranial her an den das kraniale Ende der Neuralplatte umrändernden schmalen Neuralwulst grenzt, zu entwickeln. Er ist im Stadium der Neuralplatte noch ganz leicht verdickt, hat aber nach der Vollendung des Neuralrohres schon konisch gewuchert, richtet seine Spitze kaudalwärts und legt sich der Hirnbasis an. Er wird danach zungenförmig, ferner löffelförmig und erreicht das kraniale Ende des Infundibulums. Die Verbindung mit seinem Mutterboden wird schliesslich abgetrennt, worauf er sich an der ventralen Fläche des Infundibulums kaudalwärts verschiebt. Sein kaudales Ende erreicht das gleiche Querschnittsniveau wie das kaudale Ende des Infundibulums. Etwas vorher trennen sich Zellen vom dorsokaudalen Teil des Lobus glandularis $a b$ und beteiligen sich an der Entstehung des Zwischenlappens (Genaueres s. unter „Histogenese des Zwischenlappens “). Der Lobus glandularis ist von den Mesenchymzellen umgeben, abgesehen von seiner dorsalen Fläche, welche die ventrale Fläche des Infundibulums und die Anlage des Zwischenlappens berührt. Er bleibt dort in solchem Zustand. Wenn die umgebenden Mesenchymzellen verschwinden, werden die Basalplatte, Hirnhäute usw. gebildet, und der Lobus glandularis wird nun grösstenteils von den Hirnhäuten umgeben. Nur ein Teil seines kranialen Abschnittes verbindet sich direkt mit dem kranialen Wandabschnitt des Infundibulums, welches schon zu dem primitiven Lobus nervosus geworden ist. Ein Paar Höcker beginnen sich weit später vom kranialen Ende des Lobus glandularis her zu entwickeln. Diese Höcker verlängern sich allmählich kranialwärts und trennen sich schliesslich bei Annäherung der Metamorphose vom Mutterboden ab. Sie sind die Pars tuberalis. Sie liegen an der ventralen Fläche des kranialen dickwandigen Abschnittes des Infundibulums und, genauer gesagt, in einem Paar Hirnhautsäckchen. Der Lobus glandularis wuchert nach der Bildung der Basalplatte auffallender. Er kann infolgedessen einen starken Druck dorsalwärts an der ventralen Wand des Infundibulums ausüben. Sein Gewebe tritt ebenfalls weiter kaudal als das kaudale Ende des Infundibulums hervor (Abb, $6 \mathrm{a}$ ). Die Lage des Lobus glandularis entspricht beinahe dem Querschnittsniveau des Ganglion prooticum (Abb. 6 b).

\section{Experimente an der Anlage des Infundibulums.}

I. Bestimmung der Anlage.

Was die Anlage des Infundibulums in der Neuralplatte anbetrifft, besitzen wir noch keine Studien. Die X-Y-Figur (s. unter , X-Y-Figur der Neuralplatte ") als Merkmal benutzend, habe ich einen Defektversuch mit dem von $X$ 
und $\mathrm{Y}$ umgebenen Bezirke ausgeführt; es gelang mir, ein Individuum ohne Infundibulum zu züchten. Um festzustellen, ob dies wirklich der Bezirk der Anlage des Infundibulums sei, habe ich die lokale Farbmarkierung mit Nilblausulfat ausgeführt. Nachdem sich das Infundibulum gebildet hatte, d.h. die Larven zu schwimmen begonnen hatten, wurden letztere nach der Lehmannschen Methode behandelt. Paraffineinbettung und Serienschnitt (гон).

Aus dem Resultat konnte ich erkennen, dass der Bezirk gerade der Anlage des Infundibulums entspricht.

Indem ich nämlich ( $\mathrm{I}$ ) den Scheitel des Winkels, welchen die zwei Linien von $\mathrm{X}$ kaudal von ihrem Kreuzungspunkt fassen, als Merkmal des kranialen Endes der lokalen Farbmarkierung benutzte, stach ich ein mit Nilblausulfat durchtränktes Agarstäbchen dort senkrecht zur Neuralplatte ein und zog es nach einigen Minuten wieder heraus (Abb. 7 a). Das kraniale Ende des gefärbten Teiles entsprach dem kranialen Ende des Infundibulums (Abb. 7 b).

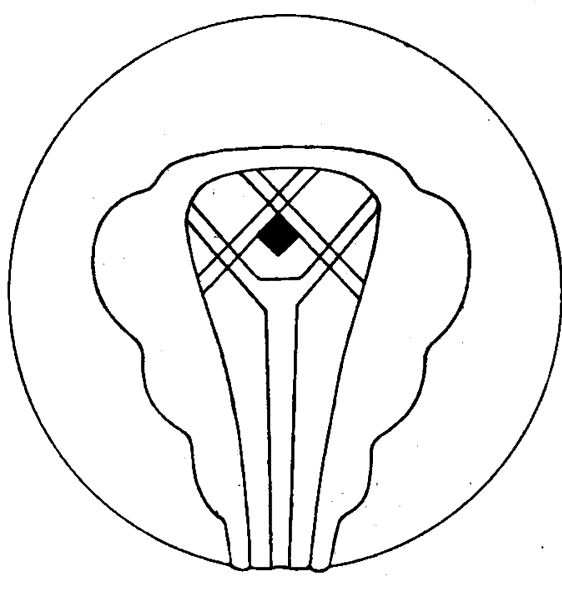

a

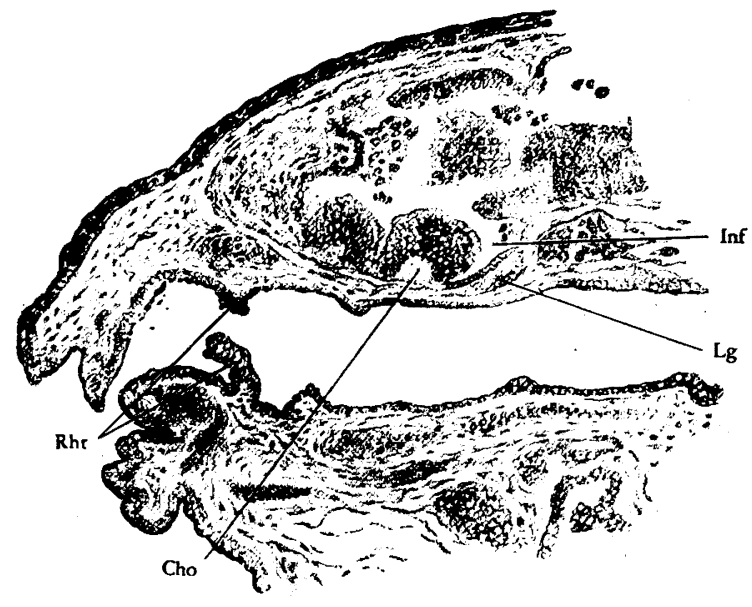

b

Abb. 7. Bestimmung der Anlage des Infundibulums. Lokale Farbmarkierung ihres kranialen Endes. a: Schema der Markierungsstelle. b: Ergebnis. Sagittalschnitt, Zeichnung, Vergr. etwa 7omal. Markierte Stelle blau. Cho=Chiasma opticum, Rhr=Reste der Rachenhaut.

(2) Das kraniale Ende des Stieles von Y als Merkmal des kaudalen Endes der lokalen Farbmarkierung benutzend (Abb. 8 a), wurde das Agarstäbchen ebenfalls derart eingestochen, dass es kranial ans kraniale Ende des Stieles von $Y$ grenzte. Das kaudale Ende des gefärbten Teiles entsprach dem kaudalen Ende des Infundibulums (Abb. 8 b).

(3) Der Scheitel des medialen Winkels, welcher durch die Kreuzung von $\mathrm{X}$ mit $\mathrm{Y}$ gebildet wird, wurde ebenfalls als Merkmal des lateralen Endes der 

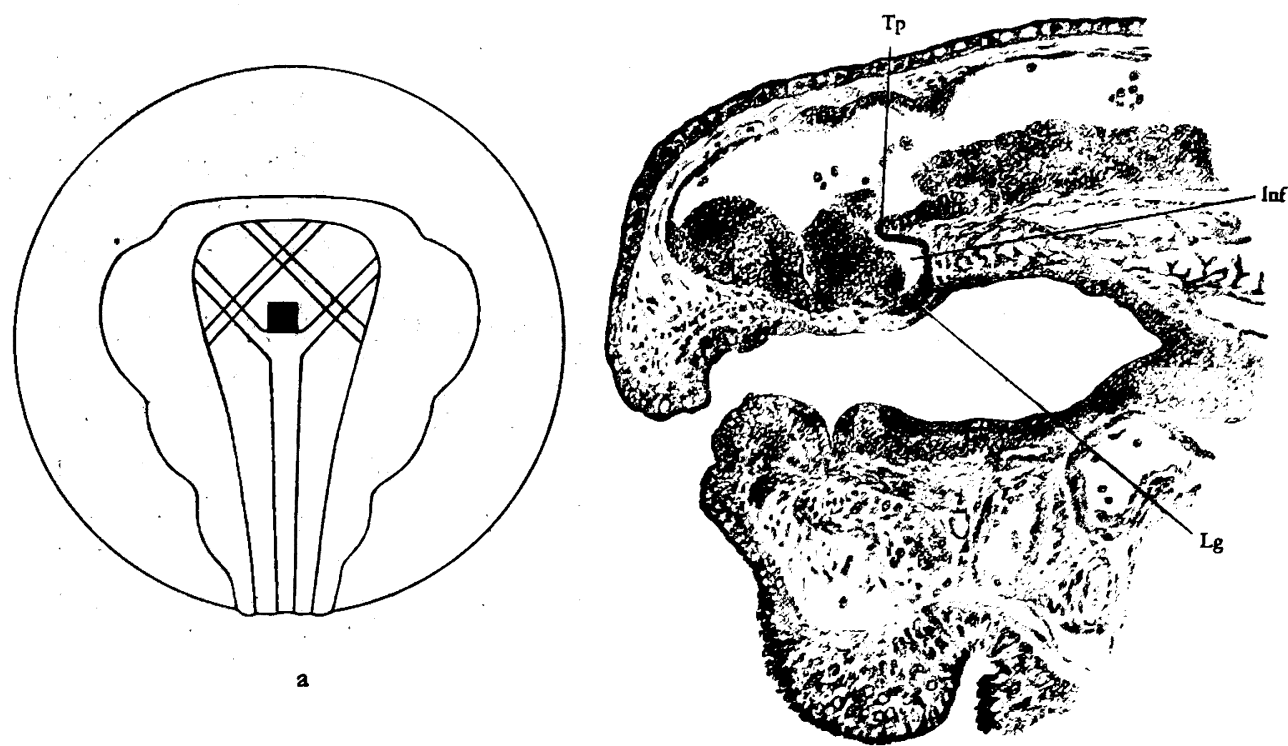

$\mathrm{b}$

Abb. 8. Bestimmung der Anlage des Infundibulums. Lokale Farbmarkierung ihres kaudalen Endes. a : Schema der Markierungsstelle. b : Ergebnis. Sagittalschnitt, Zeichnung, Vergr. etwa 7omal. $\mathrm{Tp}=$ Tuberculum posterius.

lokalen Farbmarkierung benutzt (Abb.9 a). Die laterale Grenze des gefärbten Teiles entsprach der des Infundibulums (Abb.9 b).

Ausserdem konnte ich dem Resultat entnehmen, dass der grössere Teil des kranialen Abschnittes des von $\mathrm{X}$ und $\mathrm{Y}$ umgebenen Bezirkes zum dickwandigen Teil des Infundibulums, der kleinere Teil des kaudalen Abschnittes dagegen zum dünnwandigen Teil desselben wird und sich stark ventrokaudalwärts ausdehnt.

Man kann am Stiel von Y nicht wie im Vorhergehenden die seitlichen Begrenzungen, welche man an den Schenkeln von $\mathrm{X}$ und $\mathrm{Y}$ bemerkt, beobachten. Die kaudale Grenze der Anlage, d.h. das kraniale Ende des Stieles von $\mathrm{Y}$, ist deshalb undeutlich. Genauer gesehen, bemerkt man aber viele feine punktförmige Grübchen im Stiel von Y. Wenn man daher die Grübchen kranialwärs bis an ihr kraniales Ende verfolgt, so vermag man die kaudale Grenze der Anlage zu bestimmen. Oder man kann auch die kaudale Grenze wie folgt feststellen. Wenn man ein von $\mathrm{X}$ und $\mathrm{Y}$ umgebenes Quadrat annimmt, so sind seine kraniale und seine beiden lateralen Ecken die wahren, seine kaudale Ecke jedoch ist nur eine angenommene. Zieht man nun eine Linie durch die beiden Kreuzungsstellen von X und Y, so wird das Quadrat in ein kraniales und ein kaudales Dreieck halbiert. Die Linie, welche die Mittel- 

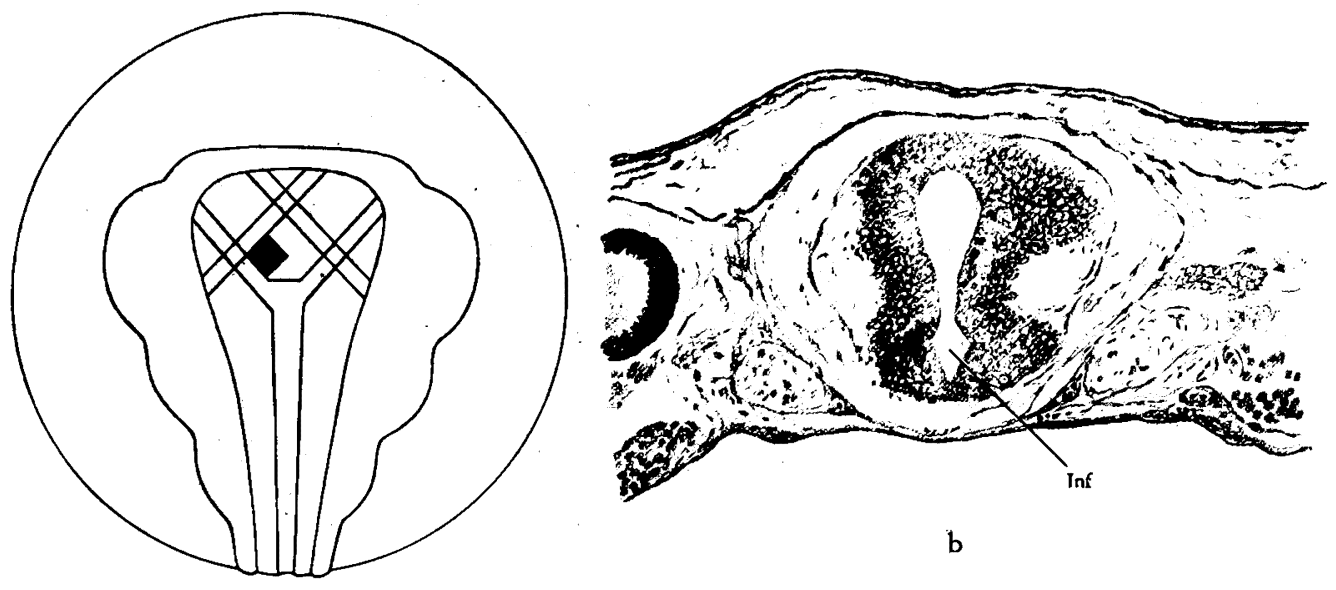

a

Abb. 9. Bestimmung der Anlage des Infundibulums. Lokale Farbmarkierung ihrer lateralen Grenze. a: Schema der Markierungsstelle. b: Ergebnis. Querschnitt, Zeichnung, Vergr. etwa $70 \mathrm{mal}$.

punkte zweier Ränder des vermuteten kaudalen Dreieckes verbindet, entspricht beinahe dem kranialen Ende des Stieles von Y. Daher entspricht die Form der Anlage einem Quadrat, bei welchem die kaudale Ecke offen ist.

Anhang: Die Anlage des Chiasma opticum und das kraniale Ende der Chorda dorsalis.

Aus den mittels der obigen lokalen Farbmarkierung erhaltenen Resultaten ist ersichtlich, dass die Kreuzungsstelle der Linien von X der Anlage des Chiasma opticum entspricht. Ferner liess sich ihnen auch entnehmen, dass das Niveau des kranialen Endes des Stieles von Y beinahe dem kranialen Ende der Chorda dorsalis entspricht.

\section{Schluss.}

Beim Bufokeim tritt die von mir so genannte X-Y-Figur frühzeitig in der Neuralplatte auf. Der von X und Y umgebene Bezirk entspricht ungefähr der Anlage des Infundibulums.

2. Totale Exstirpation.

Drei Fälle vollendeten die Metamorphose frühzeitig. Bei zwei von diesen Fällen waren das Infundibulum und die Hypophyse ebenso wie sonst, d.h. ganz normal gebildet worden. Ein anderer Fall wies kein Infundibulum auf, doch unterschied sich das betreffende Individuum von anderen infundibulumlosen Individuen dadurch, dass es die Metamorphose frühzeitig vollendete und die Anlage der Pars tuberalis deutlich bildete. 
Alle sonstigen Individuen waren vollständig infundibulumlos. Sie begannen fast gleichzeitig mit ihren Kontrollen die Metamorphose und vollendeten bald die vier Beine. Doch verzögerte sich die Verkürzung des Schwanzes deutlich. Um zu sehen, ob der Schwanz vollständig verloren ging, beobachtete ich die Tiere möglichst lange Zeit, soweit es die Umstände erlaubten. Doch verloren schliesslich keine Individuen den Schwanz während der Züchtung vollständig.

Alle infundibulumlosen Individuen zeigten bis etwa zum Eintritt der Metamorphose den normalen Farbton der Haut. Später wiesen sie jedoch verschiedene Farbtöne auf : sie sahen braun, gelblich braun, grün, grünlich silbern, grau usw. aus. Einige von ihnen wurden zuerst grünlich silbern und später grau. Aber ich konnte nicht feststellen, ob ein und dasselbe Individuum im Verlaufe der Zeit eine bestimmte Reihenfolge in der Veränderung dieser Farbtöne einhielt.

Ich beschreibe unten den Befund der 30 infundibulumlosen Individuen mit Ausnahme von zwei Fällen, welche völlig ebenso wie die normalen waren.

a. Befund nach der Operation.

Der Zwischenhirnboden ist ganz geschlossen. An der Stelle, welche normalerweise das Infundibulum einnimmt, hat sich weder das Infundibulum noch eine Ausbuchtung gebildet (Abb. 10). Diese Gegend ist dickwandig und zeigt die gleiche Struktur wie die anderen Wandabschnitte; die Ependymzellen liegen am Ventrikel und die weisse und die graue Substanz folgen ventral davon schichtenweise. Man kann also die Stelle, welche normal vom Infundibulum eingenommen werden soll, am Hirnboden nicht genau erkennen.

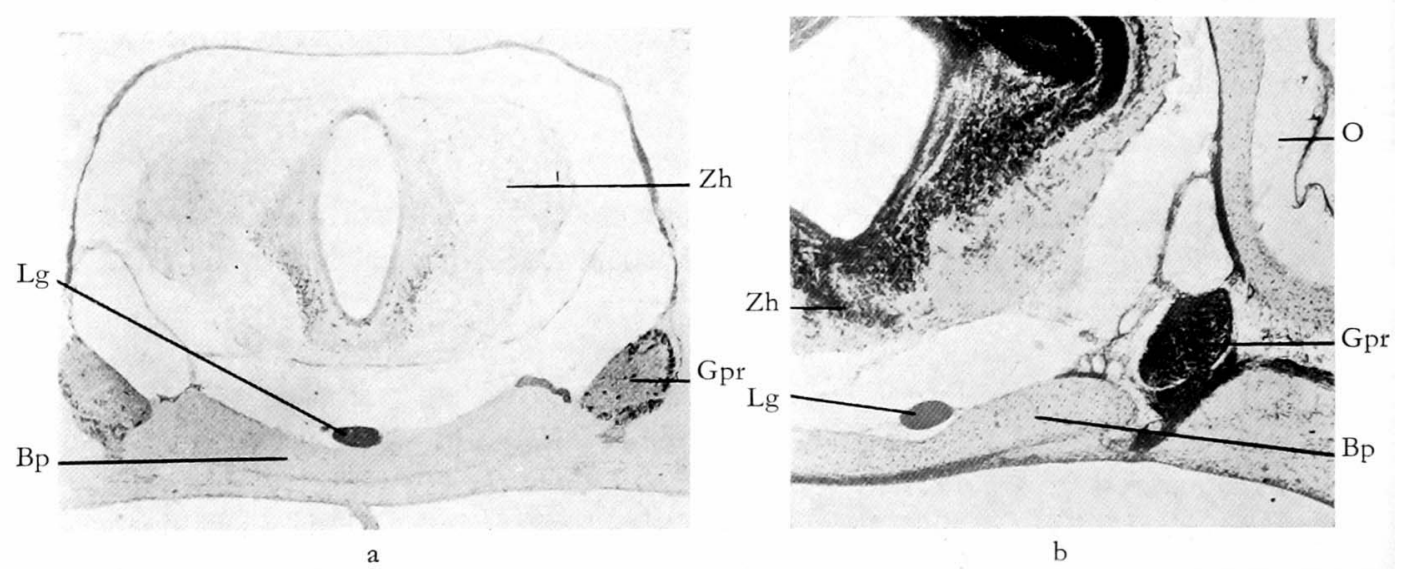

Abb. xо. Totale Exstirpation der Anlage des Infundibulums. Lobus glandularis sowie Zwischenhirnboden beim Fehlen des Infundibulums. Querschnitte, Vergr. etwa somal. $\mathrm{Bp}=\mathrm{Ba}-$ salplatte, $\mathrm{Gpr}=$ Ganglion prooticum, $\mathrm{Lg}=$ Lobus glandularis, $\mathrm{O}=\mathrm{Ohr}, \quad \mathrm{Zh}=\mathrm{Zwischenhirn}$. 
Der Recessus opticus ist entstanden. Die kraniale Hälfte des Chiasma opticum hat sich ebenso wie im normalen Falle gebildet, aber die kaudale Hälfte desselben, d.h. der kraniale Teil des Infundibulums, hat sich nicht entwickelt. Die Dicke des Hirnbodens nimmt vom Chiasma opticum kaudalwärts bis zum Boden des Rhombencephalóns allmählich ab. Freilich hat sich kein Tuberculum posterius gebildet.

b. Lobus glandularis beim Fehlen des Lobus nervosus.

I. Grösse.

Auch hier ist schon bei einfacher Mikroskopierung leicht ersichtlich, dass der Lobus glandularis weit kleiner als normal ist. Um aber die Grösse noch genauer festzustellen, zeichnete ich den Lobus glandularis mit dem A b b é schen Zeichenapparat den Serienschnitten nach auf Papier und wog ihn. Zum Vergleich benutzte ich das Gewicht statt des Volums.

Tabelle I.

A) Lobus glandularis der normalen Individuen gerade nach der Metamorphose.

\begin{tabular}{|c|c|c|c|c|c|}
\hline $\begin{array}{c}\text { Züchtungs- } \\
\text { tage }\end{array}$ & Präparate & \begin{tabular}{|} 
Datum der \\
Neuralplatte
\end{tabular} & $\begin{array}{l}\text { Datum dex } \\
\text { Fixation }\end{array}$ & $\begin{array}{c}\text { Körpergrösse } \\
(\mathrm{cm})\end{array}$ & $\begin{array}{l}\text { Gewicht des } \\
\text { Lobus glan- } \\
\text { dularis (mg) }\end{array}$ \\
\hline 64 & A. $64,271, b$ & $24 / \mathrm{III}$ & $27 / \mathrm{V}$ & K.L. : I.00 & $\begin{array}{l}3.8 \% \\
(3.6)\end{array}$ \\
\hline 50 & H. 50,356 & $4 / \mathrm{V}$ & $23 / \mathrm{VI}$ & K.L. : 0.75 & $\left(\begin{array}{l}3.3 \\
3.1\end{array}\right)$ \\
\hline 36 & N. ${ }_{36,318}$ & $10 / \mathrm{V}$ & $\mathrm{I} 5 / \mathrm{VI}$ & K.L. : 1.00 & $\begin{array}{l}3.8 \\
(3.5)\end{array}$ \\
\hline 34 & IS7 II & $2 \mathrm{I} / \mathrm{V}$ & $24 / \mathrm{VI}$ & K.L. : 0.62 & $\begin{array}{l}4.5 \\
(4 . I)\end{array}$ \\
\hline 25 & I4I I & $27 / \mathrm{V}$ & $2 \mathrm{I} / \mathrm{VI}$ & K.L. : 0.70 & $\begin{array}{l}3.2 \\
(2.7)\end{array}$ \\
\hline$"$ & I4I II & $"$ & $"$ & K.L. : $c .62$ & $\begin{array}{l}4.2 \\
(3.8)\end{array}$ \\
\hline
\end{tabular}

* Die in Klammer gesetżte Zahl gibt das Gewicht des Lobus glandularis allein an. Die nicht in Klammer gesetzte Zahl zeigt das gesamte Gewicht des Lobus glandularis und der Pars tuberalis.

B) Lobus glandularis beim Fehlen des Lobus nervosus.

(x) Lobus glandularis im Cavum cranii,

\begin{tabular}{|c|c|c|c|c|c|c|}
\hline $\begin{array}{l}\text { Züchtungs- } \\
\text { tage }\end{array}$ & Präparate & $\begin{array}{l}\text { Datum der } \\
\text { Operation }\end{array}$ & $\begin{array}{l}\text { Datum der } \\
\text { Fixation }\end{array}$ & $\underset{(\mathrm{cm})}{\text { Körpergrösse }}$ & $\begin{array}{l}\text { Gewicht des } \\
\text { Lobus glan- } \\
\text { dularis (mg) }\end{array}$ & Lage \\
\hline 77 & 205 & 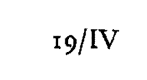 & $5 / \mathrm{VII}$ & $\begin{array}{ll}\text { K.L.: } & 2.00 \\
\text { S-A-L. : } 0.82\end{array}$ & 0.5 & $\begin{array}{l}\text { Zwischen } \\
\text { Himbasis und } \\
\text { Basalplatte }\end{array}$ \\
\hline $7^{2}$ & E. $72,387, b$ & $2 \mathrm{I} / \mathrm{IV}$ & $2 / \mathrm{VII}$ & K.L. : $\quad$ I. .98 & 0.8 & " \\
\hline
\end{tabular}


B) (r) (Fortsetzung).

\begin{tabular}{|c|c|c|c|c|c|c|}
\hline $\begin{array}{l}\text { Züchtungs- } \\
\text { tage }\end{array}$ & Präparate & $\begin{array}{l}\text { Datum der } \\
\text { Operation }\end{array}$ & $\begin{array}{l}\text { Datum der } \\
\text { Fixation }\end{array}$ & $\begin{array}{c}\text { Körpergrösse } \\
(\mathrm{cm})\end{array}$ & $\begin{array}{l}\text { Gewicht des } \\
\text { Lobus glan- } \\
\text { dularis (mg) }\end{array}$ & Lage \\
\hline 70 & E. $70,3^{8} 3$ & $21 / \mathrm{IV}$ & $30 / \mathrm{VI}$ & K.L. : $\quad 1.20$ & 0.8 & $\begin{array}{l}\text { Zwischen } \\
\text { Hirnbasis und } \\
\text { Basalplatte }\end{array}$ \\
\hline 66 & E. $66, b,{ }_{3}^{6} 64$ & $"$ & $26 / \mathrm{VI}$ & K.L.: I.30 & 0.7 & $"$ \\
\hline 63 & E. $63,350,1$ & $"$ & $23 / V I$ & K.L. : $1.4^{\circ}$ & 0.5 & $\eta$ \\
\hline 59 & $: 74,1$ & 30/IV & $28 / \mathrm{VI}$ & K.L.: $\quad 1.45$ & 0.8 & ” \\
\hline$"$ & 173 & $"$ & $"$ & $\begin{array}{l}\text { K.L.: } \quad \text { I.95 } \\
\text { S-A-L.: }: 0.75\end{array}$ & 0.5 & $"$ \\
\hline$"$ & 174,2 & $"$ & $"$ & $\begin{array}{l}\text { K.L.: } \quad 1.80 \\
\text { S-A-L.: } 0.65\end{array}$ & 0.8 & $"$ \\
\hline 58 & E. 58,335 & $2 \mathrm{I} / \mathrm{IV}$ & $18 / V I$ & K.L.: 2.30 & 1.2 & $"$ \\
\hline 57 & 197 & $9 / \mathrm{V}$ & s/VII & $\begin{array}{l}\text { K.L.: } 2.10 \\
\text { S-A-L.: } 0.85\end{array}$ & 1.5 & $"$ \\
\hline 54 & 198 & $12 / V$ & $"$ & $\begin{array}{l}\text { K.L.: } 2.00 \\
\text { S-A-L.: } 0.75\end{array}$ & I. 2 & $"$ \\
\hline 51 & 176 & $8 / \mathrm{V}$ & $28 / \mathrm{VI}$ & & 1.5 & $"$ \\
\hline ” & 175 & $"$ & $"$ & K.L.: $\quad 1.35$ & 0.6 & ” \\
\hline$"$ & $180 \mathrm{I}$ & $"$ & $"$ & & I.I & $"$ \\
\hline$"$ & $180 \mathrm{II}$ & $"$ & $"$ & & 2.2 & $"$ \\
\hline ” & 172 & $"$ & $"$ & $\begin{array}{l}\text { K.L.: } \quad 1.45 \\
\text { S-A-L.: } 0.65\end{array}$ & 0.8 & $"$ \\
\hline 36 & 178 & $23 / \mathrm{V}$ & $"$ & $\begin{array}{l}\text { K.L.: } 2.10 \\
\text { S-A-L.: } 0.85\end{array}$ & $x .5$ & $"$ \\
\hline
\end{tabular}

(2) Lobus glandularis ausserhalb des Cavum cranii.

\begin{tabular}{|c|c|c|c|c|c|c|}
\hline $\begin{array}{l}\text { Züchtungs- } \\
\text { tage }\end{array}$ & Präparate & $\begin{array}{l}\text { Datum der } \\
\text { Operation }\end{array}$ & $\begin{array}{l}\text { Datum der } \\
\text { Fixation }\end{array}$ & $\underset{(\mathrm{cm})}{\text { Körpergrösse }}$ & $\begin{array}{l}\text { Gewicht des } \\
\text { Lobus glan- } \\
\text { dularis (mg) }\end{array}$ & Lage \\
\hline 72 & E. 72,390 & $21 / \mathrm{IV}$ & $2 / \mathrm{VII}$ & K.L.: $\quad$ I.75 & 0.2 & $\underset{\text { Gaumendach }}{\operatorname{Im}}$ \\
\hline 66 & E. $66, a, 364$ & " & $26 / \mathrm{VI}$ & K.L. : $\quad 1.00$ & 0.8 & $"$ \\
\hline 63 & E. $63,350,2$ & " & $23 / \mathrm{VI}$ & $\begin{array}{ll}\text { K.L.: } & 1.20 \\
\text { S-A-L.: } 0.55\end{array}$ & 2.2 & $"$ \\
\hline $6 x$ & F. 61, 400 & $3 / \mathrm{V}$ & $3 / \mathrm{VHI}$ & K.L. : $\quad 2.00$ & 2.7 & $\begin{array}{c}\text { In der } \\
\text { Basalplatte }\end{array}$ \\
\hline$"$ & F. 6I, a, 398 & " & " & K.L. : $\quad \mathrm{I} .4^{\circ}$ & 2.6 & ” \\
\hline $5^{8}$ & F. 58,384 & $"$ & $30 / \mathrm{VI}$ & $\begin{array}{ll}\text { K.L.: } & \text { 1.25 } \\
\text { S-A-L.: } & 0.75\end{array}$ & 2.3 & $\begin{array}{l}\text { Im } \\
\text { Gaumendach }\end{array}$ \\
\hline $4^{8}$ & E. 48,354 & $6 / \mathrm{V}$ & ${ }_{23} / \mathrm{VI}$ & 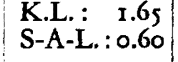 & 2.5 & $"$ \\
\hline $4 \mathrm{I}$ & 208 & $27 / \mathrm{V}$ & 7/VII & & 2.3 & $n$ \\
\hline
\end{tabular}

K.L.: ganze Körperlänge, S-A-L.: Schnauzen-Anus-Länge.

Bemerkung. $\mathrm{Da}$ ich in Tabelle $\mathrm{x}$ die an verschiedenen Tagen operierten Individuen bequemlichkeitshalber einfach nach der Reihenfolge der Züchtungstage anordnete, zeigt diese Anordnung somit nicht das Stadium der wahren Entwicklung der Larve. 
Aus dieser Tabelle kann man die Tatsache ablesen, dass der Lobus glandularis beim Fehlen des Lobus nervosus weit kleiner ist als normal. Er entwickelt sich auch in diesem Falle bis zu einem gewissen Grade, verkleinert sich danach aber im Verlaufe der Zeit in auffallerfdem Masse.

Ausserdem erhält man bei Mikroskopierung folgenden Befund. Die Ablagerung des tiefbraunen Pigmentes ist im ganzen Lobus glandularis weit auffallender als normal. In einigen Fällen sieht der Lobus glandularis vollständig schwarz aus, so dass seine Zellen fast nicht gesehen werden. Auch die strangartige Anordnung der Zellen ist in den meisten Fällen undeutlicher als im normalen Falle.

Kurz, der Lobus glandularis ist also nur kümmerlich entwickelt.

2. Lage.

(I) Kaudale Verschiebung.

Der Lobus glandularis kann sich kaudalwärts verschieben, auch wenn das Infundibulum nicht vorhanden sein sollte. Die Lage, da der Lobus glandularis schliesslich verblieb, war meist verschieden. Man stellte ihn auf der Strecke zwischen dem kaudalen Ende der Hemisphäre und dem Querschnittsniveau des Ganglion prooticum fest. Niemals bewegt er sich kaudalwärts über das Querschnittsniveau des Ganglion prooticum hinaus, d.h. der grösste Abstand, den der Lobus glandularis beim Fehlen des Lobus nervosus selbständig von seinem Mutterboden aus durch kaudale Verschiebung erreichen kann, entspricht fast dem Querschnittsniveau, wo er sich normal befindet (Abb. Io u. $6 \mathrm{~b})$.

(2) Lage des Lobus glandularis in bezug auf Schädel und Querschnittsebene.

Der Lobus glandularis liegt bald im Cavum cranii, bald ausserhalb desselben. Er ist im Cavum cranii von den Hirnhäuten umgeben.

In 19 von 30 Fällen befindet sich der Lobus glandularis im Cavum cranii zwischen der Hirnbasis und der Basalplatte. In 18 von diesen i9 Fällen wiederum berührt er nicht die Hirnbasis ; in den meisten Fällen liegt er vielmehr auf der Basalplatte (Abb. 16 b), doch hängt er in einigen Fällen in der Mitte zwischen der Hirnbasis und der Basalplatte (Abb. IO). In einem anderen Falle berührt er die Hirnbasis mit seinem kranialen und die Basalplatte weiter kaudal davon mit seinem kaudalen Ende (Abb. I 5 ).

Bei 6 anderen Fällen liegt er ventral von der Basalplatte und wird vom Bindegewebe des Gaumendaches umgeben (Abb. II).

In zwei anderen Fällen ist er durch die Basalplatte in zwei Teile geschieden ; der eine Teil liegt dorsal von der Basalplatte, der andere ventral von derselben. 


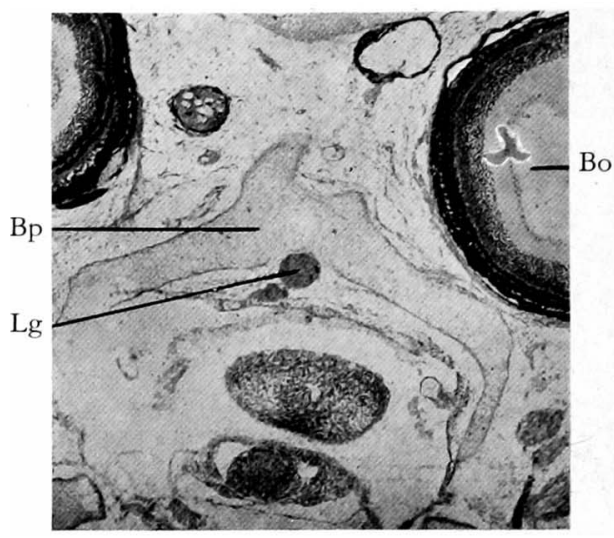

In dem einen Falle findet der grössere Teil sich im Cavum cranii und der kleinere Teil liegt der ventralen Fläche der Basalplatte an (Abb. 12.) In dem anderen Falle ist das Verhältnis umgekehrt. Die Basalplatte ist $z$ wischen diesen beiden getrennten Teilen unvollkommen geschlossen und hinterlässt eine kleine Lücke.

In einem Falle wird der

Abb. I1. Lobus glandularis beim Fehlen des Infundibulums. Querschnitt, Vergr. etwa 4omal. Lobus glandularis unterhalb der Basalplatte. $\mathrm{Bo}=$ Bulbus oculi.

Abb. 12. Lobus glandularis beim Fehlen des Infundibulums. Querschnitt, Vergr. etwa 8omal. Lobus glandularis, durch die $\mathrm{Ba}$ salplatte in zwei Teile geschieden. Ro $=$ Recessus opticus.

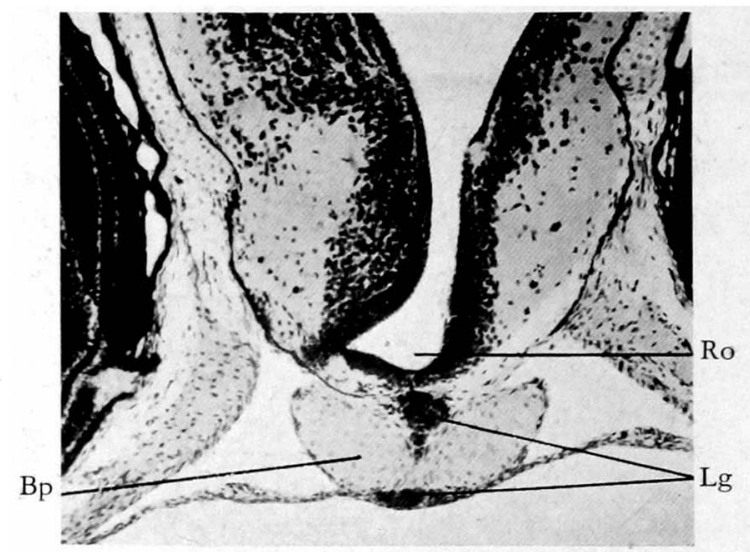

Lobus glandularis gerade in die

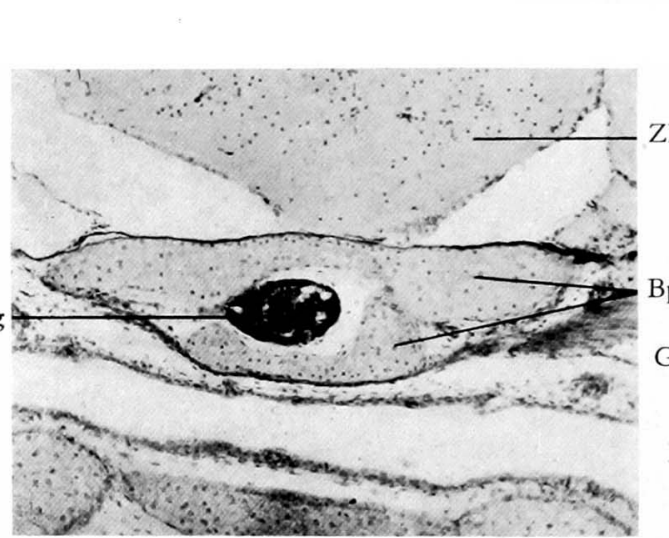

Abb. 13. Lobus glandularis beim Fehlen des Infundibulums. Querschnitt, Vergr. etwa $70 \mathrm{mal}$. Lobus glandularis wird gerade in die Basalplatte eingeschlossen.

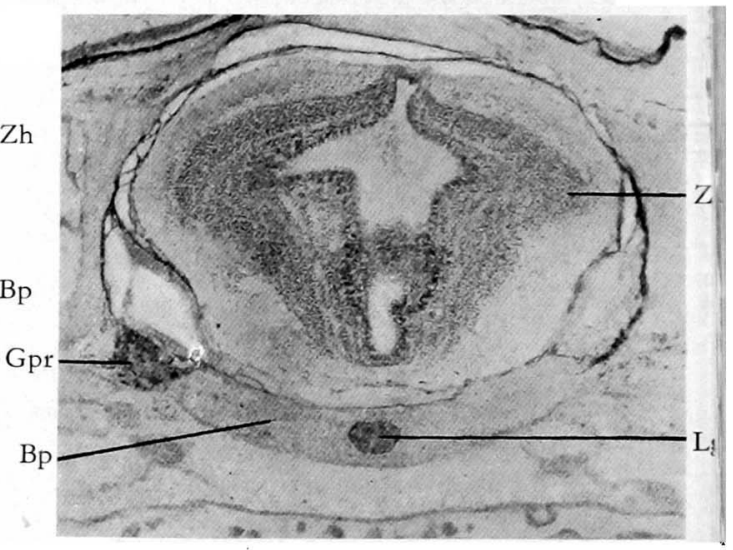

Abb. 14. Lobus glandularis beim Fehlen des Infundibulums. Querschnitt, Vergr. etwa 40mal. Lobus glandularis ist völlig in der Basalplatte eingeschlossen. 
Basalplatte eingeschlossen (Abb. 13).

In 2 Fällen ist er bereits von der Basalplatte vollständig eingeschlossen worden (Abb. I4).

In bezug auf die Querschnittsebene befindet er sich in I 8 von $30^{\circ}$ Pällen auf der Medianebene. In den übrigen I 2 Fällen weicht er lateralwärts ab. Die Seite aber, nach der hin die Abweichung stattfindet, ist verschieden : bald nach rechts, bald nach links.

\section{Zwischenlappen und Pars tuberalis.}

Der Zwischenlappen wurde in allen Fällen gar nicht gebildet.

Die Pars tuberalis findet sich in allen Fällen nicht vom Lobus glandularis abgetrennt. Nur in 2 Fällen wurde die Anlage der Pars tuberalis in Form von 2 Höckern am kranialen Ende des Lobus glandularis erkennbar. In einem Falle überbrückt der Lobus glandularis die Hirnbasis und die Basalplatte d.h.

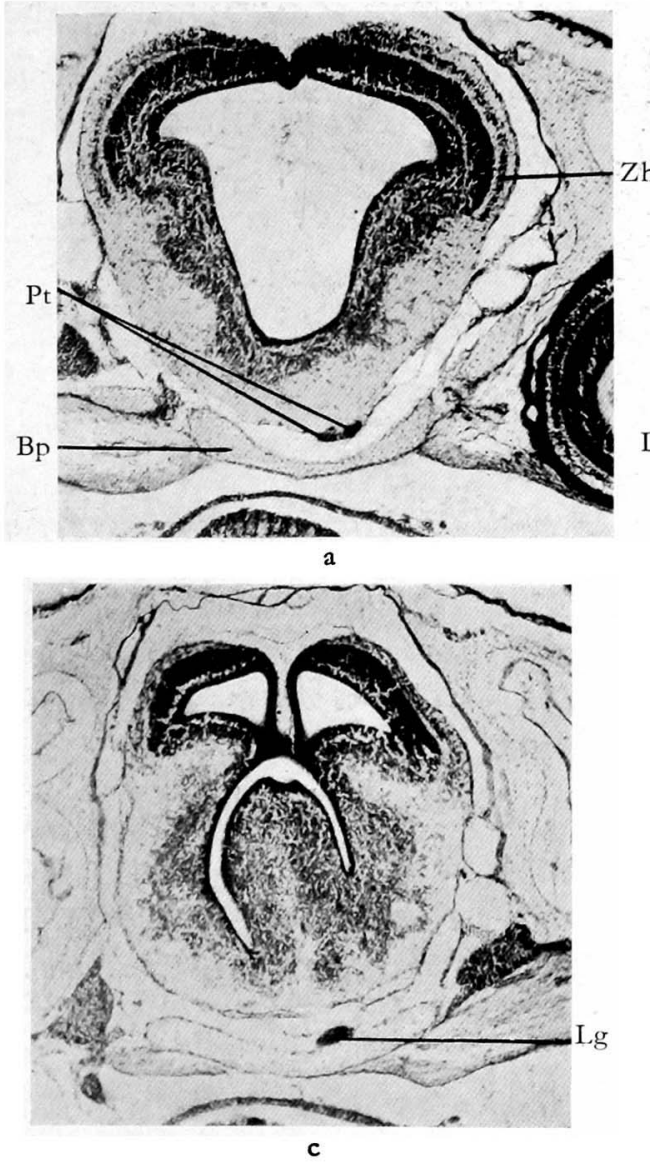

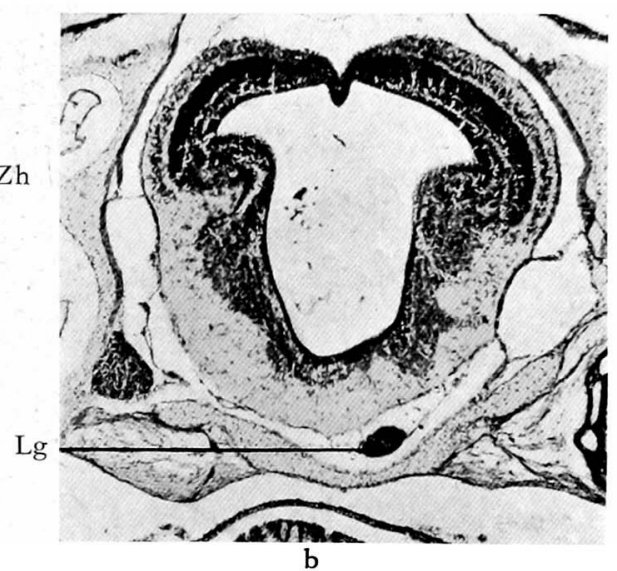

-Abb. Is. Lobus glandularis beim Fehlen des Infundibulums. Querschnitte, Vergr. etwa 4omal. Anlage der Pars tuberalis an der Hirnbasis.

a : Anlage der Pars tuberalis.

b: Weiter kaudal als a; mittlerer Abschnitt des Lobus glandularis.

c: Weiter kaudal als b; kaudales Ende des Lobus glandularis. $\mathrm{Pt}=\mathrm{Pars}$ tuberalis (Anlage). 
er berührt die Hirnbasis mit seinem kranialen und die Basalplatte weiter kaudal mit seinem kaudalen Ende. Eine paarige Anlage der Pars tuberalis hat sich in Gestalt zweier deutlicher Höcker am kranialen Ende des Lobus glandularis und zugleich an der Hirnbasis gebildet (Abb. I ). Es war dieses Individuum, welches von den infundibulumlosen Individuen seine Metamorphose während der Züchtung vollendete. In einem anderen Falle liegt der Lobus glandularis auf der Basalplatte und lässt am kranialen Ende zwei kleine Höcker vorspringen (Abb. I6).
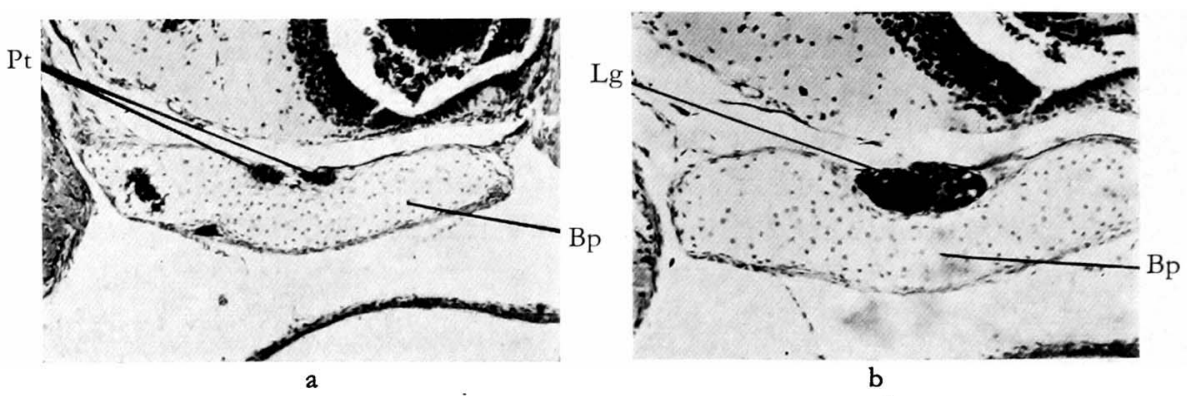

Abb. 16. Lobus glandularis beim Fehlen des Infundibulums. Querschnitte, Vergr. etwa 6omal. Anlage der Pars tuberalis auf der Basalplatte.

a: Anlage der Pars tuberalis.

b : Weiter kaudal als a ; mittlerer Abschnitt des Lobus glandularis.

In den sonstigen Fällen wurden solche Anlagen der Pars tuberalis überhaupt nicht gebildet.

\section{Diskussion.}

Ueber die Ursache, warum der Lobus glandularis nach seiner Entwicklung bis zu einem gewissen Grade auffallend kleiner wird, vermag ich nichts Sicheres anzugeben. Doch dürfte die kümmerliche Entwicklung des Lobus glandularis darauf hindeuten, dass die Entwicklung des Lobus glandularis vom Lobus nervosus abhängig ist. Der Lobus glandularis bedarf also des Vorhandenseins des Lobus nervosus und letzterer ist unentbehrlich für seine vollständige Entwicklung. Blount $\mathbf{t}^{\mathbf{4}}$ (1932, Larve von Amblystoma punctatum Linn., A. mexicanum und A. tigrinum) hat homoioplastische Transplantation der ganzen Hypophyse und ebenso der Anlage des Lobus glandularis ausgeführt. Bei letztgenannter Transplantation hat er vorher lokale Farbmarkierung mit Nilblausulfat an der Transplantationsstelle vorgenommen. In dem Falle, wo die ganze Hypophyse transplantiert wurde, entwickelte der Lobus glandularis sich ebenso wie normal. Transplantierte man nur die isolierte Anlage des Lobus glandularis, so liess sich der Lobus glandularis gar nicht auffinden. Blount hat hieraus den Schluss gezogen, dass der Lobus glandularis zu seiner 
Entwicklung der Verbindung mit dem Lobus nervosus bedürfe. Um aber die Entwicklung des Lobus glandularis allein wirklich zu erkennen, ist es vielleicht auch nötig, dass man im Gegensatz zu der Arbeit von Blount die Anlage des Lobus glandularis intakt lässt und mittels anderer Methoden die Verbindung des Lobus glandularis mit dem Lobus nervosus unterbindet. Vorläufig kann ich also nur auf Grund meines Befundes behaupten, dass der Lobus glandularis zu seiner völligen Entwicklung absolut des Vorhandenseins des Lobus nervosus bedarf.

Der Lobus glandularis erreichte, wie vorher beschrieben wurde, nicht nur in kraniokaudaler Richtung die verschiedenen Querschnittsniveaus, sondern fand sich auch in dorsoventraler Richtung in den verschiedenen Niveaus. Die Ursache ist vielleicht wie folgt. $\mathrm{Da}$ bei der Operation die Unterlage gleichzeitig mit der Anlage des Infundibulums entfernt wurde, ist der Regulationsvorgang des Gaumendaches und der Basalplatte vielleicht in den einzelnen Fällen verschieden. Der Lobus glandulariș würde also bei seiner kaudalen Verschiebung dort gestört und gleichzeitig von seiner Umgebung anders als im normalen Falle beeinflusst werden.

Der Lobus glandularis vermochte auch beim Fehlen des Infundibulums d.h. des Lobus nervosus sein normales Querschnittsniveau zu erreichen und verschob sich dann nicht weiter kaudal. Dies macht das Problem, warum der Lobus glandularis sich von seinem Mutterboden kaudalwärts verschiebt, noch interessanter.

Der Grund für die Nichtentstehung des Zwischenlappens ist ein anderer als die schlechte Entwicklung des Lobus glandularis (s. unter „, Histogenese des Zwischenlappens ").

28 von 30 Fällen zeigten überhaupt keine Anlage der Pars tuberalis, obgleich die Larven nach ihrem Eintritt in die Metamorphose noch eine längere Zeit gezüchtet wurden. Die Pars tuberalis bildet sich im normalen Falle schon lange vor dem Eintritt in die Metamorphose in Gestalt eines Höckerpaares am kranialen Ende des Lobus glandularis, um sich bei beginnender Metamorphose vom Lobus glandularis abzutrennen. In meinen Fällen ist die Entwicklung der Pars tuberalis deshalb deutlich gehemmt. Die Ursache dürfte vielleicht die sein, dass der Lobus glandularis sich in diesem Falle nur kümmerlich entwickelt. Für die Entwicklung der Pars tuberalis ist es anscheinend nötig, dass der Lobus glandularis sich besser als bei vorliegendem Experimente entwickelt. Ueberhaupt finden sich noch viele Unklarheiten, was die Entwicklung der Pars tuberalis anbetrifft, wofür sich wohl erst durch Experimente eine Lösung ergeben mag.

Die operierten Larven traten fast gleichzeitig mit den normalen in die Metamorphose ein und vollendeten auch die vier Beine ebenso früh. Dagegen 
verzögerte sich bei ihnen die Verkürzung des Schwanzes sehr lange. Dies steht vielleicht damit in Beziehung, dass der Lobus glandularis sich nach seiner Entwicklung bis zu einem gewissen Grade im Verlaufe der Zeit verkleinert.

Die Veränderung der Farbtöne der Haut mag wohl durch die Kontraktion der Melanophoren, welche auf das Fehlen des Zwischenlappens zurückgeführt wird, verursacht worden sein.

2 Fälle zeigten ganz dieselbe Entwicklung wie die normalen Individuen. Die Ursache liege vielleicht darin, dass das Operationsstadium gerade dem Determinationsstadium des Infundibulums entsprach (s. unter „, Kraniokaudale Umkehrung (Determinationsfrage) “).

\section{Schluss.}

I. Der Lobus glandularis entwickelt sich auch beim Fehlen des Lobus nervosus bis zu einem gewissen Grade, er ist aber weit kleiner als normal d.h. kümmerlich entwickelt. Er verkleinert sich später im Verlaufe der Zeit und bedarf demnach zu seiner vollständigen Entwicklung absolut des Vorhandenseins des Lobus nervosus.

2. Der Lobus glandularis kann, sei das Infundibulum auch nicht vorhanden, sich kaudalwärts verschieben und das gleiche Querschnittsniveau wie normal erreichen. Doch verschiebt er sich nicht weiter kaudal über dieses hinaus. Der grösste Abstand, welchen er also selbständig von seinem Mutterboden her durch kaudale. Verschiebung erreichen kann, ist das Querschnittsniveau des Ganglion prooticum.

3. Der Zwischenlappen entwickelt sich nicht vom Lobus glandularis allein.

4. Wenn der Lobus glandularis allein vorhanden ist, so wird die Entwicklung der Pars tuberalis stark gehemmt, ihre Entstehung ist jedoch auch in diesem Falle möglich.

5. Die Metamorphose beginnt beim Fehlen des Lobus nervosus fast zu der normalen Zeit, ihre Vollendung aber verzögert sich deutlich. Die Ursache liegt vielleicht darin, dass der Lobus glandularis sich nach seiner Entwicklung bis zu einem gewissen Grade allmählich verkleinert.

6. Der Farbton der Haut verändert sich beim Fehlen des Lobus nervosus, was eine Folgeerscheinung des Fehlens des Z wischenlappens darstellt.

3. Teilweise Exstirpation.

Io Fälle, welche direkt nach der Vollendung der Metamorphose fixiert worden sind, wurden bei der Mikroskopierung in die 3 folgenden Gruppen eingeteilt.

(I) Gruppe, welche in der operierten Hälfte eine membranöse Wand hat (4 Fälle).

In der Gegend des Recessus opticus und Chiasma opticum bemerkt man 
einen Substanzdefekt. Dort ist die Hirnwand also dünner als in den anderen Gegenden geworden. Ausserdem zeigen die Hirnwand und der Ventrikel dort eine abnorme Form (Abb. 17 a).

Infundibulum: Es zeigt in der gesunden Hälfte die normale Bildung, lässt aber in der operierten Hälfte ebenfalls in dem kranialen Abschnitt, welcher im normalen Falle dickwandig ist, eine membranöse Wand erkennen.

Hypophyse: Der Lobus glandularis berührt die dünnere Hälfte des Infundibulums und stösst diese in den Trichter hinein (Abb. 17 b). Auch der Lobus nervosus entwickelt sich in derselben Hälfte. Er ist weit kleiner als normal, während der Lobus glandularis fast die normale Grösse hat. Der Lobus nervosus ist ungefähr ein Drittel kleiner als der normale. Der Zwischenlappen und die Pars tuberalis haben sich bereits gebildet.

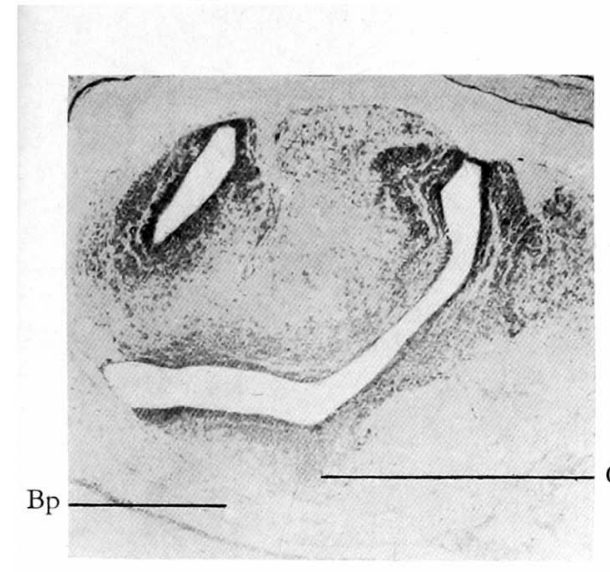

a

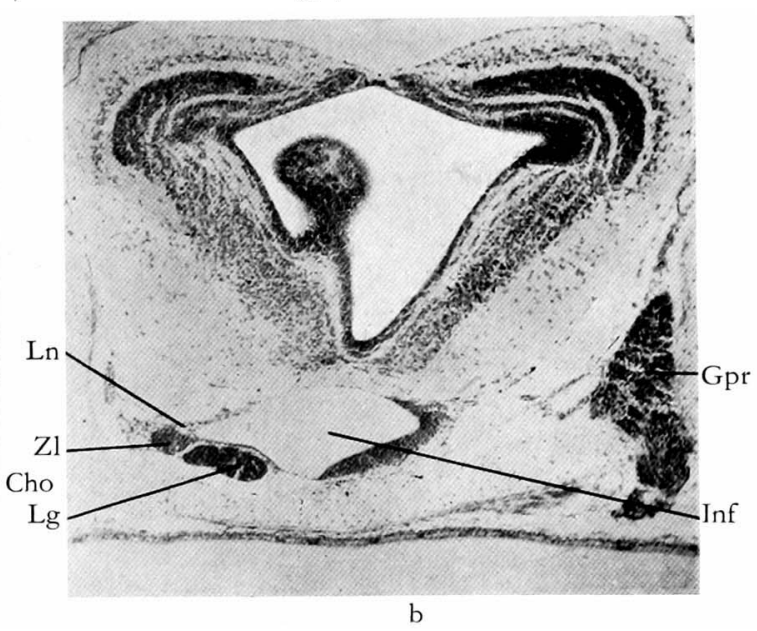

Abb. 17. Teilweise Exstirpation der Anlage des Infundibulums. Gruppe, welche in der operierten Hälfte eine membranöse Wand hat. Querschnitte, Vergr. etwa somal.

a : Querschnittsniveau des Chiasma opticum. Substanzdefekt der operierten Hälfte.

b: Weiter kaudal als a; die in der membranösen Hälfte gebildete Hypophyse.

(2) Gruppe, bei welcher die operierte Hälfte ebenso wie die gesunde Hälfte gebildet ist, d.h. das Infundibulum weist eine ganz normale Entwicklung auf (2 Fälle).

Man bemerkt keinen Substanzdefekt am Chiasma opticum und Recessus opticus. Auch die Bildung des Infundibulums und der Hypophyse ist völlig ebenso wie normal.

(3) Gruppe, bei welcher die gesunde Hälfte dünner als die operierte Hälfte ist (4 Fälle).

Man bemerkt einen Substanzdefekt in der operierten Hälfte am kranialen Teil des Chiasma opticum; die Wand ist dort dünn (Abb. I 8 a). 
T. Uyematsu,
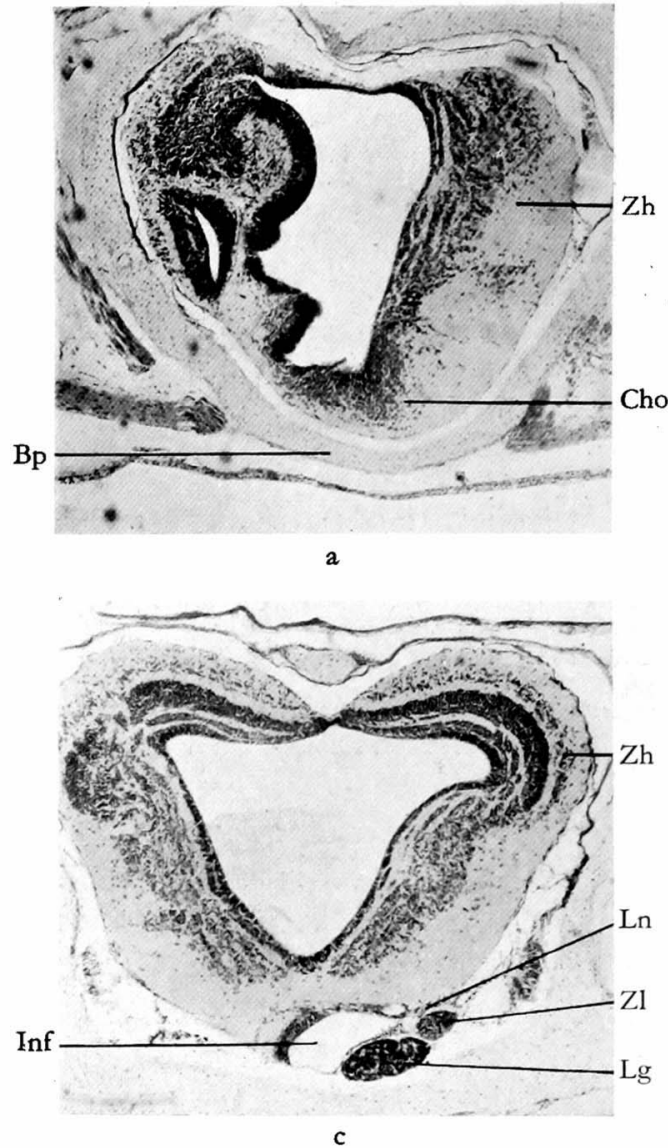

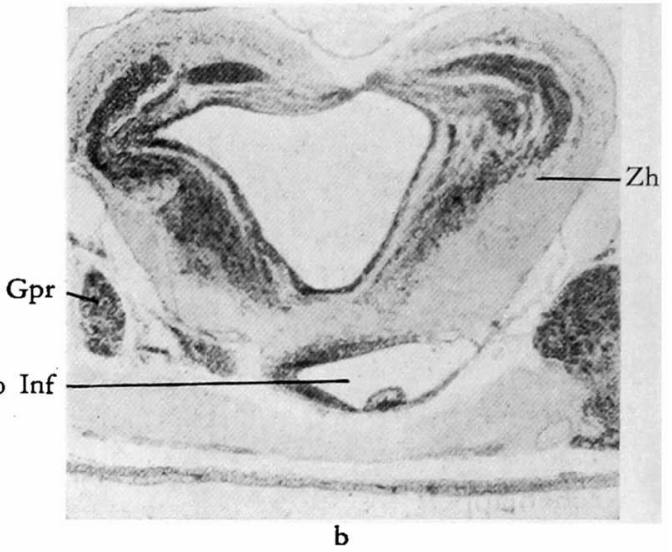

Abb. 18. Teilweise Exstirpation der Anlage des Infundibulums. Gruppe, bei welcher die gesunde Hälfte dünner als die operierte Hälfte ist. Querschnitte, Vergr. etwa 40mal.

a: Querschnittsniveau des Chiasma opticum. Substanzdefekt der operierten Hälfte.

b : Weiter kaudal als a; die gesunde Hälfte ist dünner als die operierte.

c: Weiter kaudal als $\mathrm{b}$; die in der dünneren Hälfte gebildete Hypophyse.

Infundibulum : Es ist als ganzes normal geformt, doch ist seine operierte Hälfte im kranialen Teil weit dicker als seine gesunde Hälfte (Abb. I8 b).

Hypophyse: Der Lobus glandularis berührt die ventrale Fläche des Infundibulums an der dünneren gesunden Hälfte und stösst sie in den Trichter hinein (Abb. 18 c). Der Lobus nervosus entwickelt sich in eben der Hälfte, welche der Lobus glandularis berührt. Letzterer ist fast normal gross, während der Lobus nervosus weit kleiner als normal ist. Der Lobus nervosus ist ungefähr ein Drittel kleiner als der normale. Auch die Bildung des Zwischenlappens und der Pars tuberalis hat stattgefunden.

\section{Diskussion.}

Bei der Gruppe, welche ebenso wie normal ist, und bei der Gruppe, bei welcher die operierte Hälfte dicker als die gesunde Hälfte ist, sind die Operationsdefekte wieder ausgeglichen, d.h. reguliert worden. Doch bei der Grup- 
pe, welche in der operierten Hälfte eine membranöse Wand aufweist, war die stattgefundene Regulierung keine genügende. Das Stadium der Operation entsprach gerade dem der Determination des Infundibulums (s. unter "Determinationsfrage "). Die Grösse des Exstirpationsgebietes wurde mittelst der X-Y-Figur möglichst vorsichtig bestimmt. Die zwei Gruppen, d.h. die regulierte und die nicht regulierte, traten jedoch gleichzeitig auf. Welches hierfür der Grund sein mag, lässt sich an Hand nur dieses Experimentes nicht sagen.

Falls die Wand des Infundibulums in ihren beiden Hälften einen Unterschied in der Dicke aufweist, berührt der Lobus glandularis die dünnere Hälfte. Dies erklärt sich folgendermassen. Der Lobus glandularis verschiebt sich unter die Hälfte, unter welcher der Druck zwischen ihr und der Basalplatte der schwächere ist. Der Lobus glandularis befindet sich in demselben Querschnittsniveau wie normal. Wenn er, wie vorher gesagt wurde, lateralwärts abweicht und eine Hälfte des Infundibulums berührt, so entsteht der Lobus nervosus in eben dieser Hälfte. Man gewinnt daher den Eindruck, als ob die Entwicklung des Lobus nervosus vom Lobus glandularis hervorgerufen werde. Der Lobus nervosus entwickelt sich zwar, wie das später angegeben wird, auch beim Fehlen des Lobus glandularis (s. unter ", Exstirpation des Lobus glandularis "), der obige Befund deutet jedoch vielleicht darauf hin, dass die Existenz des Lobus glandularis die Entstehung des Lobus nervosus begünstigt.

S mith ${ }^{11)}$ (1920) hat die Anlage des Lobus glandularis exstirpiert, wobei er zwei Gruppen bildete, indem der Lobus glandularis bei der einen Gruppe vollständig entfernt wurde, bei der anderen aber zu einem Teil zurückblieb. Er konstatierte dann, dass der Lobus nervosus nicht nur in der ersteren, sondern auch in der letzteren Gruppe deutlich kleiner als normal ausfiel. Bei meinem Experiment war der Lobus glandularis im Gegensatz zum S mith'schen Experiment intakt; die Operation wurde nur an der Anlage des Infundibulums ausgeführt. Der Lobus glandularis war normal gross, der Lobus nervosus dagegen ungefähr ein Drittel kleiner als normal. Vorher stellte ich fest, dass das Vorhandensein des Lobus nervosus für die vollständige Entwicklung des Lobus glandularis absolut notwendig ist. Doch musste ich hierbei die Frage offen lassen, ob die Verbindung der beiden Lappen nötig sei. Bei vorliegendem Experiment zeigte es sich jedoch klar, dass der Lobus glandularis zu seiner vollständigen Entwicklung unbedingt der Verbindung mit dem Lobus nervosus bedarf. Aus den Versuchsergebnissen scheint hervorzugehen, dass der Lobus glandularis nur der Verbindung mit dem Lobus nervosus zu seiner vollständigen Entwicklung bedürfe, nicht immer aber auch der normalen Entwicklung des Lobus nervosus. Doch vermag ich nichts Bestimmtes zu sagen, da die Anzahl meiner Fälle nicht gross ist. Das Problem, ob der intakte Lobus 
glandularis sich bei kleinem Lobus nervosus im weiteren Verlaufe der Zeit verkleinere, müsste noch erst weiter studiert werden. Jedenfalls ging aus diesem Experiment klar hervor, dass der Lobus glandularis sich durch seine Verbindung mit dem Lobus nervosus gut entwickelt.

\section{Schluss.}

I. Wenn das Infundibulum infolge der Operation einen Unterschied in der Dicke seiner beiden Hälften aufweist, so berührt der Lobus glandularis die dünnere Hälfte.

2. Wenn der Lobus glandularis das Infundibulum bei seiner lateralen Abweichung von der normalen Lage berührt, so entwickelt sich der Lobus nervosus auf der vom Lobus glandularis berührten Seite. Das heisst, der Lobus nervosus wird zwar auch beim Fehlen des Lobus glandularis gebildet, man erhält jedoch den Eindruck, als ob er bei Vorhandensein des Lobus glandularis in günstigerer Weise entstehen würde.

3. Der Lobus glandularis bedarf für seine Entwicklung der Verbindung mit dem Lobus nervosus.

Anhang: Exstirpation der kaudalen Hälfte der Anlage des Infundibulums.

Die kaudale Hälfte der Anlage des Infundibulums wurde im X-Y-Stadium der Neuralplatte entfernt (Abb. I9 a), um das Infundibulum ohne dünnwandigen Teil zu bilden. Die operierten Kaulquappen wurden direkt nach der Vollendung der Metamorphose fixiert.

Das Infundibulum ist klein und nur dickwandig entwickelt, während sich

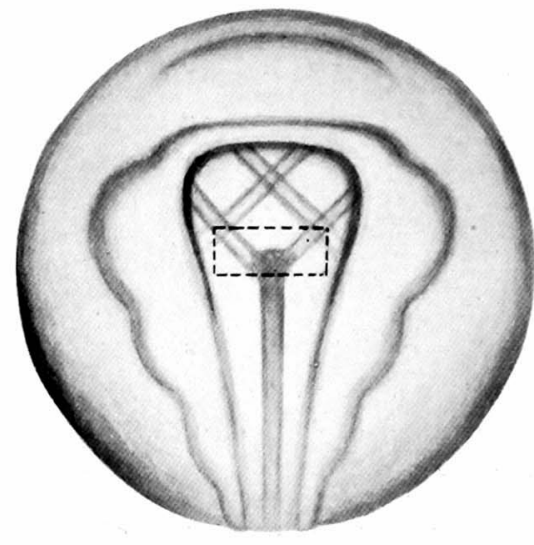

a

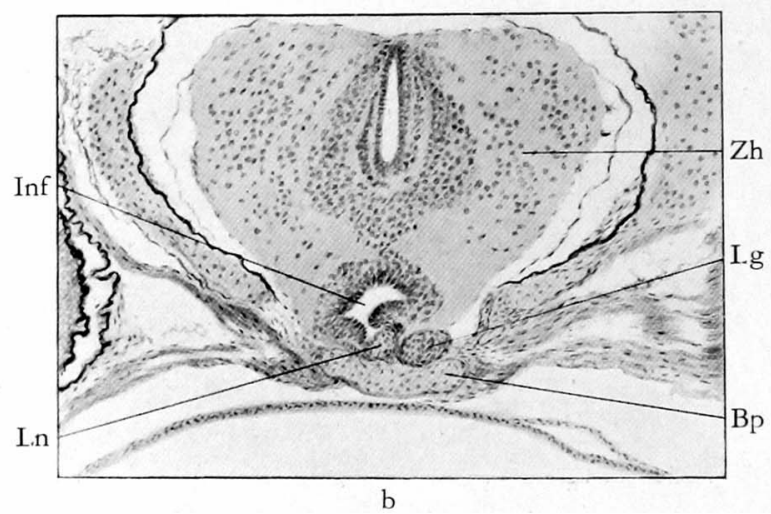

b

Abb. 19. Exstirpation der kaudalen Hälfte der Infundibulumanlage.

a : Schema der Operation. b: Ergebnis. Infundibulum und Hypophyse. Querschnitt, Zeichnung, Vergr. etwa Gomal. 
der kaudale dünnwandige Abschnitt gar nicht gebildet hat. Der Lobus glandularis berührt den ventrolateralen Teil des Infundibulums, wo sich der Lobus nervosus entwickelt hat. Letzterer ist klein, aber er nimmt die ganze Dicke der Wand des Infundibulums ein ( $A$ bb. ig b). Deshalb grenzt er direkt an den Ventrikel des Trichters. Ein Paar Pars tuberalis und ein kleiner Zwischenlappen sind gebildet. Dieser Fall erweckt besonders den Anschein, als ob die Bildung des Lobus nervosus durch die Berührung des Lobus glandularis mit dem Infundibulum hervorgerufen worden wäre.

\section{Kraniokaudale Umkehrung (Determinationsfrage).}

Unter Determination versteht man, wie bekannt, die Erscheinung, dass das künftige Schicksal eines gewissen Keimteiles schon vor seiner Differenzierung vorausbestimmt ist. Ich drehte nun die Anlage des Infundibulums um $180^{\circ}$ kraniokaudal um, indem ich so einen Beweis für seine Determination zu erlangen suchte.

Die 2I Fälle wurden mittels Mikroskopierung in die drei folgenden Gruppen eingeteilt. Um zu bestimmen, ob das Infundibulum umgekehrt sei oder nicht, benutzte ich die zwei folgenden charakteristischen Kennzeichen, welche das normale Infundibulum hat. (I) Das normale Infundibuium zeigt von kranial nach kaudal eine eigentümliche Orientierung, dazu ist seine Wand im kranialen Abschnitt dick und im kaudalen dünn. (2) Der grösste Teil des Lobus nervosus entwickelt sich im kaudalen dünnen Teil der ventralen Wand. Sonst benutzte ich, um die Lage des Infundibulums zu bestimmen, als Merkmal das Querschnittsniveau des Ganglion prooticum.

a. Gruppe mit umgekehrtem Infundibulum.

7 Fälle gehören zu dieser Gruppe. Das Infundibulum weist kaudal den normalen kranialen Teil und kranial den normalen kaudalen Teil auf. Der Lobus nervosus hat sich in allen Fällen im kranial gelegenen dünnwandigen Teil gebildet, d.h. das ganze Infundibulum ist kraniokaudal um $180^{\circ}$ schön umgekehrt entwickelt (Abb. 20), doch liegt er, wie bei der Beschreibung der Methode gesagt wurde, meist etwas weiter kaudal als im normalen Falle.

Nur in dem Falle, in welchem das Infundibulum in seiner normalen Lage umgekehrt ist, verbindet sich der Lobus glandularis mit dem Lobus nervosus und bildet die Hypophyse. Wenn das Infundibulum weiter kaudal als normal liegt, verbindet sich der Lobus glandularis nicht mit dem Lobus nervosus. Der Lobus glandularis hat sich auch hierbei zwischen der Hirnbasis und der Basalplatte bis zu seinem normalen Querschnittsniveau verschoben, über dieses hinaus aber geht er nicht weiter kaudal (Abb. 20 a). Nur in einem Falle wurde die Hypophyse gebildet (Abb. 21). Der Lobus glandularis berührte hierbei das Infundibulum im kranialen dickwandigen Abschnitt und unter geringer 


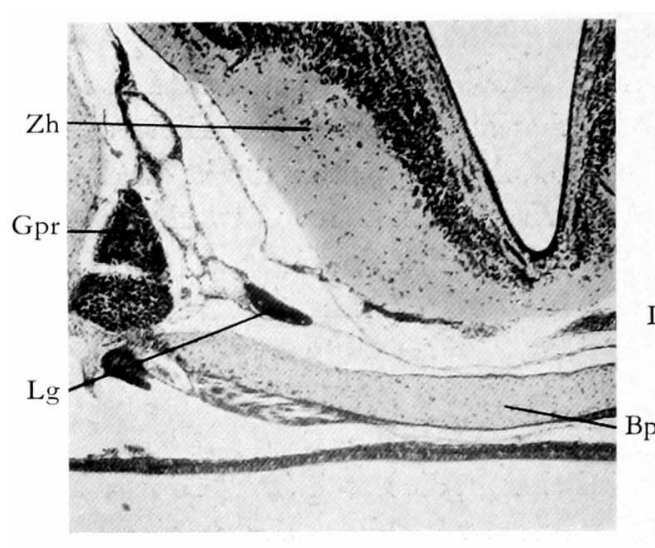

2

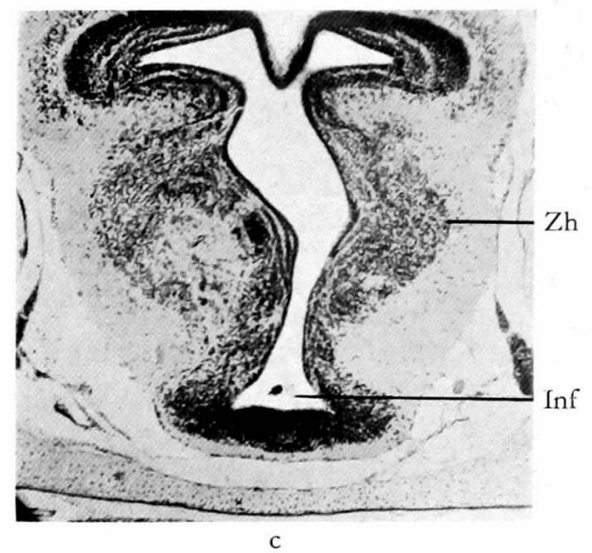

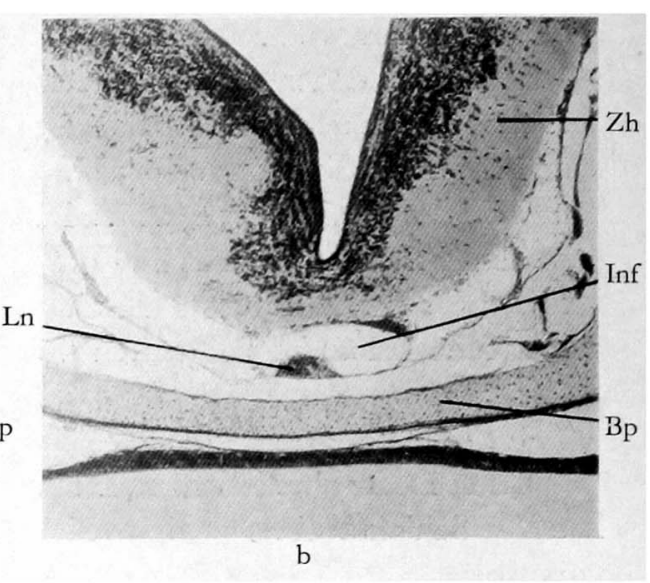

Abb. 20. Kraniokaudale Umkehrung der Anlage des Infundibulums. Querschnitte, Vergr. etwa 4omal. Úmgekehrtes Infundibulum ohne Hypophyse.

a: Querschnittsniveau des Ganglion prooticum und Lobus glandularis.

b : Weiter kaudal als a ; dünnwandiger Teil des Infundibulums und Lobus nervosus.

c: Weiter kaudal als b; dickwandiger Teil des Infundibulums.

Abweichung nach einer Seite. Die Pars tuberalis wurde kaudalwärts vom Lobus glandularis, d.h. nach dem kaudalen Ende des Infundibulums zu gebildet. Wenn man die Richtung der Pars tuberalis von der Lage des Lobus glandularis aus betrachtet, gewinnt man den Eindruck, als ob auch der Lobus glandularis kraniokaudal umgekehrt worden sei. Der Zwischenlappen wurde im mittleren Querschnittsniveau des Lobus glandularis dorsobilateral vom Lobus glandularis zwischen dem Lobus glandularis und dem Lobus nervosus gebildet. Man gelangt deshalb zu der Annahme, dass die Differenzierung des Lobus glandularis vom Infundibulum abhängig ist.

b. Gruppe mit normaler Orientierung des Infundibulums.

Das Infundibulum zeigt in allen diesen Fällen grössere oder kleinere Unterschiede in seiner Bildung, d.h. es ist bald gut, bald schlecht gebildet. Seine ganze Gestaltung aber ist ähnlich wie im normalen Falle und die Dicke 


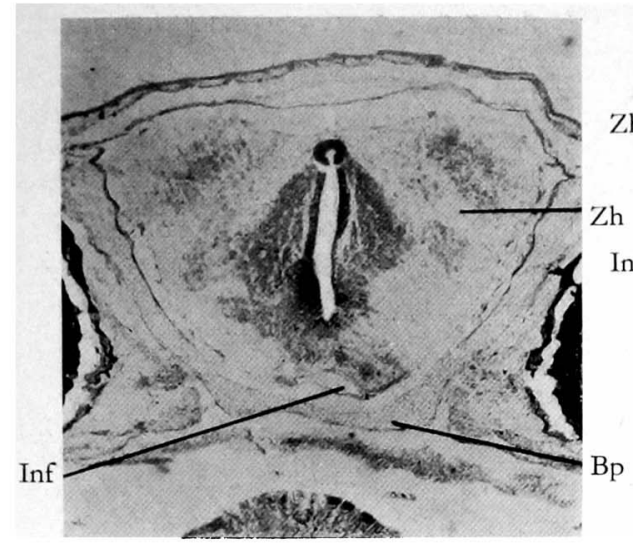

a

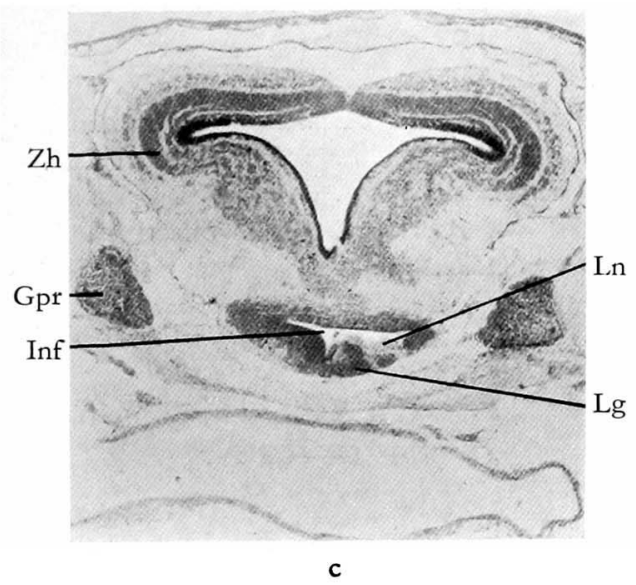

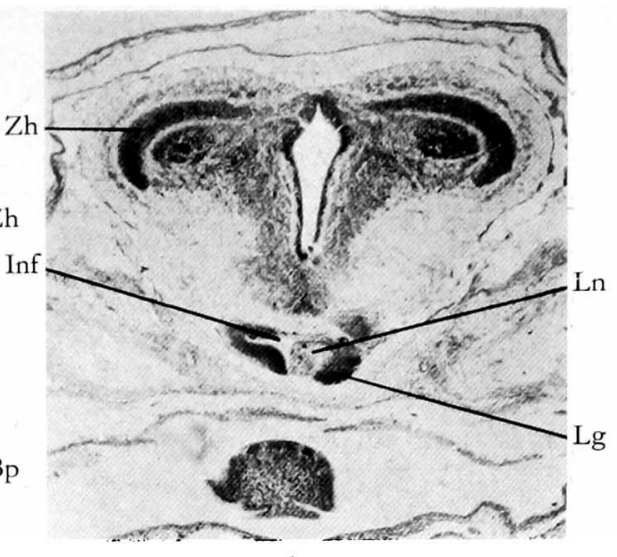

$\mathrm{b}$

Abb. 21. Kraniokaudale Umkehring der Anlage des Infundibulums. Querschnitte, Vergr. etwa 4omal. Umgekehrtes Infundibulum mit Hypophyse.

a: Dünnwandiger Teil des Infundibulums.

b : Weiter kaudal als a ; Querschnittsniveau der Hypophyse.

c: Weiter kaudal als b; dickwandiger Teil des Infundibulums.

der Wand ist gleichfalls kranial dick und kaudal dünn. 8 Fälle gehören zu dieser Gruppe. Der Lobus glandularis verbindet sich mit dem Lobus nervosus auch bei dieser Gruppe nur in den Fällen, in denen das Infundibulum seine normale Lage innehat, und die Hypophyse wird in normaler Weise gebildet (Abb. 22). Wenn das Infundibulum sich weiter kaudal als im normalen Falle verschoben entwickelt, so verbindet sich der Lobus glandularis nicht mit dem Lobus nervosus. Daher wird in diesem Falle keine Hypophyse gebildet. Der Lobus glandularis liegt zwischen der Hirnbasis und der Basalplatte in seinem normalen Querschnittsniveau, verschiebt sich aber nicht weiter kaudal über dieses hinaus. Der Lobus nervosus entwickelt sich beim Infundibulum selbständig. 

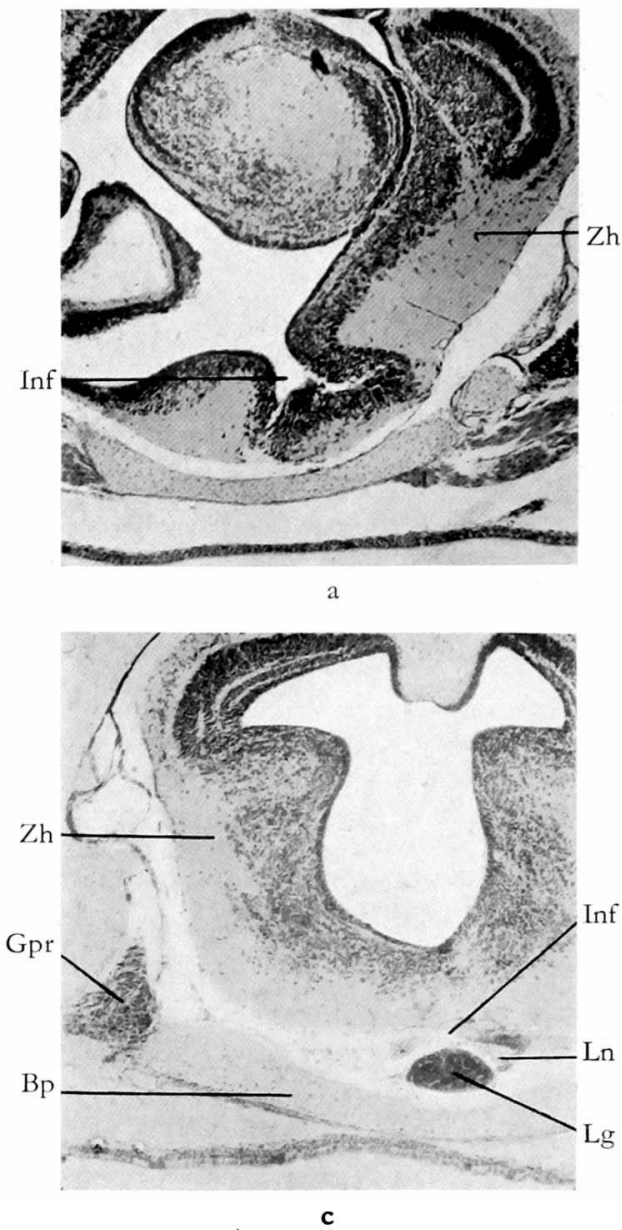

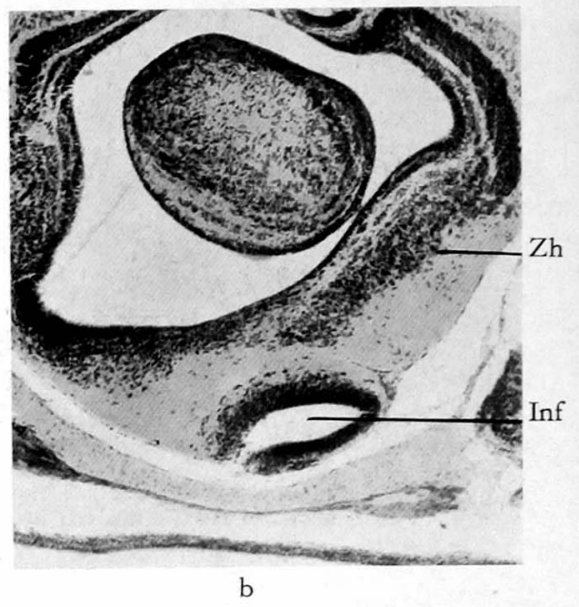

Abb. 22. Kraniokaudale Umkehrung der Anlage des Infundibulums. Querschnitte, Vergr. etwa 4omal. Aehnlich wie im normalen Falle orientiertes Infundibulum mit Hypophyse.

a: Kraniales Ende des Infundibulums.

b : Weiter kaudal als a.

c : Weiter kaudal als b; Querschnittsniveau der Hypophyse.

c. Gruppe mit ganz fehlendem Infundibulum.

Es wurde überhaupt kein Infundibulum gebildet. Die Hirnbasis bietet denselben Befund wie bei der totalen Exstirpation der Anlage des Infundibulums. 6 Fälle gehören zu dieser Gruppe. Der Lobus glandularis liegt gleichfalls zwischen der Hirnbasis und der Basalplatte in seinem normalen Querschnittsniveau.

Der Lobus glandularis und der Lobus nervosus sind in jeder der obigen Gruppen in den Fällen, in denen sich die beiden Lappen nicht miteinander vereinigen, weit kleiner als im normalen Falle. Der Lobus glandularis entwickelt sich hierbei so kümmerlich wie bei der totalen Exstirpation der Infundibulumanlage. Die Pars tuberalis bildet er gar nicht. Auch der Lobus ner- 
vosus ist ebenso klein wie bei der Exstirpation der Anlage des Lobus glandularis.

Der Zwischenlappen entwickelt sich ausschliesslich in den Fällen; in denen sich der Lobus glandularis und der Lobus nervosus miteinander vereinigen und die Hypophyse bilden. Doch entsteht er weder am Lobus glandularis noch am Lobus nervosus in den Fällen, in denen die letzteren zwei Lappen voneinander getrennt liegen.

In den Fällen, in denen die Hypophyse nicht gebildet wird, zeigt der Farbton der Haut dieselben Veränderungen wie bei der totalen Exstirpation der Anlage des Infundibulums.

Die Individuen mit Hypophyse vollendeten die Metamorphose in derselben Weise wie im normalen Falle. Die Individuen ohne Hypophyse vollendeten die vier Beine ebenso frühzeitig wie die normalen, doch verzögerte sich die Verkürzung des Schwanzes deutlich. Sie verloren den Schwanz schliesslich während der Züchtung nicht vollständig.

\section{Diskussion.}

Ich benutzte das obige Merkmal, um zu bestimmen, ob das Infundibulum umgekehrt sei, Es ist klar, dass dieses Merkmal beim Infundibulum mit der Hypophyse Geltung hat. Doch bedarf es wohl einiger Erklärung, was seine Gültigkeit beim Infundibulum ohne Hypophyse anbelangt. : Wird keine Hypophyse am Infundibulum gebildet, so beobachten wir, was die.Gestaltung des Infundibulums und die Lokalisation des Lobus nervosus anbetrifft, dasselbe Verhalten wie beim Fehlen des Lobus glandularis (s. unter „Exstirpation der Anlage des Lobus glandularis "). Das Infundibulum hat in dem letzteren Falle die gleiche Form wie im normalen Falle, mit Ausnahme der Austreibung seiner ventralen Wand. Auch die Dicke der Wand ist normal. Obgleich Form und Grösse des Lobus nervosus anders als normal sind, liegt der Lobus nervosus im Gebiet seiner normalen. Lokalisation. Daher gilt das obige Merkmal ebenfalls auch in den Fällen, wo keine Hypophyse gebildet wird.

Mittels einer etwa stattfindenden Regulation kann nur das Infundibulum mit der normalen kraniokaudalen Orientierung entstehen, aber niemals das umgekehrte Infundibulum. Da bei vorliegendem Experiment das schön umgekehrte Infundibulum gebildet wird, kann man die Annahme einer Regulation ausschliessen. Es ist also anzunehmen, dass das Resultat dieses Experimentes auf das Phänomen der Determination zurückzuführen ist, d.h. das Infundibulum mit der kraniokaudal umgekehrten Orientierung zeigt, dass die Anlage schon im Operationsstadium determiniert war. Das Infundibulum dagegen, welches dasselbe Bild bietet wie im normalen Falle, beweist, dass die Anlage noch nicht determiniert war. Obgleich die Operation in demselben 
Stadium ausgeführt wurde, erhielt ich doch gleichzeitig diese beiden entgegengesetzten Ergebnisse. Das X-Y-Stadium entspricht also bei der Anlage des Infundibulums gerade dem der Determination. Die Ursache, warum infundibulumlose Individuen gebildet wurden, ist vielleicht die, dass das umgekehrte Stück in seiner umgekehrten Lage nicht einheilte.

Wenn sich das Infundibulum in normaler Lage befindet, so verbindet sich der Lobus glandularis mit dem Lobus nervosus. Liegt das Infundibulum etwas weiter kaudal als normal, so verbindet sich der Lobus glandularis jedoch nicht mit dem Lobus nervosus. Diese Tatsache machte das Problem, warum der Lobus glandularis sich von seinem Mutterboden kaudalwärts bis zum Infundibulum verschiebt, noch interessanter. Eine Affinität zwischen der Anlage des Lobus glandularis und der des Lobus nervosus dürfte in der Regel leicht als Ursache, betrachtet werden. Das Resultat meines Experiments erweckt jedoch den Anschein, als ob ein anderer Umstand als die Affinität zwischen den beiden Anlagen die Ursache der kaudalen Verschiebung des Lobus glandularis sei.

Wenn der Lobus glandularis und der Lobus nervosus sich nicht miteinander verbinden, so sind beide Lappen kümmerlich gebildet. Dieses Resultat zeigt vielleicht, dass jeder Lappen zu seiner vollständigen Entwicklung absolut der Verbindung mit dem andern Lappen bedarf. Ich behauptete zuerst in dem Abschnitt "Totale Exstirpation der Anlage des Infundibulums ", dass der Lobus glandularis beim Fehlen des Infundibulums d.h. des Lobus nervosus kümmerlich entwickelt ist und daher zu seiner völligen Entwicklung absolut der Existenz des Lobus nervosus bedarf. Betreffs der Entwicklung des Lobus glandularis müssen aber die beiden Fragen beantwortet werden : einerseits, ob hierbei nur die Existenz des Lobus nervosus nötig ist,-oder anderseits, ob vielmehr die Verbindung des Lobus glandularis mit dem Lobus nervosus nötig ist. Für die Lösung dieses Problems war aber leider das obige Experiment nicht zureichend, da es keinen Beweis für die letztere Frage gab. Erst später in dem Abschnitt „,Teilweise Exstirpation der Anlage des Infundibulums “ vermochte ich zu erkennen, dass der Lobus glandularis zu seiner Entwicklung seiner Verbindung mit dem Lobus nervosus bedarf. Auch das vorliegende Experiment erwies folgendes. Wenn der Lobus glandularis und der Lobus nervosus voneinander getrennt liegen, so entwickelt sich der Lobus glandularis ebenso kümmerlich wie bei der totalen Exstirpation der Anlage des Infundibulums. Fasst man die Resultate dieser Experimente zusammen, so darf man nun wohl mit Bestimmtheit sagen, dass der Lobus glandularis zu seiner vollständigen Entwicklung absolut seiner Verbindung mit dem Lobus nervosus bedarf.

Betreffs der Entwicklung des Lobus nervosus mag man vielleicht das 
gleiche behaupten auf Grund der Resultate des vorliegenden Experimentes und der „Exstirpation der Anlage des Lobus glandularis“, wie später genauer ausgeführt wird.

Der Grund, warum die Pars tuberalis vom isoliert vorhandenen Lobus glandularis nicht gebildet wird, ist vielleicht derselbe wie bei der totalen Exstirpation der Anlage des Infundibulums.

Die Erklärung dafür, dass der Zwischenlappen nur bei der Entstehung der Hypophyse gebildet wird, findet sich in dem Abschnitt „Histogenese des Zwischenlappens".

Die Veränderungen der Hautfarbe beim Fehlen der Hypophyse werden vielleicht durch die Kontraktion der Melanophoren, welche wiederum dem Fehlen des Zwischenlappens zugeschrieben wird, verursacht.

Der Grund, warum die Metamorphose langsamer vonstatten geht, ist vielleicht derselbe wie bei der totalen Exstirpation der Anlage des Infundibulums.

Als die Hypophyse beim umgekehrten Infundibulum gebildet wurde, sandte der Lobus glandularis die Pars tuberalis kaudalwärts hervor, d.h. man erhielt den Eindruck, als ob die Differenzierung des Lobus glandularis vom Infundibulum abhängig sei. Ich kann aber nichts Bestimmtes sagen, da die Anzahl dieser Fälle gering war. In dieser Hinsicht sind noch weitere Versuche nötig.

\section{Schluss.}

I. Im X-Y-Stadium der Neuralplatte hatte ich die Anlage des Infundibulums an seiner Stelle um $180^{\circ}$ kraniokaudal umgedreht. Als Ergebnis erhielt ich gleichzeitig zwei verschiedene Gruppen, nämlich eine Gruppe, bei welcher das Infundibulum normal gebildet war, und eine andere, bei welcher es die kraniokaudal umgekehrte Orientierung hatte.' Ich konnte hieraus entnehmen, dass das für das Experiment gewählte Stadium gerade dem Determinationsstadium des Infundibulums entsprach.

2. Der Lobus glandularis verschiebt sich immer bis zu seinem normalen Querschnittsniveau kaudalwärts. Weiter kaudal aber bewegt er sich nicht.

Wenn das Infundibulum in seiner normalen Lage gebildet wird, verbindet sich, ob es nun umgekehrt oder normal orientiert ist, in jedem Fall der Lobus glandularis mit dem Lobus nervosus und bildet die Hypophyse. Liegt das Infundibulum etwas weiter kaudal als im normalen Falle, so verbindet sich der Lobus glandularis mit dem Lobus nervosus durchaus nicht.

3. Der Lobus glandularis, welcher sich nicht mit dem Lobus nervosus verbindet, ist ebenso "kümmerlich entwickelt wie bei der totalen Exstirpation der Anlage des Infundibulums. Die Pars tuberalis bildete er überhaupt 
nicht. Der Lobus nervosus hat sich beim Infundibulum gebildet. Dem Lobus glandularis ist also die Verbindung mit dem Lobus nervosus unentbehrlich für seine vollständige Entwicklung.

4. Der Lobus nervosus, welcher sich nicht mit dem Lobus glandularis verbunden hat, ist ebenfalls klein, auch wenn der Lobus ghandularis isoliert vorhanden ist. Auch für den Lobus nervosus ist somit die Verbindung mit dem Lobus glandularis unentbehrlich zu seiner vollständigen Entwicklung.

5. Der Zwischenlappen entsteht ausschliesslich in den Fällen, in denen sich der Lobus glandularis mit dem Lobus nervosus verbindet.

\section{Experimente an der Anlage des Lobus glandularis.}

I. Exstirpation.

Ich führte hierbei, wie bei der Beschreibung der Methode erwähnt wurde, die vier folgenden Operationen aus: (I) einfache Exstirpation der Anlage, (2) Exstirpation der Anlage und homoioplastische Transplantation der Anlage des Saugnapfes auf diese Stelle, (3) Exstirpation der Anlage und homoioplastische Transplantation des Ektoderms des präsumtiven seitlichen Rumpfteiles auf diese Stelle und (4) Exstirpation der Anlagen zweier Keime und deren Parabiose. Die drei letzten Versuche wurden ausgeführt, um die Regulation der Anlage zu stören. Da sich aber bei ihnen derselbe Befund wie bei der einfachen Exstirpation der Anlage ergab, so gebe ich unten alle Fälle zusammen wieder.

Was das Wachstum anbetrifft, wurden die meisten Larven normal gross, wenige blieben nur so klein wie zu Beginn des Schwimmens. Der Farbton der Haut veränderte sich allmählich zu braun, gelblich braun, grünlich gelb usw. Die gelbliche Färbung war die letzte, welche ich nach rootägiger Züchtung beobachtete. Es schien mir jedoch, als ob der Farbton auch von der Art des Zimmers, vom Licht usw. mehr oder weniger beeinflusst werde. Die Metamorphose fand gar nicht statt. Die hinteren Beine blieben im Zustand der Beinknospe.

a. Infundibulum beim Fehlen des Lobus glandularis.

Auch bei fehlendem Lobus glandularis beginnt das Infundibulum sich zu derselben Zeit wie normal zu entwickeln und gewinnt ebenso die glciche Gestalt wie normal, d.h. die Entwicklung des Infundibulums selbst ist vom Vorhandensein des Lobus glandularis völlig unabhängig. Das ausgebildete Infundibulum hat die gleiche Dicke der Wand und die gleiche kraniokaudale Orientierung wie normal. Nur die Form seiner ventralen Wand weicht von der Norm ab. Das normale Infundibulum scheint an seiner Berührungsstelle 


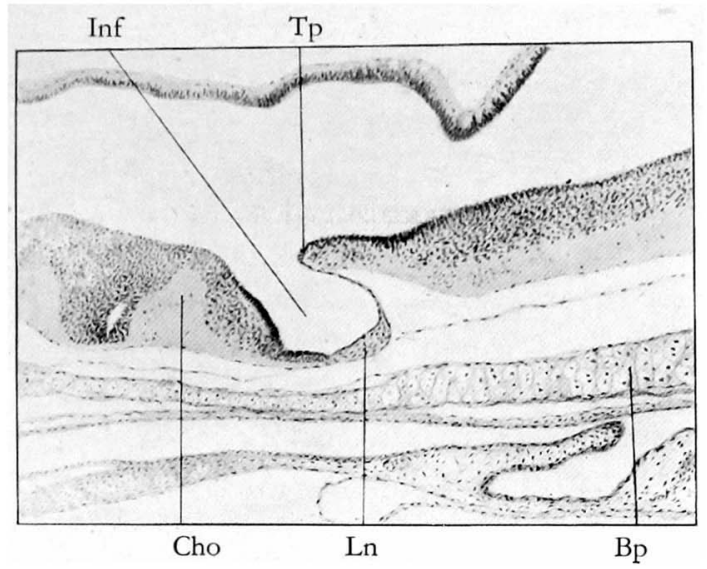

Abb. 23. Exstirpation der Anlage des Lobus glandularis. Sagittalschnitt, Zeichnung, Vergr. etwa Gomal. Infundibulum sowie Lobus nervosus beim Fehlen des Lobus glandularis. $\mathrm{Bp}=$ Basalplatte, Cho=Chiasma opticum, $\mathrm{Ln}=$ Lobus nervosus, $\mathrm{T} \mathrm{p}=$ Tuberculum posterius. mit dem Lobus glandularis, einen der dorsalen Wölbung des Lobus glandularis entsprechenden Eindruck zu erhalten. Wenn der Lobus glandularis fehlt, erfährt die ventrale Wand des Infundibulums jedoch eine Ausbuchtung und befindet sich fast parallel der Basalplatte (Abb. 23). Das Infundibulum verhält sich somit in diesem Falle nicht anders als im normalen Falle, mit Ausnahme davon, dass seine ventrale Wand ihre Form je nach dem Vorhandensein oder Fehlen des Lobus glandularis -verändert.

b. Lobus nervosus beim Fehlen des Lobus glandularis.

Der Lobus nervosus wird auch beim Fehlen des Lobus glandularis gebildet (Abb. 24). Der Zwischenlappen jedoch wird in diesem Falle gar nicht entwickelt. Der Lobus nervosus verhält sich hierbei, in einer Hinsicht ähnlich wie im normalen Falle, in anderer Hinsicht verschieden. An dem
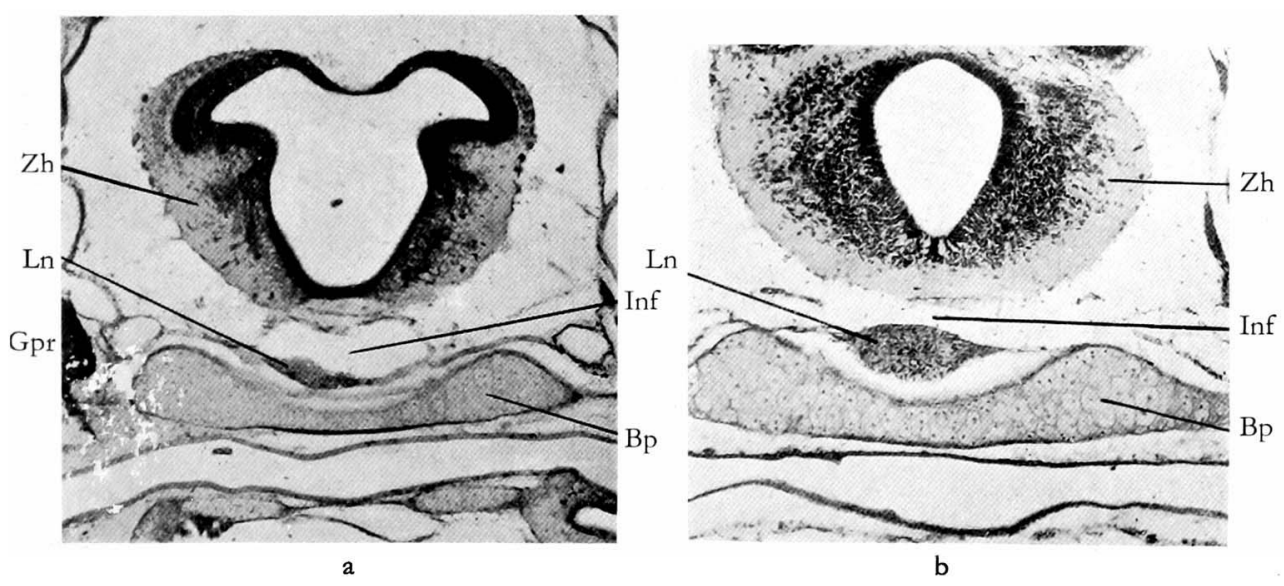

Abb. 24. Exstirpation der Anlage des Lobus glandularis. Querschnitte, Vergr. etwa somal. Lobus nervosus beim Fehlen des Lobus glandularis. $\mathrm{Gpr}=\mathrm{Ganglion}$ prooticum, $\mathrm{Zh}=\mathrm{Zwi}$ schenhirn. 
Punkte aber, wo scheinbar ein nïht normales Verhalten vorliegt, lässt sich jedoch, bei einem Vergleich mit dem normalen entsprechenden Fall, eine gewisse Beziehung feststellen.

(I) Grösse.

Ich zeichnete den Lobus nervosus mit dem Abbéschen Zeichenapparat aus den Serienschnitten auf Papier und wog ihn. Zum Vergleich benutzte ich das Gewicht statt des Volums.

Tabelle 2.

A) Lobus nervosus normaler Individuen gerade nach der Metamorphose.

\begin{tabular}{|c|c|c|c|c|c|}
\hline $\begin{array}{l}\text { Züchtungs- } \\
\text { tage }\end{array}$ & Präparate & $\begin{array}{l}\text { Datum der } \\
\text { Neuralplatte }\end{array}$ & $\begin{array}{c}\text { Datum der } \\
\text { Fixation }\end{array}$ & $\begin{array}{c}\text { Körpergrösse } \\
(\mathrm{cm})\end{array}$ & $\begin{array}{c}\text { Gewicht des } \\
\text { Lobus } \\
\text { nervosus (mg) }\end{array}$ \\
\hline 64 & A. $64,271, b$ & $24 / \mathrm{III}$ & $27 / \mathrm{V}$ & K.L. : $\quad$ 1.00 & 3.5 \\
\hline 50 & H. 50,356 & $4 / \mathrm{V}$ & 23/VI & K.L. : $\quad 0.75$ & 4.0 \\
\hline 36 & N. 36,318 & $10 / \mathrm{V}$ & IS/VI & K.L. : 1.00 & $4 \cdot 7$ \\
\hline 34 & I 57 II & $2 \pi / V$ & $24 / V I$ & K.L. : $\quad 0.62$ & 2.5 \\
\hline & 14I I & $27 / \mathrm{V}$ & $2 \mathrm{I} / \mathrm{VI}$ & K.L.: $\quad 0.70$ & 3.2 \\
\hline " & 14I II & " & ” & K.L. : 0.62 & 3.5 \\
\hline
\end{tabular}

B) Lobus nervosus beim Fehlen des Lobus glandularis.

\begin{tabular}{|c|c|c|c|c|c|}
\hline $\begin{array}{c}\text { Züchtungs- } \\
\text { tage }\end{array}$ & Präparate & $\begin{array}{l}\text { Datum der } \\
\text { Operation }\end{array}$ & $\begin{array}{c}\text { Datum der } \\
\text { Fixation }\end{array}$ & $\begin{array}{l}\text { Körpergrösse } \\
\text { (cm) }\end{array}$ & $\begin{array}{c}\text { Gewicht des } \\
\text { Lobus } \\
\text { nervosus (mg) }\end{array}$ \\
\hline 100 & A. $100,391, b, r$ & $24 / \mathrm{III}$ & 2/VII & $\begin{array}{ll}\text { K.L.: } & 2.40 \\
\text { S-A-L. : } & 0.95\end{array}$ & I. 2 \\
\hline$"$ & A. $100,391, b, 2$ & $"$ & $"$ & $\begin{array}{ll}\text { K.L.: } & 2.45 \\
\text { S-A-L. : } & 1.00\end{array}$ & $"$ \\
\hline$"$ & A. 100,397 & $25 / \mathrm{III}$ & $3 / \mathrm{VII}$ & $\begin{array}{ll}\text { K.L.: } & 2.10 \\
\text { S-A-L. : } & 0.8 .5\end{array}$ & 2.0 \\
\hline 95 . & A. $95,375,2$ & $26 / \mathrm{III}$ & 29/VI & $\begin{array}{ll}\text { K.L.: } & 2.95 \\
\text { S-A-L.: } & 1.00\end{array}$ & 2.2 \\
\hline ” & A. $95,375, \mathrm{I}$ & $"$ & ” & $\begin{array}{ll}\text { K.L.: } & 3.00 \\
\text { S-A-L. : } & \text { I.30 }\end{array}$ & 2.7 \\
\hline 84 & A. 84,414 & $20 / \mathrm{IV}$ & $\mathrm{I}_{3} / \mathrm{VII}$ & $\begin{array}{ll}\text { K.L.: } & 1.85 \\
\text { S-A-L. : } & 0.70\end{array}$ & 2.2 \\
\hline 80 & A. 80,286 & x6/III & $4 / \mathrm{VI}$ & K.L. : $\quad 2.30$ & 2.3 \\
\hline 74 & C. 74,288 & $24 / \mathrm{III}$ & 6/VI & K.L. : $\quad 2.70$ & 3.7 \\
\hline 57 & A. 57,370 & $2 / \mathrm{V}$ & $28 / \mathrm{VI}$ & $\begin{array}{ll}\text { K.L.: } & 2.25 \\
\text { S-A-I.: : } & 0.85\end{array}$ & 2.5 \\
\hline 55 & C. 55,405 & $12 / V$ & 6/VII & $\begin{array}{ll}\text { K.L.: } & 1.60 \\
\text { S-A-L. : } & 0.60\end{array}$ & 2.3 \\
\hline 45 & A. 45,168 & I6/JII & $30 / \mathrm{IV}$ & K.L.: & 0.5 \\
\hline 40 & A. 40,163 & 20/III & $29 / \mathrm{IV}$ & K.L. : & 0.6 \\
\hline 35 & A. 35,164 & $25 / 11 \mathrm{II}$ & $"$ & S-A-L. : 0.70 & 0.4 \\
\hline
\end{tabular}

K.L. : ganze Körperlänge, S-A-L.: Schnauzen-Anus-Länge.

Bemerkung. $\mathrm{Da}$ ich in der Tabelle 2 die an verschiedenen Tagen operierten Individuen bequemlichkeitshalber einfach nach der Reihenfolge der Züchtungstage anordnete, zeigt diese Anordnung somit nicht das Stadium der wahren Entwicklung der Larve. 
Der Lobus nervosus ist in den meisten Fällen weit kleiner als im normalen Falle, und nur in einigen ist er fast normal gross. Auch eine Neigung des Lobus nervosus zur Verkleinerung wird beobachtet, nachdem er sich bis zu einem gewissen Grade entwickelt hat. Da aber diese Fälle selten sind, lässt sich nichts Bestimmtes aussagen.

(2) Entstehungsweise.

Was die Entstehungsweise des Lobus nervosus anbetrifft, so besitzen wir noch keine genauen Studien. Die normale Entwicklung des Lobus nervosus vermochte ich erst an Hand der mittels des Experimentes gewonnenen Befunde festzustellen. Es dürfte vielleicht schwer sein, nur an normalen Individuen diese Entwicklung genau zu studieren. Die Hauptursache ist vielleicht folgende. (I) Der betreffende Wandteil des Infundibulums verändert seine Struktur wiederholt und wird schliesslich zu dem vollendeten Lobus nervosus. (2) Die erste Entstehung des Lobus nervosus wird leicht übersehen, da die Anlage des Zwischenlappens relativ frühzeitig stattfindet. (3) Der Lobus nervosus hat eine komplizierte Form und zeigt an seinen einzelnen Stellen während der Entwicklung verschiedene Differenzierungsgrade, da an der ventralen Wand des Infundibulums vom Lobus glandularis nach dem Ventrikel ein starker Druck ausgeübt wird.

Der Lobus nervosus entsteht beim Fehlen des Lobus glandularis in folgender Weise. Wie bei der normalen Entwicklung des Infundibulums erwähnt wurde, verändert das Infundibulum seine Zellen und bildet schliesslich eine membranöse Wand, welche aus einer Schicht platter Zellen besteht. Kaum dass die Larve zu schwimmen beginnt, so verändern sich die platten Ependymzellen etwas kranial vom kaudalen Ende der ventralen Wand und wuchern ventralwärts zu einer kleinen Verdickung. Dort haben sich nur einige Zellen mit rundlichem oder länglich ovalem Kern gebildet (Abb. 25). Diese Zellwucherung bedeutet den Entstehungsbeginn des Lobus nervosus. Danach verändert die ventrale Wand ihre Struktur in dem ganzen Gebiet, welches den Lobus nervosus entstehen lässt. Am Ventrikel liegt eine Reihe von rundlichen oder ovalen Kernen, ventral an diese schliesst sich eine dünne kernarme Schicht an, in welcher rundliche oder länglich ovale Kerne spärlich verstreut liegen (Abb. 26). Das Bild des ausgebildeten Lobus nervosus mit vielen Kernen lässt sich noch nicht beobachten. Bis zu diesem Zustand möchte ich den Lobus nervosus einstweilen als Lobus nervosus primitiven Stadiums bezeichnen. Wenn die Differenzierung weiter fortschreitet, wird das Bild desselben ein ganz anderes als bisher. Helle Zellen mit rundlichem oder ovalem Kern treten reichlich und dicht nebeneinander auf. Der ganze Lobus nervosus wird gleichzeitig dicker. Dies ist gerade das Stadium der sog. Stammzellen (Abb. 27). Die Anhäufung der Zellen verliert sich danach 

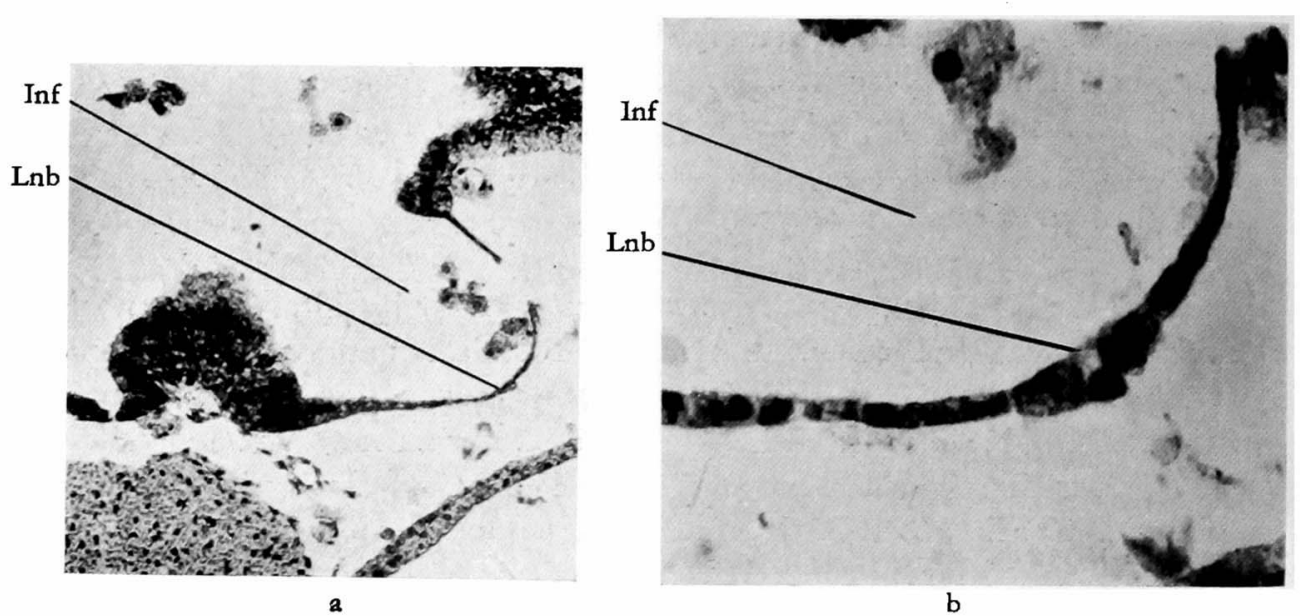

Abb. 25. Entwicklung des Lobus nervosus beim Fehlen des Lobus glandularis. Sagittalschnitte. Entstehungsbeginn des Lobus nervosus (Lnb). a : Schwache Vergrösserung (etwa 3 2omal).

b: Starke (etwa 6romal).
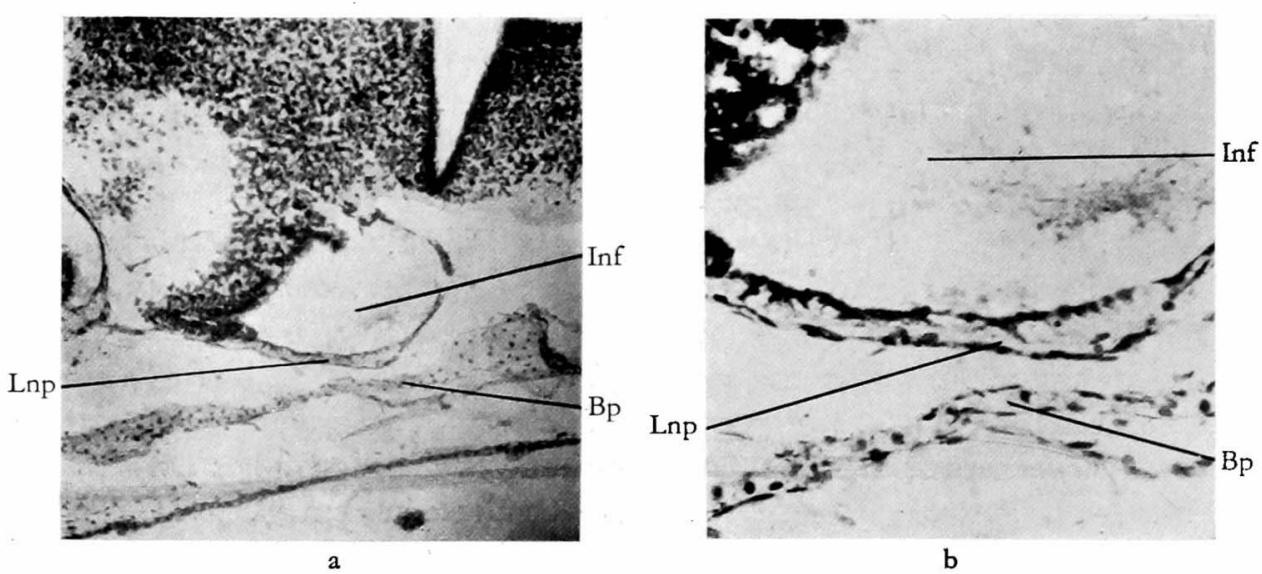

Abb. 26. Entwicklung des Lobus nervosus beim Fehlen des Lobus glandularis. Sagittalschnitte. Lobus nervosus primitiven Stadiums. (Lnp). a: Schwache Vergrösserung (etwa $80 \mathrm{mal}$ ).

b: Starke " von a (etwa $270 \mathrm{mal}$ ).

relativ schnell und der Lobus nervosus nähert sich seinem ausgebildeten Zustande.

Ich stellte obigen Befund dem normalen gegenüber und vermochte so erstmalig die normale Entstehungsweise des Lobus nervosus aufzuzeigen. Der normale Lobus nervosus entwickelt sich wie folgt. Wenn das kaudale Ende des Lobus glandularis ungefähr das kraniale Ende des Infundibulums 

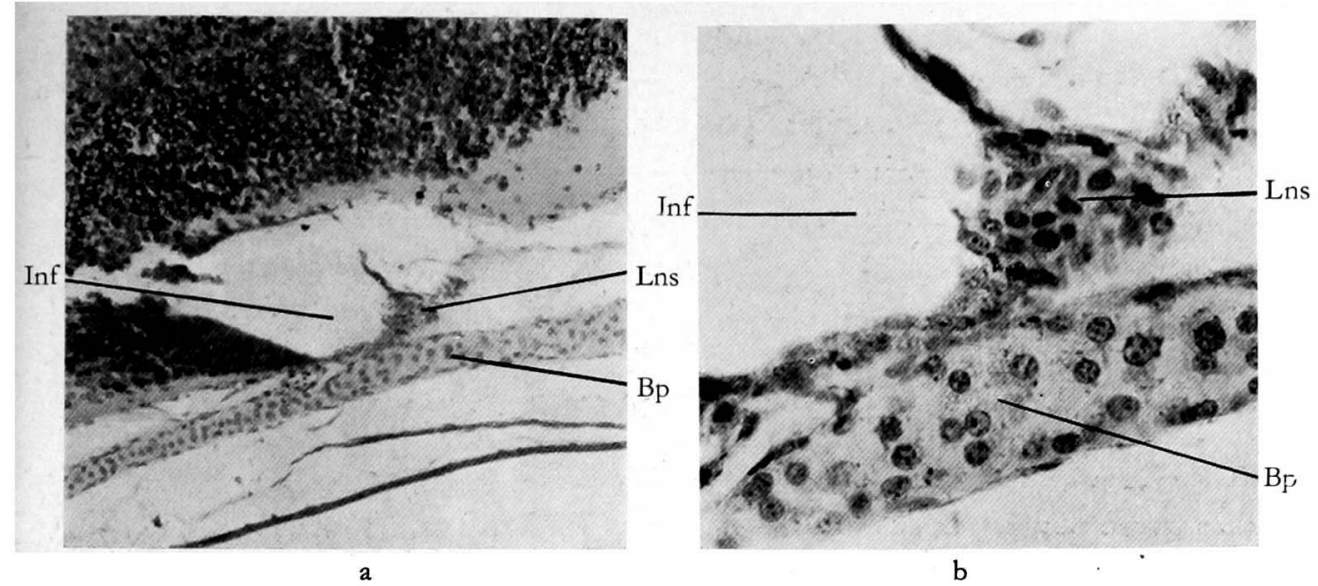

Abb. 27. Entwicklung des Lobus nervosus beim Fehlen des Lobus glandularis.

Sagittalschnitte. Lobus nervosus des Stadiums der Stammzellen (Lns).

a : Schwache Vergrösserung (etwa roomal).

b : Stakke inas.:

" von a (etwa 3 Gomal).

erreicht hat, wuchern die platten Zellen des Infundibulums, wie oben beschrieben, an derselben Stelle der ventralen Wand zu derselben Zellmasse (Abb. 28 u. 44) (und zwar ungefähr binnen einer Woche' nach dem Ablauf des Stadiums der Neuralplatte). Erreicht der Lobus glandularis den Entstehungsbeginn des Lobus nervosus, so wird letzterer durch die dort neugebildete Anlage des Zwischenlappens schwer erkennbar. Im Gebiet des Ventrikels, wo der Lobus nervosus sich entwickeln wird, findet sich danach eine Reihe von rundlichen oder ovalen Kernen und unterhalb derselben eine dünne kernarme Schicht. Die kernarme Schicht wird allmählich dicker. Die bisherige Entwicklung ist ganz die gleiche wie bei vor-

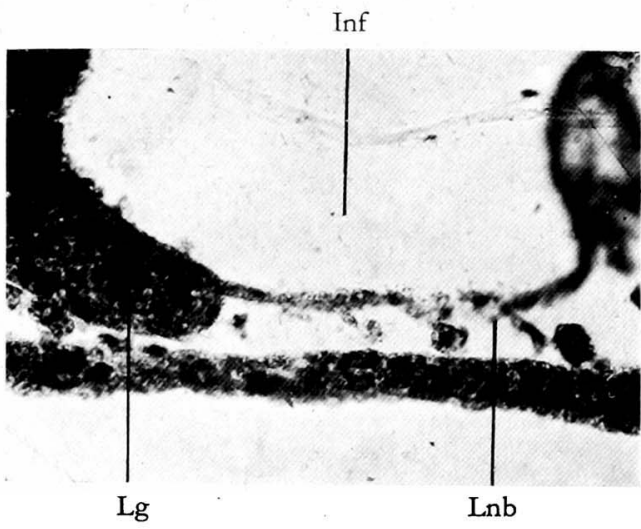

Abb. 28. Normale Entwicklung des Lobus nervosus (Normale Larve, Körperlänge : $8.0 \mathrm{~mm}$ ). Sagittalschnitt, Vergr. etwa 250mal. Entstehungsbeginn des Lobus nervosus (Lnb).

liegendem Experiment. Die fernere Entwicklung weicht aber mehr oder weniger vom Befunde dieses Experiments ab. Die weitere Differenzierung findet beim Fehlen des Lobus glandularis gleichzeitig und gleichmässig im ganzen Gebiet des Lobus nervosus statt, doch ist sie beim normalen 
Lobus nervosus der Stelle nach deutlich verschieden. Bei normalem Lobus nervosus verläuft das Stadium der sog. Stammzellen am frühesten in dem Abschnitt, welcher dorsokaudal und dorsolateral vom Lobus glandularis liegt, danach gegen Ende der Metamorphose in dem Abschnitt, welcher sich dorsokranial vom Lobus glandularis befindet. Das primitive Stadium hält sich in dem Abschnitt, welcher dorsal vom Lobus glandularis liegt, am längsten, und zwar meist bis nach der Vollendung der Metamorphose (Abb. 29).

(3) Form und Lokalisation.

Der Lobus nervosus ist im Sagittalschnitt einem Keil ähnlich, dessen Basis kaudalwärts und dessen Spitze kranialwärts gerichtet ist, d.h. er ist nahe dem kaudalen Ende der ventralen Wand des Infundibulums am dicksten und wird kranialwärts allmählich dünner (Abb. 23). Doch erreicht er meist nicht die kaudale Wand des Infundibulums. Er hat im Querschnitt meist die Form einer quer gelegten Spindel oder zeigt eine ovale Gestalt. Auch

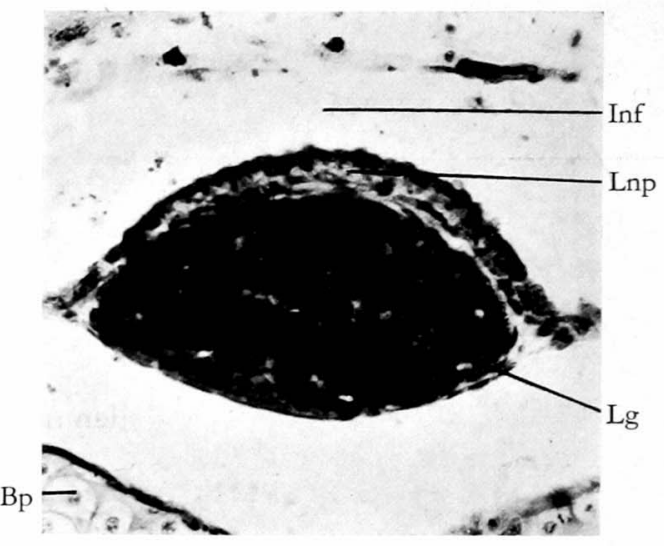

Abb. 29. Normale Entwicklung des Lobus nervosus (ein normales Individuum am Ende der Metamorphose). Ein Abschnitt des Lobus nervosus, welcher dorsal vom Lobus glandularis liegt und fast bis zum Ende der Metamorphose in seinem primitiven Stadium bleibt. Querschnitt, Vergr. etwa 25omal.

hierbei erreicht er meist nicht die laterale Wand des Infundibulums (Abb. 24). Er befindet sich also stets nur im Gebiet der ventralen Wand.

Wenn man diese Form mit der des normalen Lobus nervosus vergleicht, so bemerkt man einen deutlichen Unterschied. Ich habe den normalen Lobus nervosus etwa bis nach der Vollendung der Metamorphose beobachtet. Er nimmt nicht nur die ventrale Wand, sondern auch teilweise die kaudale Wand und die laterale Wand des Infundibulums ein. In den Abschnitten, welche dorsokaudal, dorsolateral und dorsokranial vom Lobus glandularis liegen, ist er dick; am dünnsten ist er in dem Abschnitt, welcher dorsal vom Lobus glandularis liegt. Will man daher den Lobus nervosus, welcher beim Fehlen des Lobus glandularis entsteht, mit dem normalen Lobus nervosus in Beziehung bringen, welcher etwa bei Vollendung der Metamorphose beobachtet wird, so kann man wie folgt überlegen. Wenn der beim Fehlen des Lobus glandularis relativ gut entwickelte Lobus nervosus durch den Lobus glandularis 
von ventral her einen Druck erführe, infolgedessen er nach allen Seiten ausgedehnt werden würde, so würde sein mittlerer Teil am dünnsten werden. Der so erdachten Form entspräche vielleicht die Form des normalen Lobus nervosus (Abb. 30).

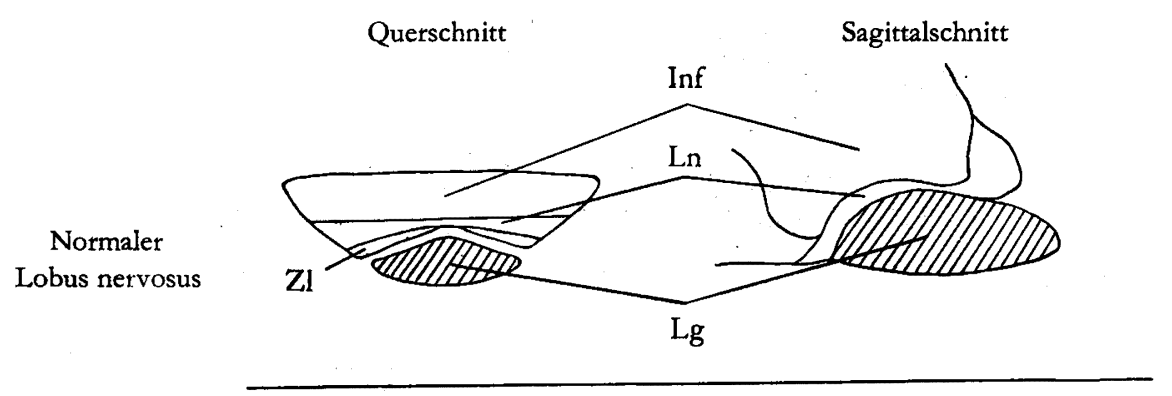

Lobus nervosus beim Fehlen des Lobus glandularis

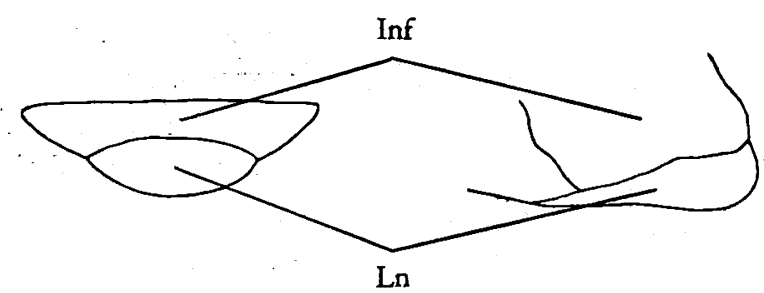

Abb. 30. Beziehung der Form des normalen Lobus nervosus (am Ende der Metamorphose) $\mathrm{zu}$ der des beim Fehlen des Lobus glandularis relativ gut entwickelten Lobus nervosus (am roo. Tage nach der Operation). Schema aus mikroskopischen Bildern gewonnen.

Der Lobus nervosus entwickelt sich in der ventralen Wand des Infundibulums etwas kaudalwärts abweichend und im ganzen in der Mediangegend. Er bildet sich meist symmetrisch, zuweilen jedoch auch asymmetrisch. Er entwickelt sich immer im Bezirk seiner normalen Lokalisation.

\section{Diskussion.}

Stein ${ }^{10)}$ (1929, Hühnerembryo) hat die Entwicklung des Infundibulums folgendermassen dargestellt. Sie hat eine Gewebskultur von einem Stücke, welches die Anlage des Lobus glandularis und die des Infundibulums zusammen enthielt, angelegt. In den meisten Fällen, in denen der Lobus glandularis nachgewiesen wurde, bildete sich ein infundibulumähnliches Gebilde. In den Fällen jedoch, in denen der Lobus glandularis nicht nachgewiesen werde, behauptete sie, bilde sich ein solches Gebilde gar nicht. Das Infundibulum sei also in seiner normalen Entwicklung vom Lobus glandularis abhängig. Doch meinem Versuch nach tritt das Infundibulum. nicht nur im Beginn seiner Bildung ebenso früh wie normal auf, sondern es ist auch seiner Gestalt 
nach ganz normal, d.h. die Entwicklung des Infundibulums ist vom Vorhandensein oder Fehlen des Lobus glandularis völlig unabhängig. Der Lobus nervosus bedarf zwar absolut der Verbindung mit dem Lobus glandularis zu seiner vollständigen Entwicklung, doch muss das Infundibulum in diesem Punkt streng vom Lobus nervosus unterschieden werden.

Nach Smith ${ }^{11)}$ (1920) bleibt beim Fehlen des Lobus glandularis die ventrale Wand des Infundibulums, welche normal den Lobus glandularis berühren und den Lobus nervosus bilden soll, membranös. Auch bei mir ergab sich derselbe Befund: die ventrale membranöse Wand blieb unverändert ausser an der Stelle, an welcher sich der Lobus nervosus gebildet hatte.

Vergleicht man die ventrale Wand des Infundibulums, welches man beim Fehlen des Lobus glandularis sieht, mit der normalen ventralen Wand, so zeigt die letztere Wand einen Eindruck, welcher nach dem Ventrikel hin konvex ist und der dorsalen Wölbung des Lobus glandularis entspricht, während die erstere Wand ventrokaudalwärts ausgedehnt ist. Man darf deshalb vielleicht annehmen, dass die normale ventrale Wand des Infundibulums vom Lobus glandularis stark nach dorsalwärts hinaufgestossen wird. Der Lobus nervosus müsste daher dem dorsalen mittleren Teil des Lobus glandularis gegenüber am stärksten gedrückt und gleichzeitig gespannt sein. Diese Faktoren stehen vielleicht damit in Beziehung, dass dort der Lobus nervosus am dünnsten und seine Differenzierung am längsten hinausgezögert ist. Von solchen Veränderungen der ventralen Wand hat $S_{m i t h}{ }^{11)}$ (1920), der das gleiche Experiment ausführte, nichts berichtet.

$\mathrm{Smith}^{11)}$ (1920) hat die Entwicklung des Lobus nervosus beim Fehlen des Lobus glandularis wie folgt beschrieben. Der Lobus nervosus sei auffallend kleiner als der des gleichgrossen normalen Individuums. Er sei daher für seine vollständige Entwicklung vom Lobus glandularis abhängig. Die Entwicklungsweise des Lobus nervosus betreffend seien zwei Möglichkeiten denkbar. (I) Der Lobus nervosus entwickele sich anfangs gut und verkleinere sich später. (2) Er zeige von Anfang an eine schlechte Entwicklung. Doch hielt $\mathrm{S}$ mith die letztere Entwicklungsweise für wahrscheinlicher. Auch in meinen Fällen ist der Lobus nervosus meist klein, doch finden sich unter allen Fälleri auch einige, wo er normal gross ist. Er hat die Neigung, sich bis zu einem gewissen Grade zu entwickeln und sich danach im Laufe der Zeit zu verkleineren. Bestimmtes lässt sich jedoch schwer sagen, da die Anzahl der Fälle gering ist. Da der Lobus glandularis beim Fehlen des Lobus nervosus dieselbe Entwicklungsweise aufwies, dürfte die eben berichtete Neigung des Lobus nervosus auch vielleicht der Wirklichkeit entsprechen. Doch ist diesbezüglich noch eine weitere Nachprüfung vonnöten. Smith hat betreffs der Entwicklung des Lobus nervosus nicht mit Sicherheit ange- 
geben, ob einerseits nur das Vorhandensein des Lobus glandularis notwendig, oder ob anderseits die Verbindung der beiden Lappen unentbehrlich sei. Nur meinem vorliegenden Experiment nach geurteilt, kann auch ich allein konstatieren, dass der Lobus nervosus zu seiner vollständigen Entwicklung absolut des Vorhandenseins des Lobus glandularis bedarf. Doch wie ich vorher unter der „,kraniokaudalen Umkehrung der Anlage des Infundibulums“ berichtete, sind die beiden Lappen bei dem kaudalwärts verschobenen Infundibulum nicht verbunden und kümmerlich entwickelt. Darum mag ich wohl ohne weiteres annehmen, dass auch der Lobus nervosus zu seiner vollständigen Entwicklung durchaus der Verbindung mit dem Lobus glandularis bedarf.

Takasima und Terato ${ }^{12}$ (1936, Bufo vulgaris japonicus, Rana nigromaculata, Rhacophorus schlegelii arborea und Cacopoides tornieri) haben den Lobus nervosus der normalen Larve in zwei verschiedene Teile geteilt, einen primären und einen sekundären Teil. Der primäre Teil entwickelt sich ihrer Ansicht nach im kaudalen Abschnitt des Infundibulums in der frühlarvalen Zeit, der sekkundäre dagegen im kranialen Abschnitt in der spätlarvalen Zeit. Der Lobus nervosus fehlt zwischen den beiden Abschnitten und dort liegt, meinen sie, die Wand des Infundibulums selbst. Ich habe den Lobus nervosus bis gerade nach der Vollendung der Metamorphose mit meiner obigen Kenntnis seiner Entwicklung untersucht. Der Teil, der dorsal vom Lobus glandularis liegt, d.h. der Teil, welcher nach Takasima und Terato am Lobus nervosus fehlt, ist nicht die Wand des Infundibulums selbst, sondern der Lobus nervosus des primitiven Stadiums. Dieser Teil erreicht das primitive Stadium gleichzeitig mit den anderen Teilen, danach verzögert sich jedoch in diesem Teil die weitere Differenzierung, Daher ist dieser Teil bei der Larve der dünnste im ganzen Lobus nervosus. Ich kann somit der Ansicht, dass die Entstehung des Lobus nervosus in zwei getrennten Teilen vor sich gehe, welche nach Takasima und Terato in zwei verschiedenen Stadien' gebildet werden, nicht beitreten.

$\mathrm{Smith}^{11)}$ (1920) beobachtete, dass Form und Lage des Lobus nervosus beim Fehlen des Lobus glandularis deutlich verändert seien. Auch in meinem Falle war die Form auffallend verändert, der Lage nach befand er sich aber in dem Gebiet, in welchem er normal lokalisiert ist.

Die Veränderung der Hautfarbe ist vielleicht durch die Kontraktion der Melanophoren verursacht, da der Zwischenlappen fehlt.

Die Ursache, warum die Metamorphose ausblieb, dürfte freilich das Fehlen des Lobus glandularis bilden. 


\section{Schluss.}

I. Die Entwicklung des Infundibulums ist vom Lobus glandularis unabhängig.

2. Das Infundibulum zeigt auch beim Fehlen des Lobus glandularis eine normale Entwicklung und Gestaltung, mit Ausnahme dessen, dass seine ventrale Wand sich hierbei ventrokaudalwärts ausbuchtet. $\mathrm{Da}$ bei der normalen ventralen Wand vom Lobus glandularis aus dorsalwärts ein Eindruck verursacht wird, so ist es denkbar, dass der Lobus nervosus in seinem mittleren Teil einen starken Druck erfährt und eine Spannung aufweist.

3. Der Lobus nervosus beginnt auch beim Fehlen des Lobus glandularis ebenso früh wie normal sich zu entwickeln. Aber er bedarf derVerbindung mit dem Lobus glandularis absolut $\mathrm{zu}$ seiner vollständigen Entwicklung. Wenngleich ich auch nichts Bestimmtes aussagen kann, verrät doch meiner Meinung nach der Lobus nervosus die Tendenz, sich nach seiner Entwicklung bis zu einem gewissen Grade im Verlaufe der Zeit zu verkleinern.

4. Die Form des Lobus nervosus ist beim Fehlen des Lobus glandularis zwar anders als normal, doch lässt sie sich mit der des normalen Lobus nervosus wie folgt in Beziehung setzen. Vorausgesetzt, dass der beim Fehlen des Lobus glandularis relativ gut entwickelte Lobus nervosus ähnlich wie im normalen Falle von ventral her durch den Lobus glandularis einen Druck erfährt, infolgedessen nach allen Seiten ausgedehnt und sein mittlerer Teil am dünnsten wird, so entspricht seine Form fast der des normalen Lobus nervosus, welcher ungefähr zur Zeit der Metamorphose beobachtet wird.

5. Der Lage nach befindet sich der Lobus nervosus beim Fehlen des Lobus glandularis im Gebiet seiner normalen Lokalisation.

6. Der Lobus nervosus erreicht seinen ausgebildeten Zustand dadurch, dass die Wand des Infundibulums in ihrem ganzen den Lobus nervosus zu bildenden Gebiet zweimal deutliche Strukturveränderungen durchmacht. Eine kleine Zellwucherung findet im Frühstadium in der ventralen Wand, welche aus platten Zellen besteht, etwas kranial vom kaudalen Ende der ventralen Wand statt und bildet in der Richtung ventralwärts eine kleine Verdickung. Dies ist der Entstehungsbeginn des Lobus nervosus. Danach entsteht eine dünne Schicht, welche am Ventrikel rundliche oder ovale Kerne besitzt und ventral davon kernarm ist, in dem ganzen Gebiet, in welchem die Entwicklung des Lobus nervosus stattfindet. Dieses ganze Gebiet durchläuft nun gleichmässig das Stadium, in welchem die sog. Stammzellen dicht nebeneinander liegen, worauf der Lobus nervosus in das Stadium seiner Vollendung tritt.

Bei dem normalen Lobus nervosus verläuft das Stadium der Stammzellen 
dagegen der Stelle nach verschieden. Er verzögert seine Differenzierung am stärksten in dem Abschnitt, welcher sich dem dorsalen mittleren Teil des Lobus glandularis gegenüber befindet.

7. Der Zwischenlappen wird nicht vom Lobus nervosus allein gebildet.

Anhang: Gleichzeitige Exstirpation der Anlage des Lobus glandularis und der des Infundibulums.

Bei den Amphibien wurden Individuen ohne Hypophyse von Adle ${ }^{1)}$ (1914, Rana temporaria), Blount4) (1932, Amblystoma punctatum Linn., A. mexicanum und A. tigrinum) u.a. gezüchtet. Adler führte das betreffende Experiment an schwimmenden Larven aus und Blount im Stadium der Schwanzknospe.

Die Haut bot auch bei meinem Experimente, wie dies auch von Adler angegeben wurde, einen goldenen Farbton. Metamorphose trat nicht auf, aber die hinteren Beine verlängerten sich ein wenig und die Gelenke und Zehen wurden bemerkbar. Die vorderen Beine dagegen wurden gar nicht nachgewiesen. Die Entwicklung des Hirnbodens war dieselbe wie bei der totalen Exstirpation der Anlage des Infundibulums. Der Lobus glandularis wurde nicht gebildet.

Die Veränderung der Hautfarbe dürfte durch die Kontraktion der Melanophoren, welche beim Fehlen des Zwischenlappens stattfindet, verursacht sein.

Die hinteren Beine blieben beim Fehlen des Lobus glandularis im Zustand der Beinknospe, beim Fehlen der Hypophyse entwickelten sie sich jedoch ein wenig. Wodurch wird dieser Unterschied im Verhalten in den beiden Fällen ohne Lobus glandularis bewirkt? Der Grund ist unklar.

\section{Schluss.}

Die Hypophyse ist mindestens für die Bufolarve kein lebenswichtiges Organ. Das gleiche wurde schon von A dle r u.a. bei anderen Amphibien und sonstigen Tieren festgestellt.

2. Affinität zwischen dem Lobus glandularis und dem Lobus nervosus bzw. den anderen naheliegenden Organen.

Die Anlage des Lobus glandularís trennt sich von ihrem Mutterboden ab, wandert eine Strecke kaudalwärts und erreicht das Infundibulum. Wodurch wird diese Erscheinung hervorgerufen ? Es ist dies ein interessantes Problem. Folgende Affinitäten sind leicht als Ursache denkbar: zuerst die Affinität zwischen der Anlage des Lobus glandularis und der des Lobus nervosus, dann die Affinität zwischen der Anlage des Lobus glandularis und den dem Infundi- 
bulum naheliegenden Organen. Meine sich auf dieses Problem beziehenden Experimente sind folgende.

(I) Totale Exstirpation der Anlage des Infundibulums (vorhergehend).

Der Lobus glandularis lässt auch beim Fehlen des Infundibulums d.h. des Lobus nervosus seine kaudale Verschiebung erkennen und erreicht seine normale Lage (Abb. ro).

(2) Kraniokaudale Umkehrung der Anlage des Infundibulums (vorhergehend).

Wenn das Infundibulum weiter kaudal als im normalen Falle gebildet wird, gelangt der Lobus glandularis, ob nun das Infundibulum umgekehrt sei oder nicht, doch nicht an den Lobus nervosus (Abb. 20). Letzterer wird hierbei beim Infundibulum gebildet, während sich der Lobus glandularis zwischen der Hirnbasis und der Basalplatte vom Lobus nervosus getrennt in seinem normalen Querschnittsniveau befindet.

(3) Autoplastische Transplantation der Anlage des Lobus glandularis.

Das Operationsstadium ist das X-Y-Stadium der Néuralplatte. Die Anlage des Lobus glandularis wurde bei einem Keim links lateral von der Anlage des Infundibulums in dem gleichen Abstand wie dem zwischen der Anlage des Infundibulums und der des Lobus glandularis transplantiert (Abb. 3 I a). Der Lobus glandularis wurde in 4 von 9 Fällen bemerkt, aber er berührte das Infundibulum nicht (Abb. 3 I b). Er lag bald auf der Basalplatte
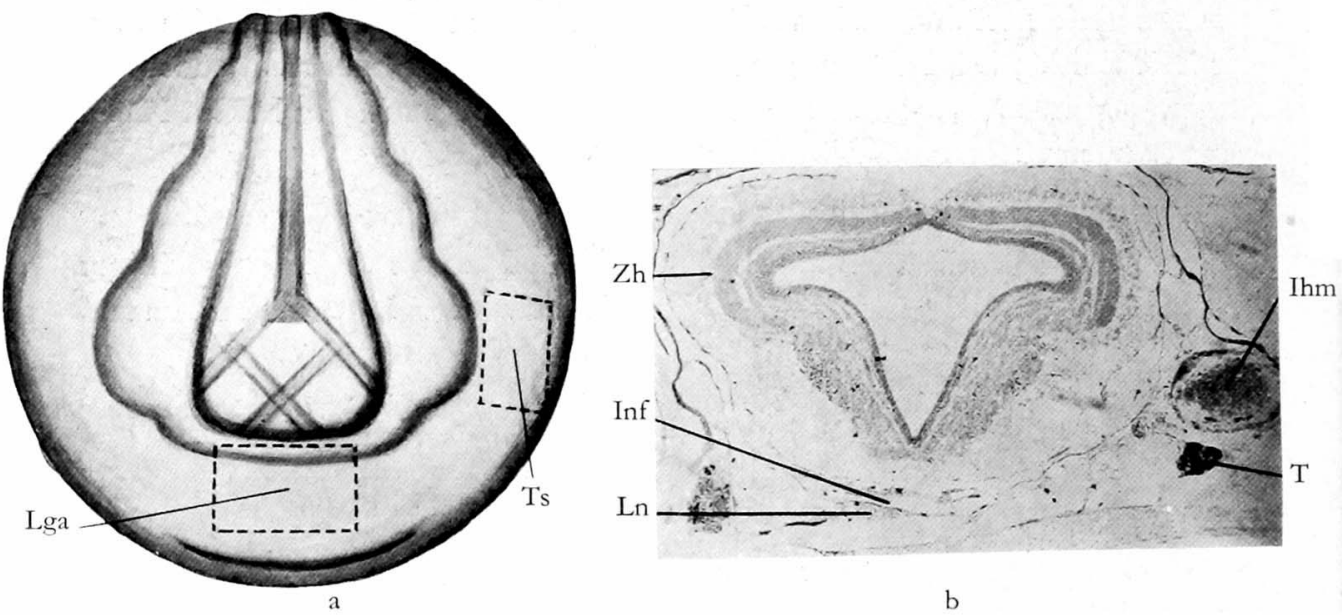

Abb. 31. Autoplastische Transplantation der Anlage des Lobus glandularis.

a : Schema der Operation.

b : Ergebnis. Querschnitt, Vergr. etwa 4omal.

$\mathrm{Ihm}=$ durch Operation isolierte Hirnmasse, Lga = Anlage des Lobus glandularis, $\mathrm{T}=$ Transplantat $:$ in diesem Falle eigener Lobus glandularis, $\Gamma \mathrm{s}=$ transplantierte Stelle. 
links ventral vom Chiasma opticum, bald lateral vom Gehirn und zugleich kranial vom Ohr usw.. Seine Entwicklung ist kümmerlich. In den übrigen s Fällen wird das Transplantat gar nicht bemerkt. Ein kleiner Lobus nervosus bildet sich in allen Fällen beim Infundibulum.

(4) Homoioplastische Transplantation der Anlage des Lobus glandularis.

In demselben Stadium wie bei der Exstirpation der Anlage des Lobus glandularis wurde die Anlage des Lobus glandularis eines anderen Keimes auf
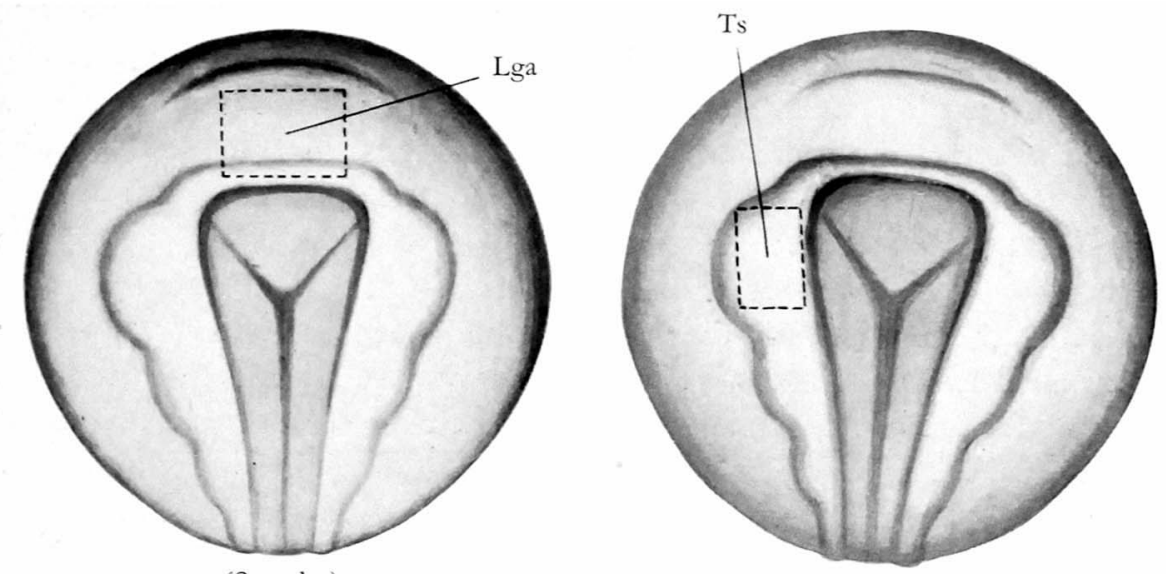

(Spender)

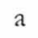

a

(Wirt)
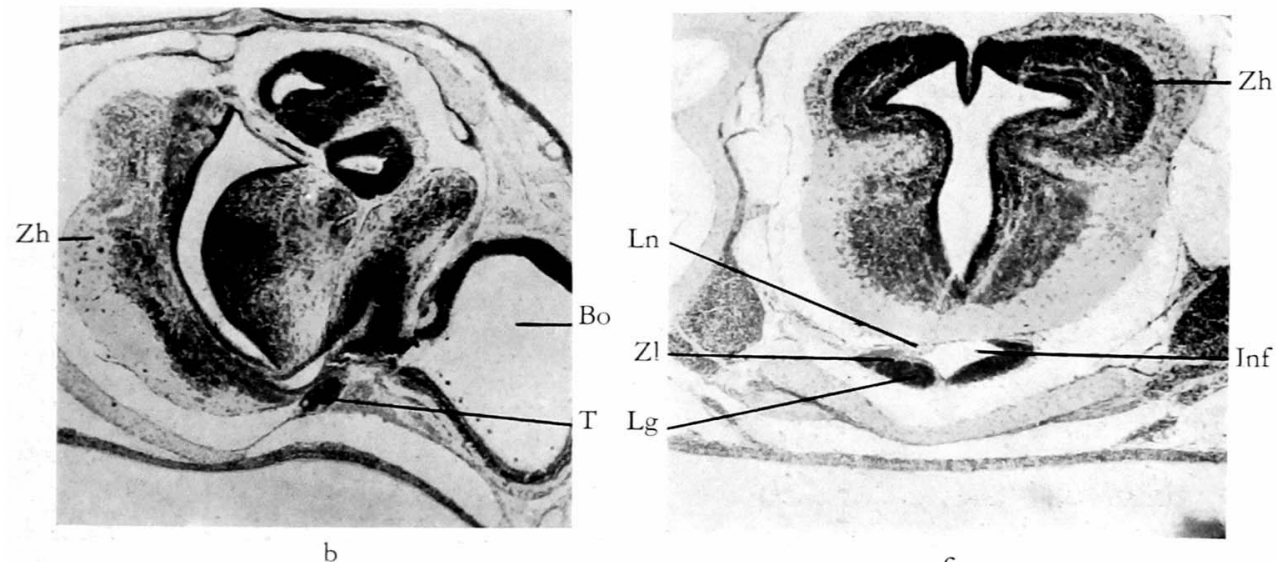

c

Abb. 32. Homoioplastische Transplantation der Anlage des Lobus glandularis.

a : Schema der Operation.

b und c: Ergebnis. Querschnitte, Vergr. etwa 4omal.

b: Querschnittsniveau des Transplantates d.h. des transplantierten Lobus glandularis.

c: Weiter kaudal als b ; Querschnittsniveau der Hypophyse.

$\mathbf{B o}=$ Bulbus oculi, Lg=hier eigener Lobus glandularis, Lga = Anlage des Lobus glandularis : in diesem Falle Transplantat, $T=$ Transplantat: in diesem Falle transplantierter Lobus glandularis, $\mathrm{Ts}=$ transplantierte Stelle, $\mathrm{Zl}=\mathrm{Z}$ wischenlappen. 
den Neuralwulst, welcher lateral von der Anlage des Infundibulums liegt, transplantiert (Abb. 32 a). Das Transplantat erreichte das Infundibulum nicht. Es berührte dicht die Seitenfläche des Hirns nahe der Hirnbasis (Abb. 23 b) oder lag etwas lateral davon getrennt. Der Lobus glandularis bildete weder die Pars tuberalis noch den Zwischenlappen. Das Infundibulum wurde nur vom Lobus glandularis des Wirts selbst berührt (Abb. $32 \mathrm{c}$ ).

(5) Exstirpation des Gehirns.

Im Anfangsstadium der Schwanzknospe (Körperlänge : ca. 3.8-4.0 mm) wurde das Gehirn exstirpiert unter Zurücklassung des Hörbläschens. Die operierten Tiere nahmen keine Nahrung zu sich. Der Körper entwickelte sich nur bis zu einem gewissen Grade und magerte danach schnell ab. Der Kopf war in dorsoventraler Richtung abgeplattet. Die Tiere bewegten sich nur gegen Reize, sonst nahmen sie die Seitenlage ein. Doch traten sie in das Stadium der Metamorphose ein. Die vier Beine verlängerten sich und bildeten ihre Gelenke und Zehen aus, der Schwanz ging jedoch während der Züchtung nicht vollstăndig verloren. Was die Metamorphose anbetrifft, verhalten sie sich also ähnlich wie die Individuen, bei denen die totale Exstirpation der Anlage des Infundibulums ausgeführt wurde. Die Individuen, bei denen der Lobus glandularis mit dem Gehirn entfernt wurde, traten in keine Metamorphose ein.

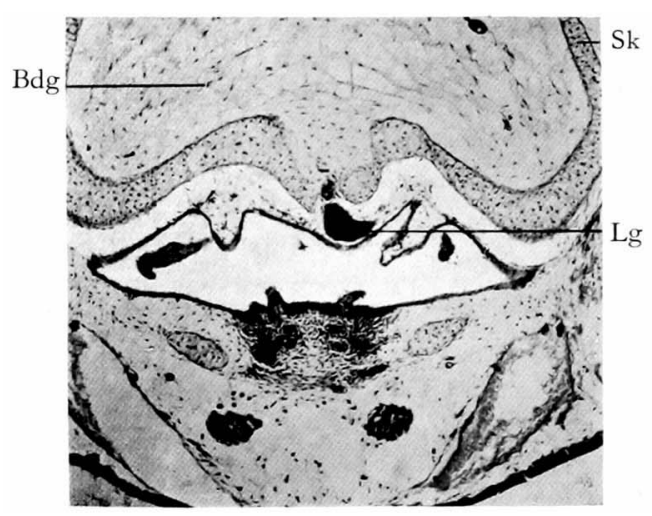

Abb. 33. Exstirpation des Gehirns. Querschnitt, Vergr. etwa 4omal. Lobus glandularis beim Fehlen des Gehirns (Querschnittsniveau etwas kranial vom $\mathrm{Ohr}$ ).

$\mathrm{Bdg}=$ Bindegewebe, $\mathrm{Sk}=$ Schädelknorpe.

Das Gehirn war meist vollständig entfernt. Der vierte Ventrikel hatte sich aber in einigen Fällen gebildet. Die dem Cavum cranii entsprechende Stelle war mit lockerem Bindegewebe gefüllt. Der Lobus glandularis erreichte fast seine normale Lage. Er war ebenfalls kümmerlich entwickelt (Abb. 33).

(6) Gleichzeitige Exstirpation des Gehirns und der Hörbläschen.

Das Operationsstadium ist dasselbe wie bei der Exstirpation des Gehirns. Auch wenn die Hörbläschen gleichzeitig mit dem Gehirn exstirpiert wurden, verschob der Lobus glandularis sich dennoch kaudalwärts. Er war ebenfalls kümmerlich entwickelt. 
Anhang : Kraniokaudale Umkehrung des Gehirns.

Ich habe das ganze Gehirn in demselben Stadium wie bei seiner Exstirpation um $180^{\circ}$ kraniokaudal gedreht, es also umgekehrt. Das Gehirn erhielt dann eine unregelmässige Form und der Ventrikel war erweitert. Das Infundibulum lag etwas weiter kaudal als im Querschnittsniveau des Ganglion prooticum. Der Lobus glandularis erlitt eine kaudale Verschiebung und erreichte fast das normale Querschnittsniveau, gelangte jedoch nicht an das Infundibulum (Abb. 34).

(7) Homoioplastische Transplantation der Anlage des Infundibulums.

Die Anlage des Infundibulums eines anderen Keimès wurde im X-YStadium rechts lateral dicht neben die Anlage des Lobus glandularis transplantiert (Abb. 35 a). Das Transplantat bildet eine grosse Hirnmasse mit einem Hohlraum rechts lateral von der Mundhöhle (Abb. 35 b). Der Hohlraum kommuniziert bald mit dem Ventrikel des Hirns, bald nicht. Der
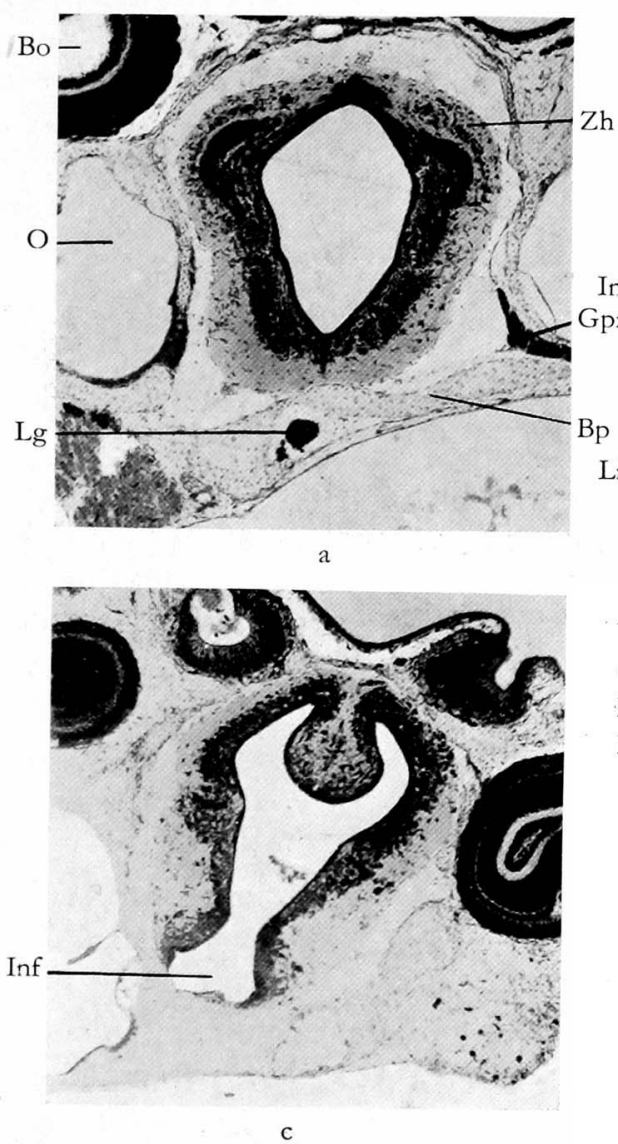

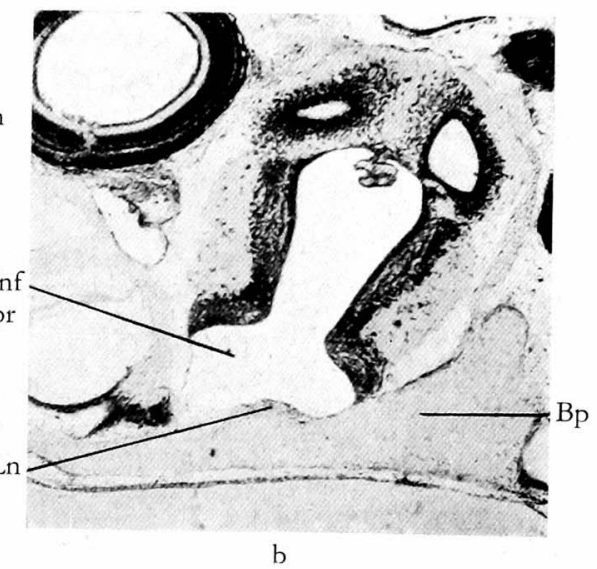

Abb. 34. Kraniokaudale Ummehrung des Gehirns. Querschnitte, Vergr. etwa 4omal. Lobus "glandularis sowie kraniokaudal umgekehrtes Infundibulum.

a: Querschnittsniveau des Lobus glandularis.

b: Weiter kaudal als a; Querschnittsniveau des dünnwandigen Abschnitts des Infundibulums, welcher sich normalerweise kaudal befindet.

c: Weiter kaudal als b; Querschnittsniveau des dickwandigen Abschnitts des Infundibulums, welcher sich normalerweise kranial befindet.

$\mathrm{Bo}=$ Bulbus oculi, $\mathrm{O}=\mathrm{Oh}$. 

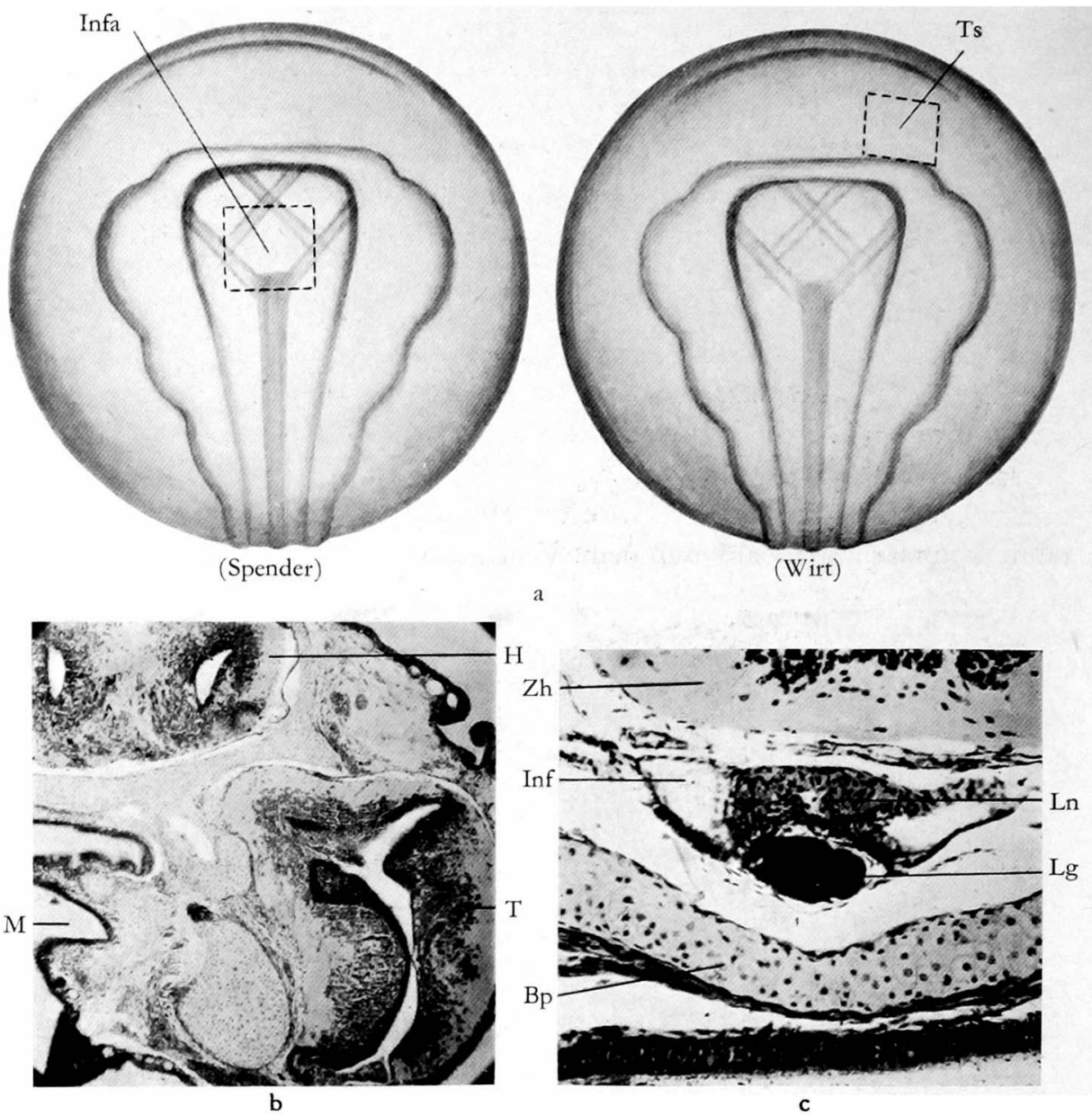

Abb. 35. Homoioplastische Transplantation der Anlage des Infundibulums.

a : Schema der Operation.

b und c: Ergebnis, Querschnitte.

b: Querschnittsniveau des Transplantates. Vergr. etwa 40mal.

c: Weiter kaudal äls b; Querschnittsniveau der Hypophyse. Vergr. etwa I romal,

$\mathrm{H}=$ Hemisphäre, Infa = Anlage des lnfundibulums : in diesem, Falle Transplantat,

$\mathrm{Lg}=$ eigener Lobus glandularis, $\mathrm{M}=$ Mundhöhle, $\mathrm{Ts}=$ transplantierte Stelle.

Lobus glandularis verbindet sich nicht mit dem Transplantat, sondern erreicht das eigene Infundibulum und bildet in normaler Weise die Hypophyse (Abb. $35 \mathrm{c})$.

Aus obigen Resultaten lässt sich folgendes entnehmen. Die Affinität zwischen der Anlage des Lobus glandularis und der des Lobus nervosus bildet nicht die Ursache der kaudalen Verschiebung des Lobus glandularis. Ausser- 
dem wirken auch Gehirn, Ohr usw. nicht direkt auf die kaudale Verschiebung desselben ein.

Ich habe hierauf die kaudale Verschiebung des normalen Lobus glandularis genauer beobachtet. Während der kaudalen Verschiebung hatte sich die Basalplatte noch nicht entwickelt. Im Raum zwischen der Hirnbasis, besonders der Basis des Infundibulums, und dem Gaumendach war die Bildung des Bindegewebes verzögert. Ich konnte bemerken, dass zwischen der kaudalen Verschiebung des Lobus glandularis und der Bildung des Bindege-

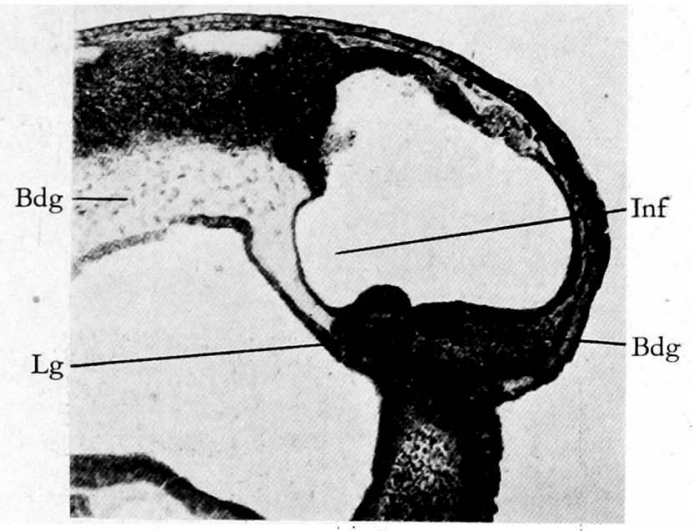

Abb. 36. Kaudale Verschiebung des Lobus glandularis. Normale Larve, Körperlänge: $7.0 \mathrm{~mm}$. Sagittalschnitt, Vergr. etwa somal. $\quad \mathrm{Bdg}=$ Bindegewebe. webes in der Richtung kaudalwärts immer eine Beziehung bestand. Das Bindegewebe hatte sich kaudal vom Lobus glandularis noch immer nicht gebildet (Abb. 36 u. 37); es entstand dort nicht eher als bis der Lobus glandularis die ventrale Fläche des Infundibulums berührte. Es war nun kranial und ventral vom Lobus glandularis vorhanden: je weiter kranial von diesem entfernt, " desto dichter. Der Lobus glandularis bot einen Anblick, als ob er vom ent-
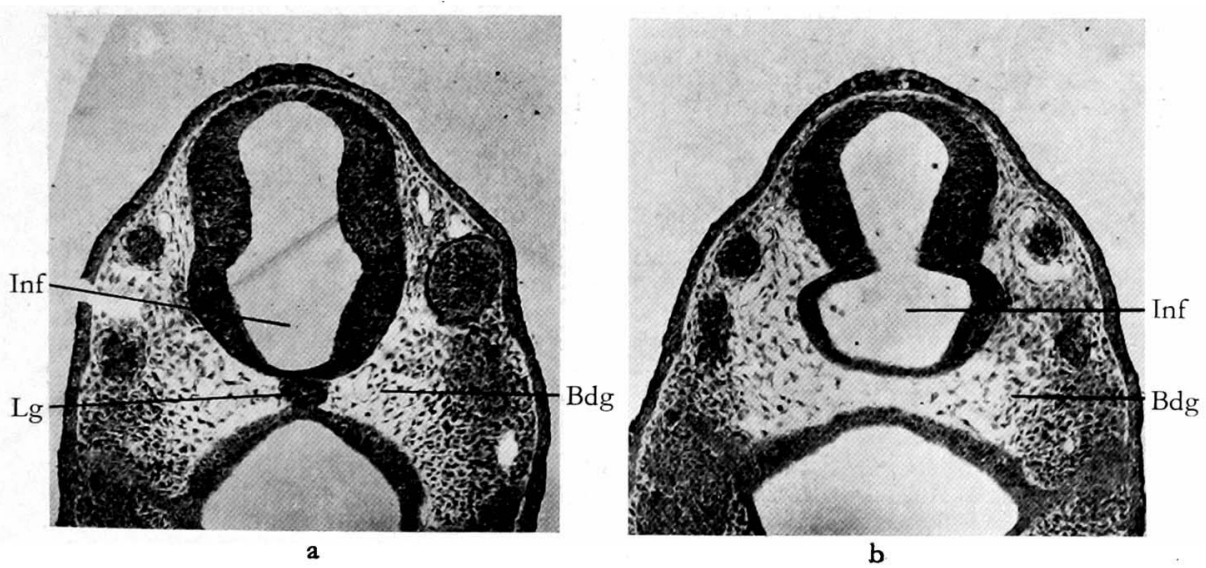

Abb. 37. Kaudale Verschiebung des Lobus glandularis. Normale Larve, Körperlänge : $6.5 \mathrm{~mm}$. Querschnitte, Vergr. etwa somal.'

a: Querschnittsniveau des mittleren Abschnitts des Lobus glandularis.

b : Weiter kaudal als a ; kaudal vom Ende des Lobus glandularis. 
stehenden Bindegewebe kaudalwärts verschoben werde. Hatte das kaudale Ende des Lobus glandularis fast das Querschnittsniveau des kaudalen Endes des Infundibulums erreicht, so wurde der Lobus glandularis vollständig vom Bindegewebe umgeben, ausser seiner dorsalen Fläche, welche das Infundibulum und die Anlage des Zwischenlappens berührte (Abb. 38). Das

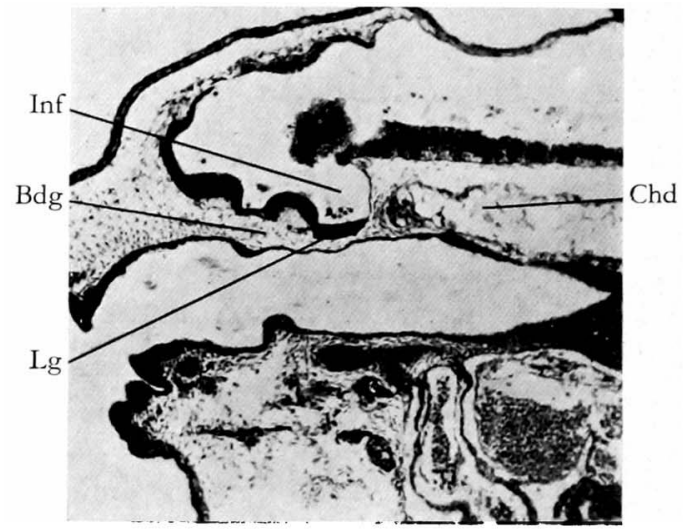

Abb. 38. Kaudale Verschiebung des Lobus glandularis. Normalc Larve, welche gerade zu schwimmen begann; Körperlänge : $13 \mathrm{~mm}$. Sagittalschnitt, Vergr. etwa 4omal. Lobus glandularis erreicht das kaudale Ende des Infundibulums und ist vom Bindegewebe umgeben. Chd =Chorda dorsalis.

Bindegewebe zeigte jetzt eine gleichmässige Dichtigkeit in der Umgebung des Lobus glandularis. In diesem Stadium hörte der Lobus glandularis auf, sich weiter kaudal $\mathrm{zu}$ verschieben. Das umgebende Bindegewebe verschwand nach einer Zeit und die Basalplatte, die Hirnhäute usw. wurden gebildet (Abb. 39). Der Lobus glandularis wurde von den Hirnhäuten umgeben und durch sie von den anderen Lappen getrennt. Nur das kraniale Ende des Lobus glandularis fehlte jedoch an den Hirnhäuten und ver-
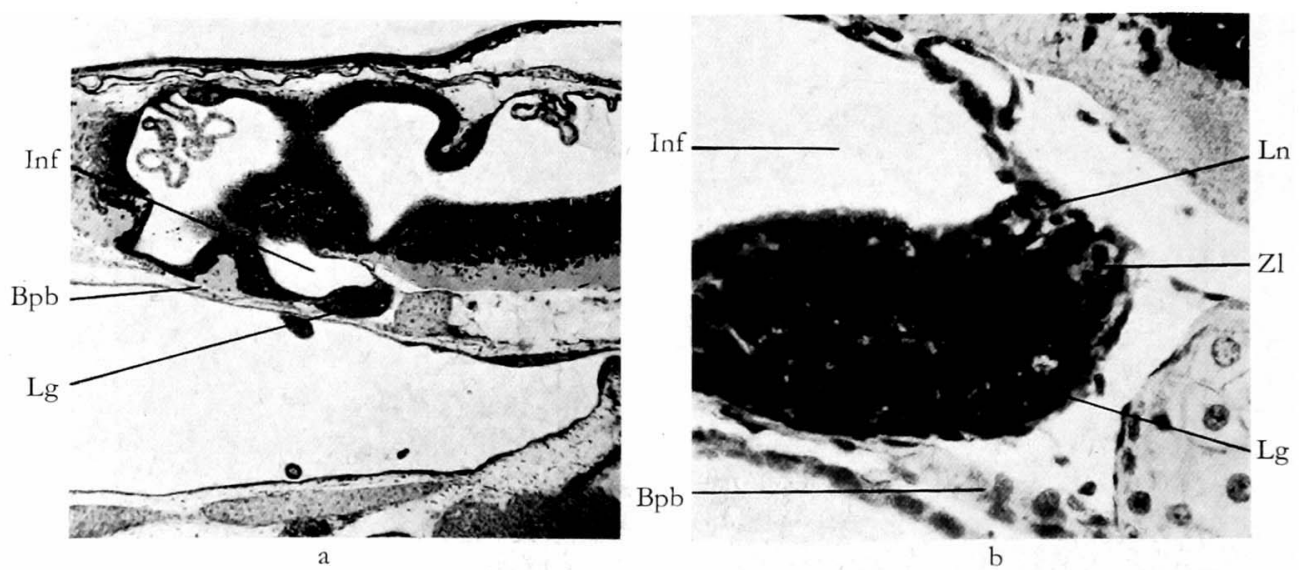

Abb. 39. Kaudale Verschiebung des Lobus glandularis. Normale Larve im Entstehungsbeginn der Basalplatte, Körperlänge : $20 \mathrm{~mm}$. Sagittalschnitt.

a : Schwache Vergrösserung (etwa 4omal).

b: Starke " von a (etwa $280 \mathrm{mal}$ ).

$\mathrm{Bpb}=$ Entstehungsbeginn der Basalplatte, $\mathrm{Zl}=\mathrm{Zwischenlappen}$. 
band sich direkt mit dem Lobus nervosus des primitiven Stadiums.

Mit kurzen Worten, das Bindegewebe wird von kranial nach kaudal, d.h. in den Raum, welcher ventral vom Infundibulum liegt, gebildet. Vorausgesetzt, dass die Differenzierung des Bindegewebes primär ist, so erweckt der Lobus glandularis den Eindruck, als ob seine kaudale Verschiebung wie folgt stattfinde. Die Anlage des Lobus glandularis wuchert bis zu einem gewissen Grade etwas schneller als die Bildung des Bindegewebes in seiner Umgebung vonstatten geht, d.h. letztere findet relativ langsam statt. Er wird danach durch das Bindegewebe, welches sich von kranial nach kaudal schrittweise bildet, kaudalwärts. verschoben und erreicht das Infundibulum. Der mikroskopische Befund dieser Gegend ist mindestens der Annahme einer kaudalen Verschiebung des Lobus glandularis günstig.

\section{Diskussion.}

Es ist am wahrscheinlichsten, dass man als die Ursache der Vereinigung des Lobus glandularis mit dem Lobus nervosus das Vorhandensein einer Taxis zwischen diesen beiden Lappen betrachtet. Nun lässt sich aber solche Taxis auf Grund der Resultate bei den obigen verschiedenen Versuchen nicht nachweisen. Da der einzige Anhaltspunkt nur der obige histologische Befund ist, möchte ich vorläufig ihm einen Hinweis auf die Ursache entnehmen.

Kôchi ${ }^{8)}$ (1935, Rhacophorus schlegelii) gab folgende Erklärung. Er meinte, der Lobus glandularis verbinde sich mit dem Infundibulum an seinem kranialen Ende bis nach der Vollendung der Metamorphose. Die Verbindung werde aber im Stadium des Erwachsenseins getrennt und der Lobus glandularis verschiebe sich weiter kaudalwärts. Die Utsache der kaudalen Verschiebung liege in dem zwischen dem Infundibulum und der Basalplatte bestehenden Druck. Kôchi hat jedoch die Ursache, warum der Lobus glandularis sich von seinem Mutterboden nach dem. Infundibulum hin verschiebe, gar nicht berührt.

Die Transplantation des Lobus glandularis betreffend, machte Bloun $\mathrm{t}^{4}$ ) (1932, Amblystoma punctatum Linn., A. mexicanum und A. tigrinum) folgende Angabe: Wenn man die homoioplastische Transplantation im Stadium der Schwanzknospe ausführe, werde das Transplantat gar nicht aufgefunden. Meiner homoioplastischen Transplantation nach ergab sich, dass das Transplantat meist nicht aufgefunden wurde, wenn die Transplantation im X-YStadium der Neuralplatte ausgeführt wurde. Das aufgefundene Transplantat war in solchem Falle sehr kümmerlich entwickelt. Wurde die Transplantation aber im nachfolgenden Stadium d.h. in demselben Stadium wie bei der Exstirpation der Anlage des Lobus glandularis ausgeführt, so wurde das Transplantat sicher gefunden. Auch im letzteren Falle war es freilich kümmerlich 
entwickelt, doch besser als im ersteren.

\section{Schluss.}

I. Um festzustellen, warum der Lobus glandularis sich von seinem Mutterboden bis zum Infundibulum verschiebe, führte ich die obigen Experimente aus. Leider vermochte ich aber keinen positiven Beweis zu erhalten. Der Lobus glandularis verschob sich in allen Fällen selbständig kaudalwärts und erreichte seine normale Lage.

2. Dem normalen histologischen Befund konnte ich folgendes entnehmen. Der Lobus glandularis macht den Eindruck, als ob er durch die Bildung des Bindegewebes unter das Infundibulum hineingesendet werde. Dies ist vielleicht eine der Bedingungen, welche die kaudale Verschiebung des Lobus glandularis begünstigen.

3. Der Lobus glandularis ist, sei es nun nach seiner Transplantation, sei es nach der Exstirpation des Gehirns, in jedem Fall kümmerlich entwickelt. Selbst nicht einmal ein Ansatz zur Pars tuberalis lässt sich hierbei nachweisen.

4. Auch der Zwischenlappen wird weder nach der Transplantation des Lobus glandularis, noch nach der Exstirpation des Gehirns gebildet. Selbst wenn der transplantierte Lobus glandularis dicht das Gehirn berührt, entwickelt sich der Zwischenlappen nicht.

5. Das Individuum, dessen Gehirn im Frühstadium der Entwicklung beseitigt wurde, vermag keine Nahrung aufzunehmen. Der Körper ist klein. Wenn der Lobus glandularis vorhanden ist, tritt er in die Metamorphose ein. Die vier Beine entwickeln sich und ihre Gelenke und Zehen vollenden sich, doch das Schwinden des Schwanzes verzögert sich. Die Metamorphose vollzieht sich hierbei ganz ähnlich wie bei der totalen Exstirpation der Anlage des Infundibulums. Wenn der Lobus glandularis gleichzeitig mit dem Gehirn beseitigt wird, findet keine Metamorphose statt.

Anhang: Scheinbare kaudale Verschiebung des Lobus glandularis, welche nach der Bildung der Basalplatte beobachtet wird.

Ich habe die Beziehung des Lobus glandularis zum Infundibulum, von der Bildung der Basalplatte an bis nach der Vollendung der Metamorphose, untersucht. Wenn das den Lobus glandularis umgebende Bindegewebe verschwindet und die Basalplatte gebildet wird, so entsteht ein grosser Raum kaudal vom Infundibulum (Abb. 39). Er ist der geräumigste zwischen der Hirnbasis und der Basalplatte. Der Lobus glandularis ist an seinem kranialen Ende mit dem Lobus nervosus des primitiven Stadiums verbunden. Er vergrössert sich danach deutlich und drückt die ventrale Wand des Infundibulums in starkem Masse ein. Das übrige Gewebe verschiebt er kaudalwärts über das 
Niveau des kaudalen Endes des Infundibulums hinaus (Abb. 39 u. 6 a). Zur Zeit der Metamorphose gewährt der Lobus glandularis einen Anblick, als ob er kaudalwärts verschoben worden sei. Doch sein kraniales Ende ist unverändert an dem Lobus nervosus befestigt (Abb. 40), d.h. es handelt sich um eine scheinbare kaudale Verschiebung. Die Beziehung, welche weiter nach der Metamorphose zwischen dem Lobus glandularis und dem Infundibulum besteht, habe ich noch nicht studiert.
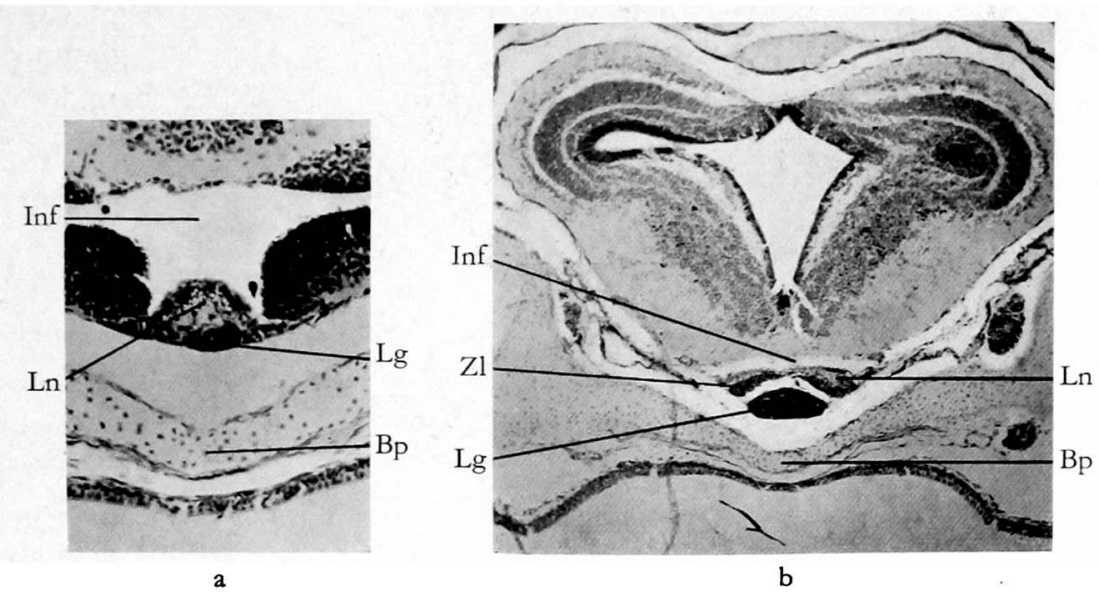

Abb. 40. Verhalten des Lobus glandularis in der Hypophyse. Ein normales Individuum am Ende der Metamorphose. Querschnitte.

a : Direkte Verbindung des kranialen Endes des Lobus glandularis mit dem Lobus nervosus. Vergr. etwa gomal.

b: Weiter kaudal als a; Lobus glandularis hier von den übrigen Lappen leicht trennbar. Vergr. etwa 4omal.

3. Histogenese des Lobus glandularis.

Die Histogenese des Lobus glandularis betreffend, finden sich zwei Meinungen vertreten. Die meisten Autoren halten den Lobus glandularis für rein ektodermal. Kupffer ${ }^{9)}$ (1894) und Terato ${ }^{13}$ (1935) haben dagegen behauptet, dass die entodermalen Zellen sich von der dorsalen Wand des Kopfdarmes in den Lobus glandularis mischen. In der Gegend, wo später die Rachenhaut gebildet wird, verschiebt sich der Lobus glandularis eigentlich durch einen engen Raum in kaudaler Richtung. Ein Präparat, bei welchem der Lobus glandularis das Entoderm berührt, gäbe daher ein Bild, als ob die entodermalen Zellen sich in den Lobus glandularis einmischten. Auch ich habe selbst die Präparate der Sagittalschnitte, welche von den normalen Individuen hergestellt wurden, mikroskopiert, konnte aber solch ein Bild nicht beobachten. Alle Autoren haben nur die Präparate, welche von den normalen 
Larven hergestellt wurden, untersucht; niemand hat diesbezügliche Experimente ausgeführt. Wenn allgemein die Meinung auch der rein ektodermalen

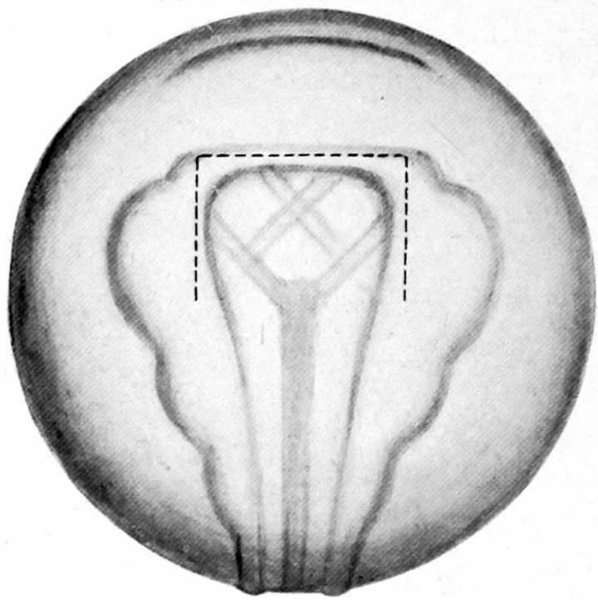

a

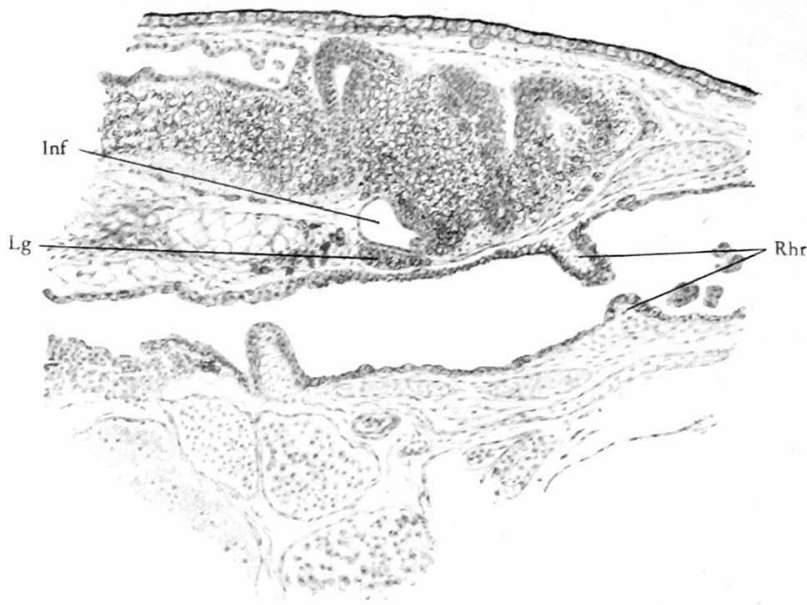

b

Auffassung zuneigt, so bleibt doch die Ansicht einiger Autoren, wonach die entodermalen Zellen sich in den Lobus glandularis einmischen, aus diesem Grunde unverändert und unnegiert bestehen, soweit das Problem mittels einer anderen positiven Metḩode keine Lösung findet.

Um dieser Frage näherzukommen, verwandte ich die lokale Farbmarkierung mit Nilblausulfat. Ich färbte nicht den Lobus glandularis, sondern das Entoderm des betreffenden Teiles und versuchte so $\mathrm{zu}$ entscheiden, ob die gefärbten entodermalen Zellen sich in Abb. 4r. Experimente über die Histogenese des Lobus glandularis. Lokale Farbmarkierung des Entoderms.

a : Schema der Operation. Operationswunde punktiert.

b: Ergebnis. Sagittalschnitt, Zeichnung, Vergr. etwa $70 \mathrm{mal}$. Markierte Stelle blau. $\mathrm{Rhr}=$ Reste der Rachenhaut. den Lobus glandularis einmischen.

Ich durchschnitt im X-Y-Stadium der Neuralplatte den kraniobilateralen Abschnitt des Neuralwulstes, welcher das kraniale Ende der Neuralplatte umrändert, und löste diese von ihrer Unterlage ab (Abb. 4I a). Ich verfuhr hierbei besonders vorsichtig, um die Anlage des Lobus 
glandularis und das Entoderm nicht zu schädigen. Das Entoderm färbte ich dann mit einem von Nilblausulfat durchtränkten Agarplättchen. Die Anlage des Lobus glandularis wurde hierbei davor bewahrt mitgefärbt zu werden. Ich beseitigte das Agarplättchen nach einigen Minuten und liess die Wunde heilen. In dem Stadium, wo der Lobus glandularis das Infundibulum ganz erreicht hatte, behandelte ich die Larven nach Lehmann. Danach Paraffineinbettung, vollständige Serienschnitte (Iо $\mu$ ) und Kernfärbung mit Karmalaun.

Das gefärbte Gebiet des Entoderms ist weit grösser als die Stelle, von welcher aus die Möglichkeit der Zelleinmischung in den Lobus glandularis denkbar ist. Das Gebiet, welches sich vom kranialen Ende des Kopfdarmes bis in die Gegend des Infundibulums erstreckt, ist blau gefärbt, die blau gefärbten Zellen (genauer gesagt, Zellen mit tiefblau gefärbten Körnchen) sind aber gar nicht in den Lobus glandularis eingemischt (Abb. 4I b).

\section{Diskussion.}

Kupffer ${ }^{5 \text { u. 9) }}$ (1894, Rana fusca) hat eine Abbildung veröffentlicht, nach welcher ein Zellstrang von der dorsalen Wand des Kopfdarmes abstammt und sich mit dem Lobus glandularis vereinigt (Gaupp, E. : Anatomie des Frosches. Dritte Abteilung. Braunschweig. 1904. SS. 7-IO). Ich vermochte jedoch keinen solchen Fall bei den Bufolarven nachzuweisen. Te ra to ${ }^{13)}$ (1935, Bufolarve) ist der Meinung K upffers beigetreten, indem er folgende Angaben machte. Im Frühstadium seien die Zellen des Lobus glandularis und die der Kopfdarmwand verschieden. Die entodermalen Zellen seien kurz nach der Zelleinmischung noch von den eigentlichen Zellen des Lobus glandularis unterscheidbar, doch werde die Unterscheidung später unmöglich. Die Mischung der entodermalen Zellen fände daher vielleicht tatsächlich statt. Meine Präparate aber bestätigten diesen Befund durchaus nicht.

Im X-Y-Stadium kann man sich über die Anlage des Lobus glandularis und des Infundibulums leicht orientieren. Die Anlage des Lobus glandulatis zeigt hierbei noch erst eine ganz leichte Verdickung. Auch die Trennung der Neuralplatte vom Entoderm ist leicht ausführbar. Das Entoderm der Stelle, welche mit Nilblausulfat gefärbt werden soll, wird also leicht vor einer Beschädigung geschützt. Wenn das Entoderm versehentlich geschädigt wird, so zeigt der Keim dort ein Loch und zerbricht sofort. Ausserdem wird das Entoderm binnen kurzer Zeit intensiv markiert. Man braucht also nicht zu sorgen, dass die Zellen des Entoderms durch die Operation verlorengehen. Wenn sich die entodermalen Zellen in den Lobus glandularis einmischen, müssen die blau gefärbten Zellen im Lobus glandularis auffindbar sein.

\section{Schluss.}

Der Lobus glandularis ist rein ektodermal ; die entodermalen Zellen des 
Gaumendaches mischen sich nicht in den Lobus glandularis.

\section{Histogenese des Zwischenlappens.}

Von alters her ist man übereinstimmend der Meinung, dass der Zwischenlappen ausschliesslich vom Lobus glandularis gebildet wird. Was den Zustand und das Stadium seiner Entstehung anbetrifft, so sind aber viele zweifelhafte Punkte zurückgeblieben. Wir besitzen trotzdem bis jetzt kein Experiment über die Histogenese des Zwischenlappens. Meine obigen Experimente, d.h. die totale Exstirpation und die kraniokaudale Umkehrung der Anlage des Infundibulums sowie die Exstirpation und die Transplantation der Anlage des Lobus glandularis ergaben betreffs der Entstehung des Zwischenlappens die folgenden Resultate. (I) Wenn der Lobus glandularis und der Lobus nervosus für sich allein oder voneinander getrennt vorhanden sind, wird der Zwischenlappen überhaupt nicht gebildet. (2) Wenn der Lobus glandularis und der Lobus nervosus miteinander verbunden sind und die Hypophyse bilden, wird auch der Zwischenlappen immer gebildet. Diese Beobachtung liess mich die Richtigkeit der bisherigen Meinung über die Entstehung des Zwischenlappens bezweifeln. Es ist aber ganz unmöglich, über die Histogenese des Zwischenlappens ohne Experiment etwas Bestimmtes auszusagen. Ich habe daher an der Anlage des Infundibulums lokale Farbmarkierung mit Nilblausulfat vorgenommen. Ich beseitigte die Deckschicht der Anlage des Infundibulums im X-Y-Stadium der Neuralplatte und verwandte die lokale Farbmarkierung mit Nilblausulfat für die tiefe Schicht (Abb. 42). Die Anlage wurde nach einigen Minuten intensiv blau gefärbt. Die Larven wurden in dem Stadium kurz nach der Bildung des Zwischenlappens, d.h. zu Beginn des Schwimmens, nach Lehmani fixiert. Darauf erfolgten Paraffineinbettung und.Herstellung der Serienschnitte (Sagittalschnitte, $\lceil\dot{\delta} \mu$ ).

\section{Ergebnisse.}

Die Wand des Infundibulums und der Lobus nervosus bestehen aus Zellen, welche tiefblau gefärbte Körnchen haben. Der Zwischenlappen bietet hierbei im Sagittalschnitt den Anblick eines Keils, dessen Spitze kranialwärts gerichtet ist und der einer-

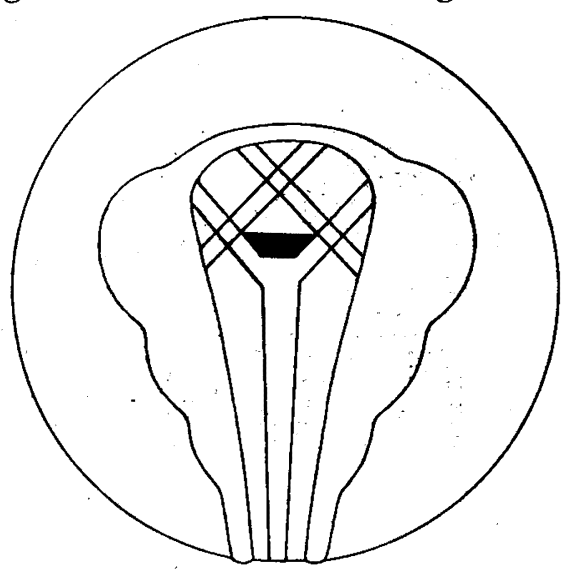

Abb. 42. Experiment über die Histogenese des Zwischenlappens. Schema der lokalen Farbmarkierung. Markierte Stelle blau. 


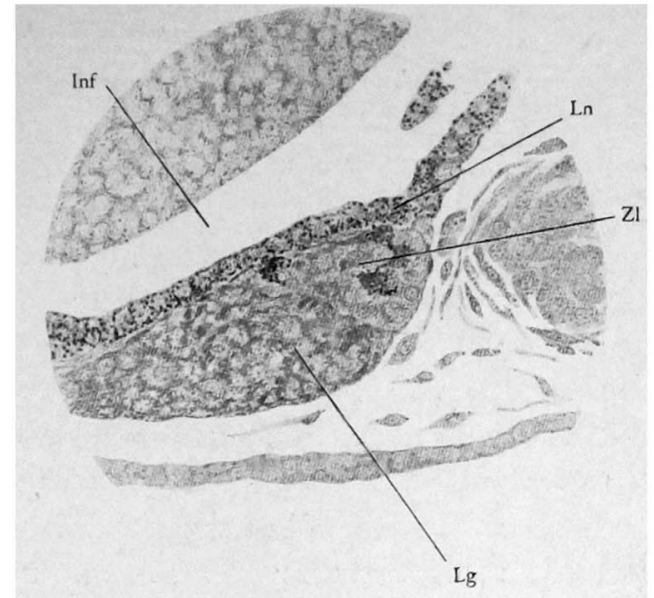

Abb. 43. Experiment über die Histogenese des Zwischenlappens. Ergebnis der lokalen Farbmarkierung. Sagittalschnitt, Zeichnung, Vergr. etwa $420 \mathrm{mal}$. $\mathrm{Zl}=\mathrm{Z}$ wischenlappen, in diesem Falle sein Entstehungsbeginn.

seits vom Infundibulum und kleinen Lobus nervosus und anderseits vom dorsokaudalen Teil des Lobus glandularis eingefasst ist. Die Zellen, welche deutlich die gleichen Körnchen wie die Zellen des Infundibulums und des Lobus nervosus haben, liegen auch in der Anlage des Zwischenlappens in der Mitte, im kaudalen Ende, in dem dem Lobus glandularis naheliegenden Abschnitt usw. zerstreut (Abb. 43). Dazwischen liegen die Zellen, welche gar keine gefärbten Körnchen haben, d.h. die Zellen des Lobus nervosus und die des Lobus glandularis erscheinen hier miteinander gemischt. Zellen mit tiefblau gefärbten Körnchen wurden bald auffallend viel, bald nur in geringem Masse gefunden. Doch bestätigte es sich in allen Fällen, dass dieselbe Zellmischung

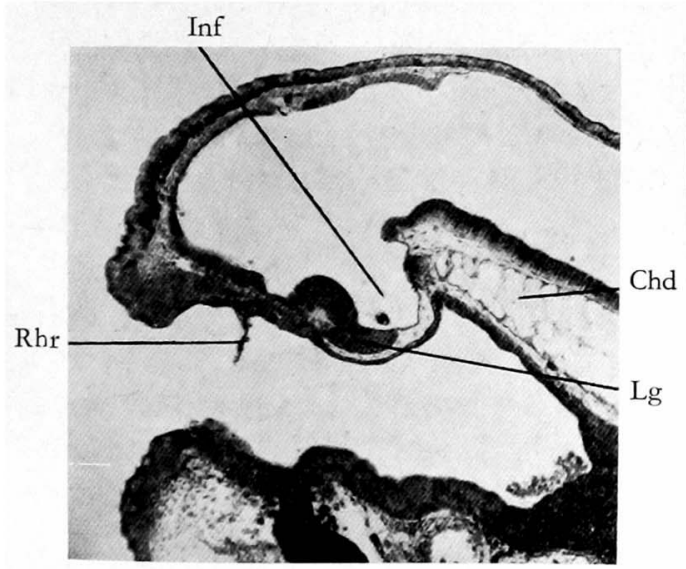

a

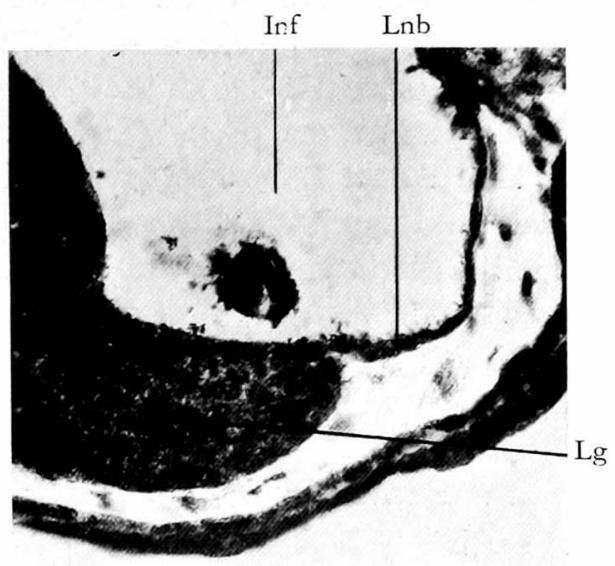

b

Abb. 44. Entstehung des Zwischenlappens. Lobus glandularis und Entstehungsbeginn des Lobus nervosus. Normale Larve, Körperlange : $9.5 \mathrm{~mm}$. Sagittalschnitt.

a: Schwache Vergrösserung (etwa 40mal).

$$
\text { b: Starke von a (etwa } 2 \text { somal). }
$$

Das kaudale Ende des Lobus glandularis ist noch rundlich und liegt dicht kranial vom entstehenden Lobus nervosus.

Chd $=$ Chorda dorsalis, Lnb $=$ Entstehungsbeginn des Lobus nervosus, Rhr $=$ Rest der Rachenhaut. 


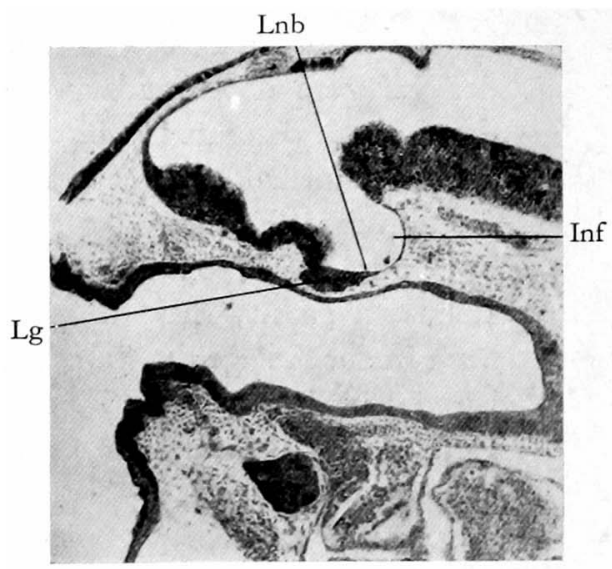

Abb. 45. Entstehung des Zwischenlappens. Vereinigung des Lobus glandularis mit dem entstehenden Lobus nervosus. Normale Larve, Körperlänge : II mm. Sagittalschnitt, Vergr. etwa 4omal. Das dorsokaudale Ende des Lobus glandularis erstreckt sich fortsatzartig bis zum entstehenden Lobus nervosus hinauf. im Zwischenlappen nachweisbar ist.

Normale Zwischenlappenbildung auf Grund des Ergebnisses der Experimente: Ich vermochte erst durch obige $\mathrm{Be}-$ funde und durch die vorher gewonnene Kenntnis der Entstehungsweise des Lobus nervosus die Entstehung und die Entwicklungsstadien des normalen Zwischenlappens festzustellen. Ich lasse hier eine kurze Zusammenfassung folgen. Wenn der Lobus glandularis fast das kraniale Ende des Infundibulums erreicht hat, beginnt der Lobus nervosus in der ventralen Wand des Infundibulums etwas kranial vom kaudalen Ende der ven-

tralen Wand sich in der Richtung ventralwärts in Form einer kleinen Verdickung zu bilden. Wenn das kaudale Ende des Lobus glandularis an diese Verdickung gelangt ist, sieht sein dorsokaudales Ende, welches bis hierher rundlich war (Abb. 44), so aus, als ob der Lobus glandularis zur Verdickung hin einen Fortsatz bilde (Abb. 45). Hierbei findet zugleich Zellmischung zwischen dem Lobus nervosus und dem Lobus glandularis, wie ich dies in meinem Experiment bestätigen konnte, statt. Auf diese Weise wird die Anlage des Zwischenlappens gebildet. Verschwindet das den Lobus glandularis und die Anlage des Zwischenlappens umgebende Bindegewebe, so wird die Anlage des Zwischenlappens in einen von Hirnhäuten gebildeten Sack eingeschlossen und vom Lobus glandularis sowie Lobus nervosus getrennt. Die weitere Entwicklung geschieht in diesem Sack. Da sie bereits von vielen Autoren beschrieben worden ist, sehe ich hier davon ab.

\section{Diskussion.}

Terato ${ }^{13)}$ (1935, Bufolarve) hat neuerdings Präparate von normalen Larven mittels der gewöhnlichen Färbemethode hergestellt und bei der Untersuchung konstatiert, dass der Zwischenlappen aus Zellen von verschiedener Färbbarkeit besteht. Wie er meint, sind vielleicht die Gliazellen des Lobus nervosus in den Zwischenlappen eingemischt. Er hat jedoch keine Gliafär- 
bung vorgenommen. Der bisher bestehenden Meinung nach hat er noch den Zwischenlappen für das Derivat des Lobus glandularis gehalten. Auch ich habe auf Grund der gleichen Präparate von normalen Larven denselben Eindruck empfangen.

Gaillard $^{\text {) }}$ (1937) hat die Vorder- und Hinterlappenexplantate des Kaninchens in hängenden Tropfen dicht nebeneinander liegen lassen. Er hat in den meisten Fällen Gewebskulturen, die im Bau dem Zwischenlappen glichen, an der Stelle, wo der Vorderlappen dem Hinterlappen anliegt, gesehen. Diese Gewebsumbildung des Vorderlappens in das zwischenlappenähnliche Gewebe hat er auf den Einfluss des Lobus nervosus und gegebenenfalls des Infundibulums zurückgeführt. Er hat gar nicht bemerkt, dass der Zwischenlappen durch Vermischung der Zellen des Lobus glandularis mit solchen des Lobus nervosus entsteht.

Atwel13) (1937, Rana sylvatica) hat die Anlage des Lobus glandularis zwischen das rechte Hörbläschen und das Hinterhirn transplantiert und als Ergebnis berichtet, dass in wenigen Fällen, wo das Transplantat mit dem Ganglion acusticum verbunden worden sei, sich ein zwischenlappenähnliches Gewebe gebildet habe. Doch hat er weiter über die Histogenese des Zwischenlappens nichts bemerkt. Ich vermag die Frage nicht zu beantworten, ob auch in solchen Fällen wirklich die Bildung des Zwischenlappens möglich sei. Bei meinem Experiment hatte sich jedenfalls auch in dem Fall, in welchem das Transplantat dicht dem anderen Hirnteile anliegt, kein Zwischenlappen gebildet.

Auch über das Stadium, in welchem der Zwischenlappen anfangs entsteht, gehen die Meinungen der einzelnen Forscher auseinander. Terato ${ }^{13)}$ (1935, Bufolarve) behauptete, dass der Zwischenlappen gerade vor Beginn der Metamorphose entstehe. Seiner Auffassung nach entstünde der Zwischenlappen nicht nur weit später als der Lobus nervosus, sondern auch später als die Anlage der Pars tubexalis. Atwel12) (1918, Rana pipiens), Kôchi ${ }^{8)}$ (1935, Rhacophorus schlegelii) und Tsutsui ${ }^{14)}$ (1937, Bufolarve) vertreten die Ansicht, dass der Zwischenlappen früher als der Lobus nervosus entstehe. Nach meinem Befund bildet sich die Anlage des Zwischenlappens aber im Anschluss an den Entstehungsbeginn des Lobus nervosus. Seine Entstehung ist deshalb früher als die Bildung der Basalplatte und natürlich darum weit früher auch als die Bildung der Anlage der Pars tuberalis. In der bisherigen Nomenklatur galt der Zwischenlappen rein für einen Abkömmling des Lobus glandularis und wurde als Pars intermedia beschrieben. Diese Auffassung ist jedoch nicht richtig. Wir müssen ihn vielmehr dem Lobus glandularis und dem Lobus nervosus gegenüberstellen und Lobus intermedius, Zwischenlappen, nennen. Nur die Pars tuberalis ist rein ein Abkömmling 
vom Lobus glandularis.

\section{Schluss.}

1. Die Anlage des Zwischenlappens bildet sich aus Zellen des Lobus glandularis zusammen mit solchen des Lobus nervosus.

2. Die Anlage des Zwischenlappens bildet sich zeitlich im Anschluss an die Entstehung des Lobus nervosus, d.h. in dem Stadium, in welchem der Raum zwischen der Hirnbasis und dem Gaumendach noch mit Bindegewebe gefüllt ist und die Hirnhäute sowie die Basalplatte sich noch nicht differenziert haben. Die Anlage des Zwischenlappens entsteht deshalb weit früher als die der Pars tuberalis.

\section{Zusammenfassung.}

1. Was die Entwicklung der Hypophyse anbetrifft, standen uns nur wenig Experimente zur Verfügung. Experimente, welche entscheidende Schlüsse gewähren, sind noch selten. Wegen des Sitzes und der eigentümlichen Entwicklung dieses Organes sind Versuche an anderen Tieren als Amphibien fast unmöglich. Auch bei letzteren lässt sich in einem späteren Stadium als dem der Neuralplatte das Experiment nicht mehr exakt ausführen. Insbesondere die Anlage des Infundibulums betreffend waren keine Experimente möglich. Ich habe meine Experimente bei Bufo im Stadium der Neuralplatte ausgeführt und vermochte in mehrfacher Hinsicht unsere Kenntnis zu erweitern.

2. Meine Experimente bezweckten die Möglichkeit einer Orientierung über die Anlage des Infundibulums, die Korrelation zwischen dem Lobus nervosus und dem Lobus glandularis, die Histogenese des Lobus glandularis und des Zwischenlappens, die Entstehungsweise des Lobus nervosus, die Determination des Infundibulums, die kaudale Verschiebung des Lobus glandularis usw..

3. Ich habe beim Keim des Neurulastadiums in der Neuralplatte eine Figur auftreten sehen, die den Anblick gewährt, als ob die unteren Schenkel von $\mathrm{X}$ mit den Schenkeln von $\mathrm{Y}$ übereinander gelegt worden seien. Ich habe sie darum als ,X-Y-Figur" der Neuralplatte und das Stadium als „XY-Stadium" bezeichnet. . Die meisten obigen Experimente wurden in diesem Stadium ausgeführt.

4. Die Anlage des Infundibulums im Neurulastadium entspricht dem Bezirk, welcher von $\operatorname{dem} \mathrm{X}$ und $\mathrm{Y}$ der $\mathrm{X}$-Y-Figur eingefasst wird. Sie zeigt fast die Form eines Quadrats, dessen eine Ecke am kranialen Ende des Stieles von $\mathrm{Y}$ fehlt. Um die Stelle dieser Anlage zu bestimmen, wandte ich 
die lokale Farbmarkierung mit Nilblausulfat an.

5. Der Lobus glandularis bedarf zu seiner vollständigen Entwicklung unbedingt der Verbindung mit dem Lobus nervosus. Die Resultate, welche die Grundlage für diesen Schluss bilden, sind die folgenden. (r) Der Lobus glandularis ist beim Fehlen des Lobus nervosus kümmerlich entwickelt. (2) Wenn die rechte Hälfte der Anlage des Infundibulums exstirpiert wird, ist der Lobus nervosus klein, der Lobus glandularis aber, welcher sich mit dem Lobus nervosus verbindet, ist normal entwickelt. (3) Wenn die Anlage des Infundibulums weiter kaudal als normal verschoben wird und der Lobus glandularis sowie der Lobus nervosus getrennt voneinander liegen, sind die einzelnen Lappen kümmerlich entwickelt.

6. Der Lobus glandularis ist beim Fehlen des Lobus nervosus weit kleiner als normal. Er entwickelt sich in diesem Falle bis zu einem gewissen Grade und verkleinert sich darauf im Verlaufe der Zeit. Auch die strangartige Anordnung seiner Zellen erscheint undeutlicher als im normalen Falle. Ferner zeigt er eine starke Pigmentablagerung, d.h. der Lobus glandularis ist kümmerlich entwickelt. Die Ursache der Verkleinerung ist unklar.

7. Der Lobus nervosus beginnt auch beim Fehlen des Lobus glandularis sich im gleichen Stadium wie normal zu bilden, doch bedarf er der Verbindung mit dem Lobus glandularis absolut zu seiner vollständigen Entwicklung. Die Resultate, auf welchen sich dieser Schluss gründet, sind die folgenden. (I) Der Lobus nervosus ist beim Fehlen des Lobus glandularis kleiner als normal. (2) Wenn die Añlage des Infundibulums weiter kaudal als im normalen Falle verschoben wird und der Lobus nervosus sowie der Lobus glandülaris getrennt voneinander liegen, zeigen sich die einzelnen Lappen kümmerlich entwickelt.

8. Der Lobus nervosus ist beim Fehlen des Lobus glandularis meist kleiner als normal, nur in einigen Fällen war er normal gross. Obgleich ich es nicht mit völliger Bestimmtheit behaupten kann, möchte ich doch betonen, dass der Lobus nervosus die Neigung erkennen lässt, sich nach der Entwicklung bis zu einem gewissen Grade im Laufe der Zeit wieder zu verkleinern.

9. Falls bei dem Infundibulum dürch die Operation ein Dickenunterschied zwischen der rechten und der linken Hälfte seiner Wand entsteht, berührt der Lobus glandularis die dünnere Hälfte. Auch der Lobus nervosus entwickelt sich hierbei hauptsächlich in der Hälfte, welche der Lobus glandularis berührt. Der Lobus nervosus entsteht aber auch beim Fehlen des Lobus glandularis. Es ist also sehr wahrscheinlich, dass das Vorhandensein des Lobus glandularis die Entstehung des Lobus nervosus begünstigt.

10. Was die Histogenese des Lobus glandularis anbetriff, finden sich zwei Meinungen vertreten: einmal die rein ektodermale, zum andern die 
Ansicht, nach welcher sich die entodermalen Zellen von der dorsokranialen Wand des Kopfdarmes in den Lobus glandularis mischen. Ich führte hierzu die lokale Farbmarkierung mit Nilblausulfat an dem betreffenden Teil des Entoderms aus und wies nach, dass die gefärbten Zellen sich nicht in den Lobus glandularis mischen. Ich vermochte also die Annahme, nach welcher der Lobus glandularis rein ektodermal ist, $\mathrm{zu}$ bestätigen.

I I. Der Zwischenlappen hat bisher ausschliesslich für einen Abkömmling vom Lobus glandularis allein gegolten. Aber ich habe durch Anwendung der lokalen Farbmarkierung bei der Anlage des Infundibulums nachgewiesen, dass die Anlage des Zwischenlappens durch Mischung der Zellen des Lobus nervosus und Lobus glandularis gebildet wird.

Ist der Lobus glandularis oder der Lobus nervosus wegen vorgenommener Operation nur allein vorhanden oder sind die beiden Lappen durch Operation voneinander getrennt worden, so wird der Zwischenlappen gar nicht gebildet. Er entsteht nur in den Fällen, in denen der Lobus glandularis und der Lobus nervosus miteinander verbunden sind. Zeitlich bildet er sich im Anschluss an den Entstehungsbeginin des Lobus nervosus, seine Entwicklung setzt also früher ein als die der Basalplatte und der Hirnhäute und natürlich weit früher als die der Anlage der Pars tuberalis.

12. Es ist schwer, die frühzeitige Entstehungsweise des Lobus nervosus nur an Hand der Präparate, welche von normalen Larven hergestellt wurden, zu studieren. Ich vermochte sie an dem Material, bei welchem die Anlage des Lobus glandularis exstirpiert worden war, zu studieren. Durch Gegenüberstellung des so erhaltenen Resultates und des Befundes bei normalen Larven konnte ich erst die Entstehungsweise des normalen Lobus nervosus aufzeigen. '

Wenn das kaudale Ende des Lobus glandularis fast das kraniale Ende des Infundibulums erreicht hat, so wuchern die platten Zellen, welche in der ventralen Wand des Infundibulums etwas kranial vom kaudalen Ende der ventralen Wand liegen, und bilden in der Richtung ventralwärts eine kleine Verdickung. Danach tritt im ganzen Teil der Wand, der später vom Lobus nervosus eingenommen wird, eine dünne Schicht auf, in der sich am Ventrikel eine Reihe rundlicher oder ovaler Kerne befindet und ventral davon rundliche oder länglich ovale Kerne spärlich zerstreut sind. Diese dünne Schicht wird allmählich dicker. Der ganze Teil differenziert sich beim Fehlen des Lobus glandularis gleichmässig weiter. In ihm liegen die hellen Zellen mit den rundlichen oder ovalen Kernen dicht nebeneinander, d.h. es handelt sich um das Auftreten der sog. Stammzellen. Der Lobus nervosus nimmt an Dicke gleichzeitig zu. Die Stammzellen verschwinden bald und der Lobus nervosus zeigt seine fertige Struktur. Im normalen Falle treten die Stammzel- 
len nicht gleichzeitig im ganzen Teil des Lobus nervosus auf. Sie treten am frühesten in dem Abschnitt, welcher dorsokaudal und dorsolateral vom Lobus glandularis liegt, und danach ungefähr im Stadium der Metamorphose in dem Abschnitt, welcher dorsokranial vom Lobus glandularis liegt, auf. Am spätesten erscheinen sie in dem Abschnitt, welcher dorsal vom mittleren Teil des Lobus glandularis liegt. Der letztgenannte Abschnitt erhält sich meist etwa bis nach der Metamorphose noch in Form der dünnen Schicht, welche den ${ }^{\circ}$ Ventrikel mit einer Reihe von rundlichen oder ovalen Kernen umgibt und ventral davon kernarm ist.

13. Die Pars tuberalis wird vom Lobus glandularis allein gebildet. Bei dem Lobus glandularis, welcher sich mit dem Lobus nervosus nicht verbindet, ist ihre Entstehung stark gehemmt. Selbst ihre Anlage, welche anfangs in Gestalt zweier Höcker am kranialen Abschnitt des Lobus glandularis nachweisbar ist, wird in den meisten Fällen nicht gebildet. Doch erhielt ich zwei Fälle; welche nach der totalen Exstirpation der Anlage des Infundibulums die Anlage der Pars tuberalis aufwiesen, Für letztere besteht also die Möglichkeit, sich auch an dem mit dem Lobus nervosus nicht verbundenen Lobus glandularis zu bilden. Aber ihre Bildung wird vielleicht gehemmt, da der Lobus glandularis kümmerlich entwickelt ist.

14. Ich drehte die Anlage des Infundibulums im Stadium der Neuralplatte in ihrer Lage um $180^{\circ}$ kraniokaudal, kehrte sie also um. In der Folge ergaben sich unter den Fällen zwei Gruppen, fast gleich an Zahl, nämlich die Fälle, bei denen das Infundibulum kraniokaudal umgekehrt war, und die, bei denen es die normale Orientierung zeigte. Hieraus konnte ich entnehmen, dass das Operationsstadium gerade dem Determinationsstadium des Infundibulums entspricht.

15. Warum vereinigen der Lobus glandularis und der Lobus nervosus sich miteinander? Mit anderen Worten, warum findet die kaudale Verschiebung des Lobus glandularis von seinem Mutterboden nach dem Infundibulum hin statt? Am wahrscheinlichsten ist es, als Ursache eine Taxis zwischen der Anlage des Lobus glandularis und der des Lobus nervosus anzunehmen. Ich konnte jedoch eine solche Taxis mittels meiner eigens dafür angestellten verschiedenen Versuche nicht nachweisen. $\mathrm{Da}$ ich als einzigen Anhaltspunkt nur den folgenden histologischen Befund aufzuweisen vermag, möchte ich in ihm vorläufig die wahrscheinlichste Ursache erkennen.

Das Bindegewebe wird von kranial nach kaudal d.h. in den Raum, welcher ventral vom Infundibulum liegt, schrittweise gebildet. Vorausgesetzt, dass die Differenzierung des Bindegewebes primär ist, so erweckt der Lobus glandularis den Eindruck, als ob seine kaudale Verschiebung wie folgt stattfinde. Er wuchert bis zu einem gewissen Grade etwas 'schneller 
als die Bildung des Bindegewebes in seiner Umgebung vonstatten geht, d.h. letztere findet relativ langsam statt. Der Lobus glandularis wird danach durch das Bindegewebe, welches sich von kranial nach kaudal schrittweise bildet, kaudalwärts verschoben und erreicht das Infundibulum.

16. Auch nach der Exstirpation der Anlage des Infundibulums, des Gehirns usw. verschiebt sich der Lobus glandularis ebenso wie im normalen Falle kaudalwärts ünd bleibt in seinem normalen Querschnittsniveau. Niemals verschiebt er sich weiter kaudal über dasselbe hinaus. Auch wenn die Bildung des Infundibulums durch die Operation kaudalwärts verschoben stattfindet, erreicht der Lobus glandularis es nicht und bleibt in seinem normalen Querschnittsniveau. Es handelt sich also um eine bestimmte Stelle, welche der Lobus glandularis durch seine kaudale Verschiebung zu erreichen vermag.

I 7. Beim Fehlen des Lobus glandularis entsteht das Infundibulum ebenso früh wie im normalen Falle und gestaltet sich auch in normaler Weise, nur dass seine ventrale Wand in der Richtung ventrokaudalwärts ausgedehnt ist. Die ventrale Wand des normalen Infundibulums erhält aber einen Eindruck, welcher der dorsalen Wölbung des Lobus glandularis entspricht. Dieser sich ergebende Unterschied beruht jedoch nur auf dem Verhalten der ventralen Wand, das je nach dem Vorhandensein oder Fehlen des Lobus glandularis verschieden ist. Die Entwicklung des Infundibulums ist somit vom Lobus glandularis unabhängig.

18. Der Lobus nervosus verändert seine Form je nach dem Vorhandensein oder Fehlen des Lobus glandularis, ist also von diesem abhängig. Seine Form ist beim Fehlen des Lobus glandularis wie folgt. Im Querschnitt ist er spindelförmig oder oval ; im Sagittalschnitt ähnelt er fast einem Keil, dessen Spitze kranialwärts gerichtet ist. Er ist am dicksten im etwas kranial gelegenen Abschnitt, d.h. er ist hier dicker als.am kaudalen Ende des Infundibulums. Die Form, welche der normale Lobus nervosus gerade bis nach der Metamorphose darbietet, lässt sich mit der Form des Lobus nervosus, welcher sich beim Fehlen des Lobus glandularis relativ gut entwickelt hat, in folgender Weise in Beziehung setzen. Der Lobus glandularis übt einen Druck auf den Lobus nervosus, welcher sich beim Fehlen des Lobus glandularis relativ gut entwickelt, von ventral her aus und dehnt ihn nach allen Seiten. In der Folge muss der mittlere Teil des Lobus nervosus am dünnsten werden. Die Form enstpräche dann fast der des normalen Lobus nervosus.

19. Der Lobus nervosus nimmt seine Lage beim Fehlen des Lobus glandularis im Gebiet seiner normalen Lokalisation.

20. Die Bufolarve lebt auch beim Fehlen der ganzen Hypophyse; zum mindesten ist letztere für diese kein lebenswichtiges Organ. Auch Adler u.a. haben in dieser Hinsicht schon das gleiche Resultat beobachtet. 
21. Der Farbton der Haut verändert sich in den Fällen, wo der vorgenommenen Operation wegen einerseits der Lobus glandularis oder der Lobus nervosus nur allein vorhanden ist, oder anderseits der Lobus glandularis und der. Lobus nervosus durch Operation voneinander getrennt sind. Das bedeutet, der Farbton verändert sich in allen Fällen, in welchen der Zwischenlappen fehlt.

22. Die. Larven gehen in den Fällen fast zu der normalen Zeit in die Metamorphose über, in denen wegen vollzogener Operation einzig allein der Lobus glandularis vorhanden ist, oder anderseits der Lobus glandularis sich wegen derselben vom Lobus nervosus getrennt entwickelt hat. Sie vollenden ihre vier Beine ebenso früh, während die Rückbildung des Schwanzes sich jedoch verzögert.

Zum Schlusse sei es mir gestattet, meinem hochverehrten Lehrer, Herrn Prof. Dr. Ch. Ogawa, für seine stete, liebenswürdige Leitung meinen herzlichsten Dank auszusprechen.

\section{Literatur.}

I) Adler, L. : Metamorphosestudien an Batrachierlarven. I. Exstirpation endokriner Drüsèn. A. Exstirpation der Hypophyse. Roux'Arch. Bd. 39. I914.

2) Atwe11, W. J.: The development of the hypophysis of the Anura. Anat. Rec. Vol. I5. I918.

3) Derselbe: Functional transplants of the primordium of the epithelial hypophysis in Amphibia. Anat. Rec. Vol. 68. 1937.

4) Blount, R. F.: Transplantation and extirpation of the pituitary rudiment and the effects upon pigmentation in the urodele embryo. J. of Exp. Zool. Vol.63. 1932.

5) Gaupp, E.: Anatomie des Frosches. Dritte Abteilung. Braunschweig. I904.

6) Gaillard, P. J.: An experimental contribution to the origin of the pars intermedia of the hypophysis. Acta neerland. Morph. I, $11-13$. 1937. (Zit. von Anat. Ber. Bd. 36. S. 233. 1938 .)

7) Goette, A.: Die Entwicklungsgeschichte der Unke (Bombinator igneus). Leipzig. I875.

8) Kôchi, T.: On the development of the hypophysis of the anura, especially of Rhacophorus schlegelii. (Japanisch). Okayama Igk. Z. Jg. 47, No. ro (No. 549). I935.

9) Kupffer, C. v.: Die Deutung des Hirnanhanges. Sitzungsber. d. Gesellsch. f. Morph. u. Physiol. zu München. S. 59. 1894. (Zit. nach Atwell igr8).

ro) Stein, Kathry n F.: Early embryonic differentiation of the chick hypophysis as shown in chorio-allantoic grafts. Anat. Rec. Vol. 43. r929.

I I) Smith, P.E.: The pigmentary, growth and endocrine disturbances induced in the anuran tadpole by the eatly ablation of the pars buccalis of the hypophysis... Amer. Anat. Mem. Nr. Ir. I920.

12) Takasima, R. und K. Terato: Eine kurze Mitteilung über die Entwicklung des Nervenlappens von Hypophysis cerebri bei einigen japanischen Anurenarten. Okajimas Fol. anat. jap. Bd. XIV, H. 4. 1936.

13) Terato, K. : Embryologische Studien über die Hypophysis cerebri bei der japanischen Kröte (B. formosus). I. Mitteilung: Úber die larvale Entwicklung der Hypophyse. (Japanisch). J. of Kumamoto med. Soc. Vol. XI, No. 5. 1935.

14) Tsutsui, R.: Entwicklungsgeschichtliche Untersuchungen über den Hypophysenhinterlappen. (Japanisch). Ig, Kenkyu. Bd. XI, H. 5. I937.

15) Woerdeman, M. W.: Versuche zur Verringerung der Sterblichkeit nach mikrochirurgischen Eingriffen an Amphibienkeimen. Roux' Arch. Bd. 121. 1930. 